NATIONAL LABORATORY

\title{
PWR Facility Dose Modeling Using MCNP5 and the CADIS/ADVANTG Variance-Reduction Methodology
}

September 2007

\author{
Prepared by \\ E. D. Blakeman \\ D. E. Peplow \\ J. C. Wagner \\ B. D. Murphy \\ D. E. Mueller
}

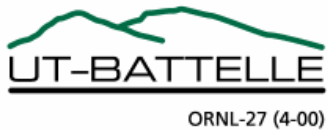




\title{
DOCUMENT AVAILABILITY
}

Reports produced after January 1, 1996, are generally available free via the U.S. Department of Energy (DOE) Information Bridge.

Web site http://www.osti.gov/bridge

Reports produced before January 1, 1996, may be purchased by members of the public from the following source.

\author{
National Technical Information Service \\ 5285 Port Royal Road \\ Springfield, VA 22161 \\ Telephone 703-605-6000 (1-800-553-6847) \\ TDD 703-487-4639 \\ Fax 703-605-6900 \\ E-mailinfo@ntis.gov \\ Web site http://www.ntis.gov/support/ordernowabout.htm
}

Reports are available to DOE employees, DOE contractors, Energy Technology Data Exchange (ETDE) representatives, and International Nuclear Information System (INIS) representatives from the following source.

Office of Scientific and Technical Information

P.O. Box 62

Oak Ridge, TN 37831

Telephone 865-576-8401

Fax 865-576-5728

E-mail reports@osti.gov

Web site http://www.osti.gov/contact.html

This report was prepared as an account of work sponsored by an agency of the United States Government. Neither the United States Government nor any agency thereof, nor any of their employees, makes any warranty, express or implied, or assumes any legal liability or responsibility for the accuracy, completeness, or usefulness of any information, apparatus, product, or process disclosed, or represents that its use would not infringe privately owned rights. Reference herein to any specific commercial product, process, or service by trade name, trademark, manufacturer, or otherwise, does not necessarily constitute or imply its endorsement, recommendation, or favoring by the United States Government or any agency thereof. The views and opinions of authors expressed herein do not necessarily state or reflect those of the United States Government or any agency thereof. 


\title{
PWR FACILITY DOSE MODELING USING MCNP5 AND THE CADIS/ADVANTG VARIANCE-REDUCTION METHODOLOGY
}

\author{
E. D. Blakeman \\ D. E. Peplow \\ J. C. Wagner \\ B. D. Murphy \\ D. E. Mueller
}

Date Published: September 2007

Prepared by

OAK RIDGE NATIONAL LABORATORY

Oak Ridge, Tennessee 37831-6283

managed by

UT-BATTELLE, LLC

for the

U.S. DEPARTMENT OF ENERGY

under contract DE-AC05-00OR22725 



\section{CONTENTS}

\section{Page}

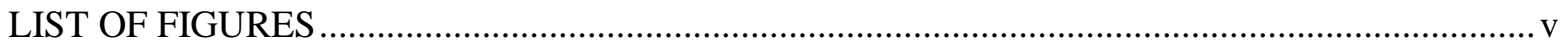

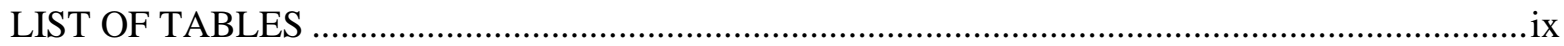

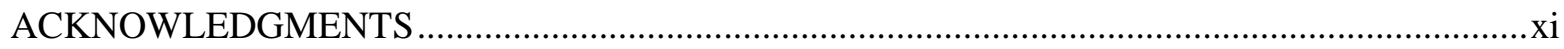

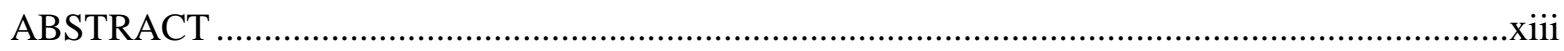

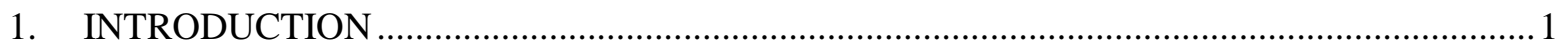

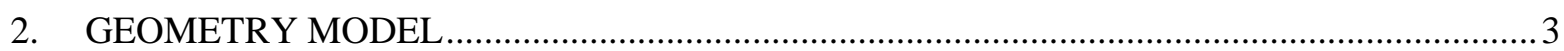

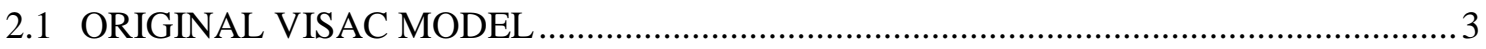

2.2 CONVERSION OF GEOMETRY FROM BRL-CAD TO MCNP …............................

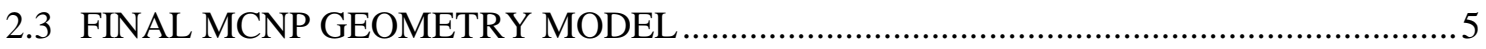

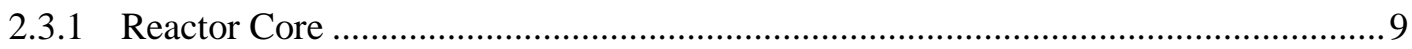

2.3.2 Biological Shielding around Reactor Core ....................................................... 10

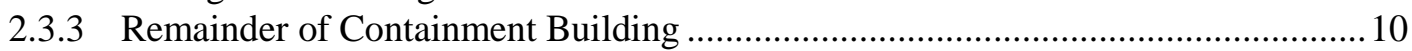

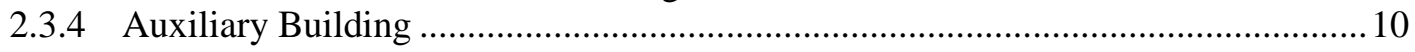

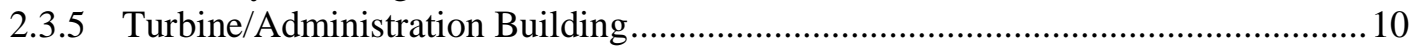

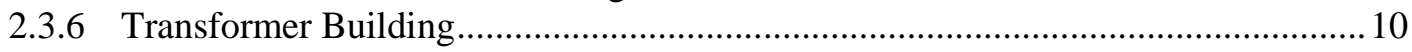

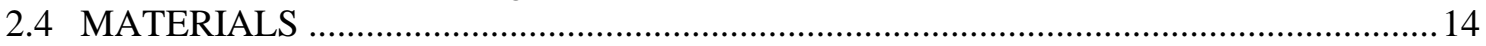

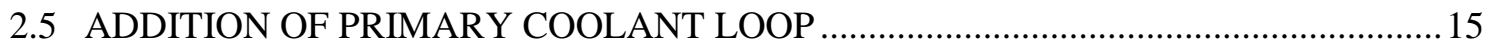

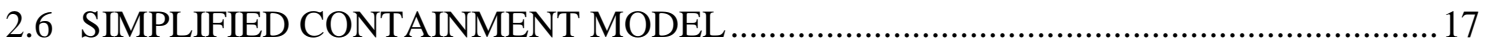

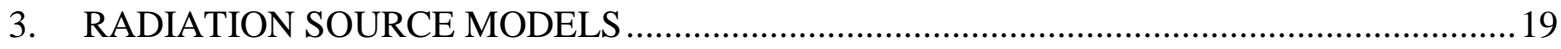

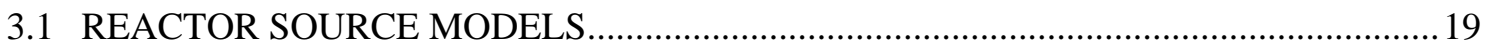

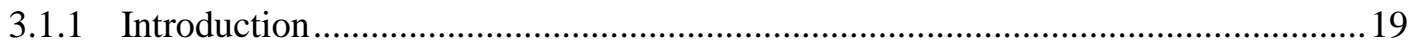

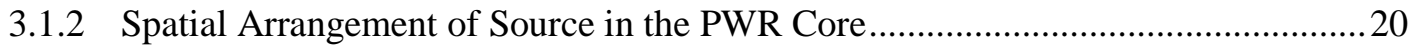

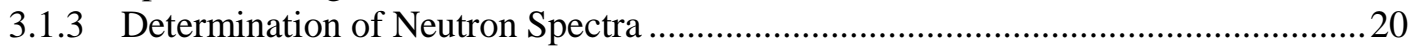

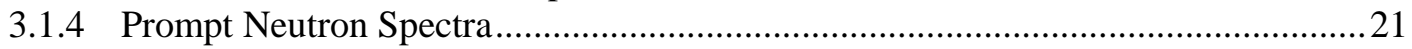

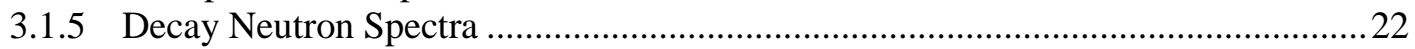

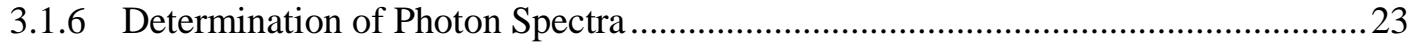

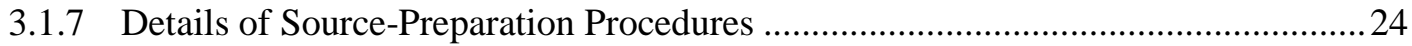

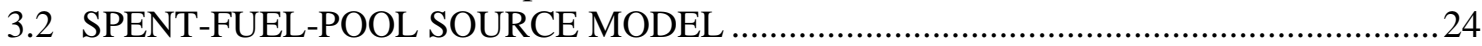

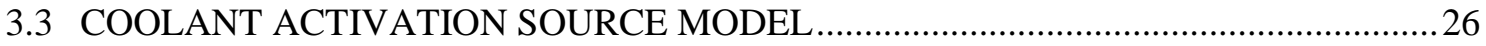

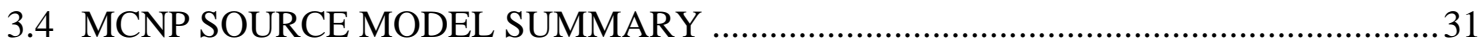

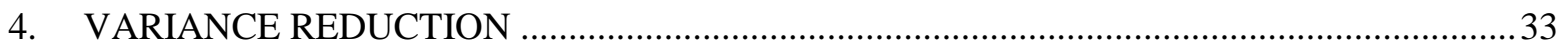

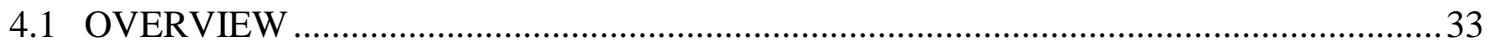

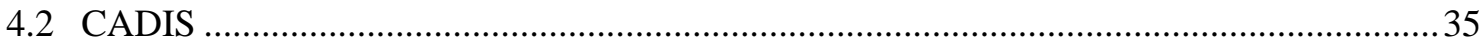

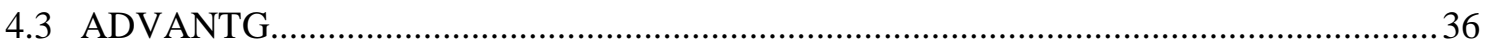

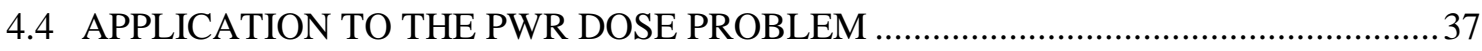

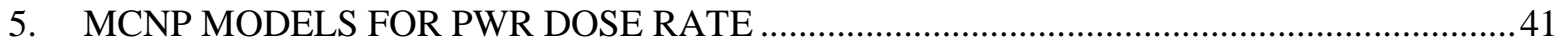

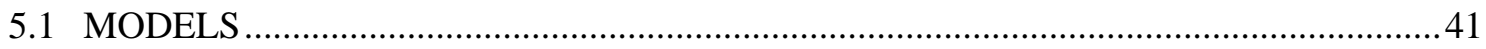

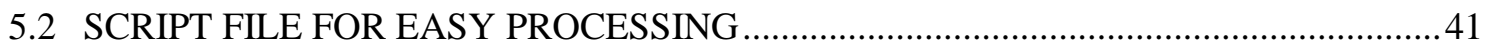

5.2.1 Run the Script to Prepare an MCNP Input Deck ..................................................42

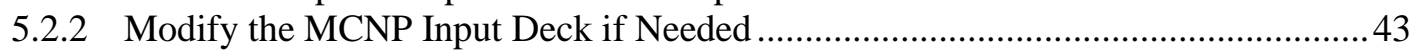

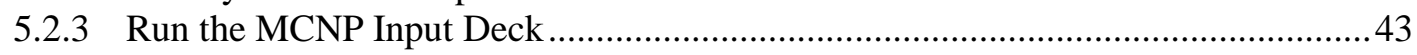

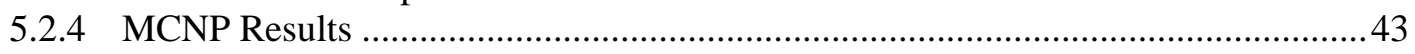




\section{CONTENTS (continued)}

\section{Page}

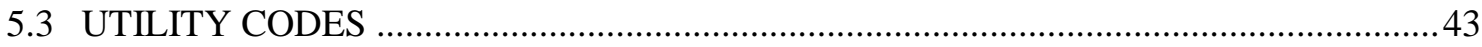

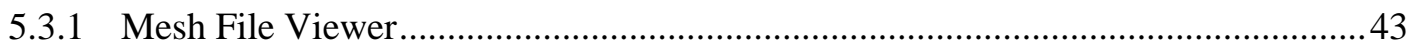

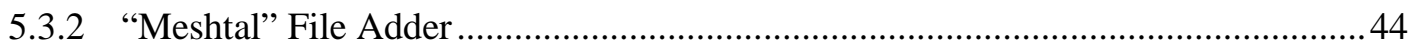

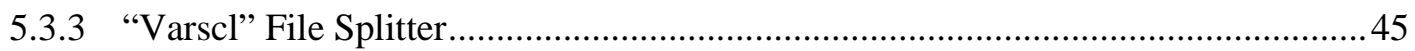

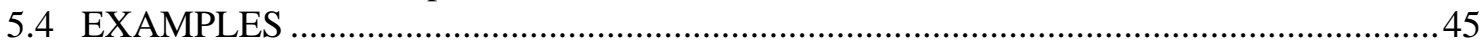

5.4.1 Neutron Dose Rates from the Full-Power Operating Reactor............................... 45

5.4.2 Photon Dose Rates from the Full-Power Operating Reactor ................................. 47

5.4.3 Neutron Dose Rates from the Spent Fuel Pool ....................................................... 49

5.4.4 Modified Geometry-Neutron Dose Rates from the Full-Power

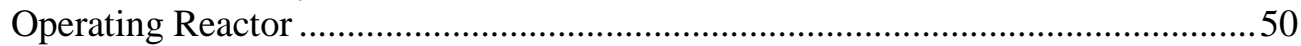

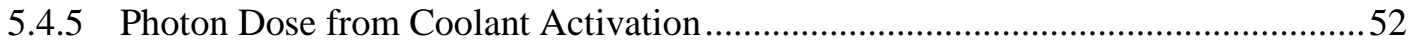

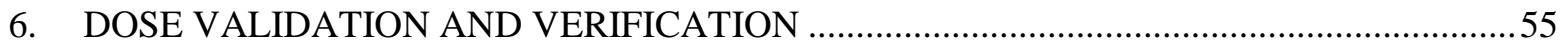

6.1 INVESTIGATION OF ADJOINT-SOURCE LOCATION WITH

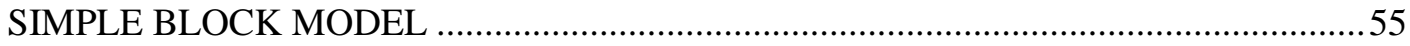

6.2 INVESTIGATION OF ADJOINT-SOURCE LOCATION WITH

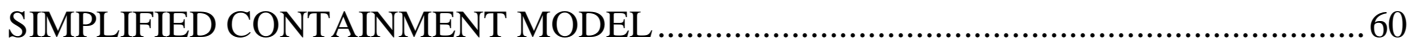

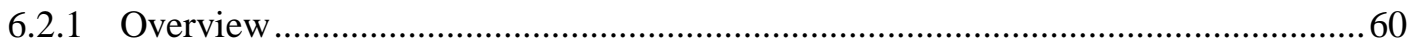

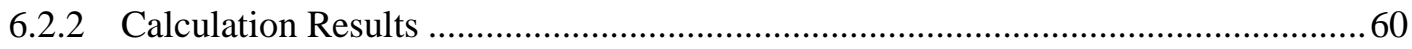

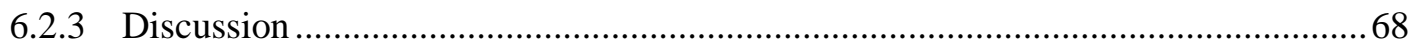

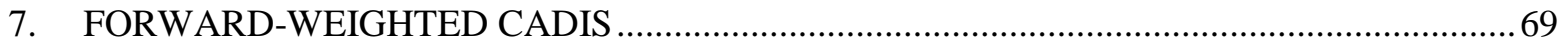

7.1 IMPLEMENTATION USING CURRENT CADIS/ADVANTG-BASED METHOD.......69

7.2 RESULTS USING FORWARD-BASED PROCEDURE ON PWR MODEL .................. 71

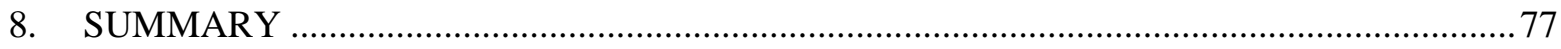

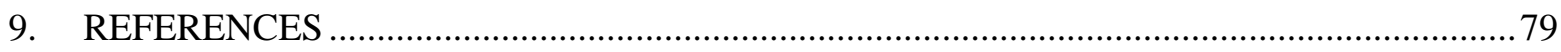




\section{LIST OF FIGURES}

Figure

Page

1 Original VISAC model, consisting of five buildings.................................................... 3

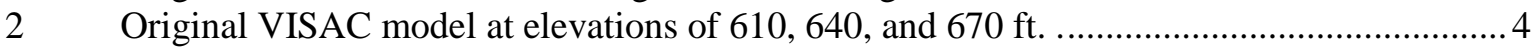

3 Cutaway view showing internal walls and critical components. ..................................... 4

$4 \quad$ Plan $(\mathrm{X}-\mathrm{Y})$ view of PWR facility at elevation $18,600 \mathrm{~cm}(610.2 \mathrm{ft})$ slightly above

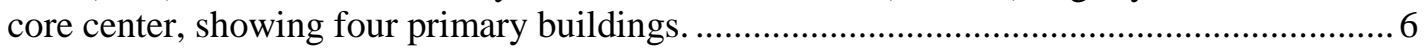

5 Plan $(\mathrm{X}-\mathrm{Y})$ view of PWR facility at elevation $19,200 \mathrm{~cm}(630 \mathrm{ft})$ at top of core,

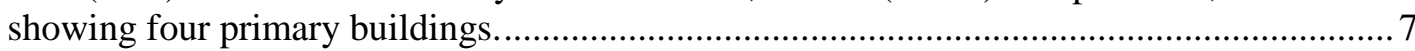

6 Elevation (Y-Z) view of PWR facility through the center of the reactor, showing the containment, auxiliary, and turbine buildings, as well as major components................... 8

$7 \quad$ Plan $(\mathrm{X}-\mathrm{Y})(\mathrm{left})$ and elevation $(\mathrm{Y}-\mathrm{Z})$ views of the homogenized reactor design ................. 9

$8 \quad$ Elevation (Y-Z) view of containment building through center of reactor........................... 11

9 Plan (X-Y) view of containment building, showing major structural and reactor components.

10 Plan (X-Y) view of auxiliary building at approximate reactor midplane showing

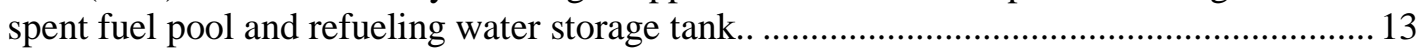

11 Elevation (Y-Z) view of the spent fuel pool showing the fuel storage racks........................ 13

12 Elevation $(\mathrm{Y}-\mathrm{Z})$ view showing turbine and condenser sections in the

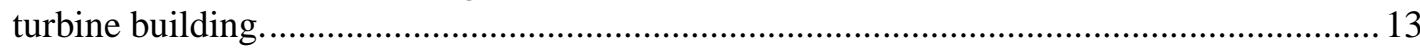

13 MCNP model showing coolant pipes from reactor to steam generators

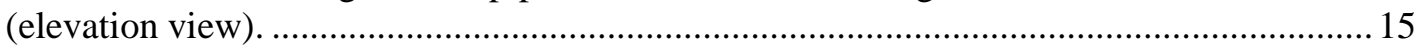

14 MCNP model showing coolant pipes from reactor to steam generators and from coolant pumps back to reactor (plan view). ............................................................ 16

15 MCNP model showing coolant pipe from Steam Generator 1a to Coolant Pump 1a (elevation view).

16 Plan view of geometry showing X-Y plane with origin at center of containment at approximate vertical center of reactor core.

17 Plan view of geometry showing X-Y plane with origin at center of containment

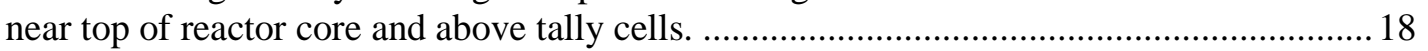

18 Elevation view of geometry showing Y-Z plane through center of reactor........................ 18

19 Elevation view of geometry showing X-Z plane through center of reactor.......................... 18

20 Axial power profile (proportional to relative burnup) assumed for source definition.......... 20

21 Radial pattern of source strengths used for the PWR source definition. ............................ 20

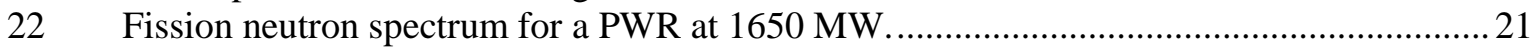

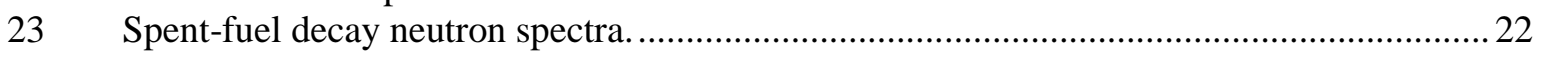

24 Fission photon spectrum calculated for a power level of 35.8 MW ................................2 23

25 Decay photon spectra for cooling times of 1 day, 1 week, and 1 month. ........................... 23

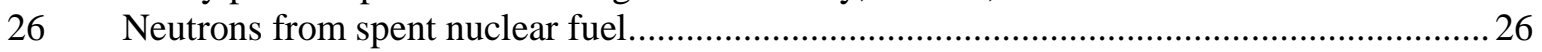

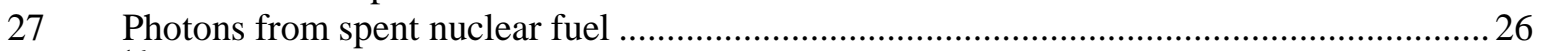

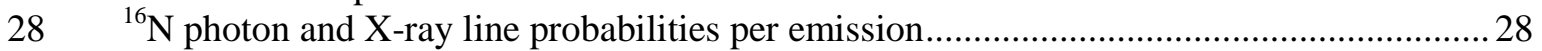

$29 \quad$ All other nuclides in a multi-energy-group distribution ................................................29

$30 \quad$ Plot showing 3158 point source locations for reactor coolant system ............................... 30

31 Two-dimensional representation of source points for the reactor coolant loop, showing points in reactor, steam generators, coolant pumps, and connecting lines............. 30

32 Close-up plan (X-Y) view of neutron mesh tally analog calculation results of the full-power reactor model at a location slightly above the center of the reactor core............. 34

33 Elevation (Y-Z) view of neutron mesh tally analog calculation results of the full-power reactor model along the center of the reactor core $(x=122 \mathrm{~cm})$.. 


\section{LIST OF FIGURES (continued)}

Figure

Page

34 Flowchart of standard ADVANTG sequence for adjoint-source-based weight windows variance reduction in MCNP.

35 Conceptual PWR facility model showing adjoint source in surrounding

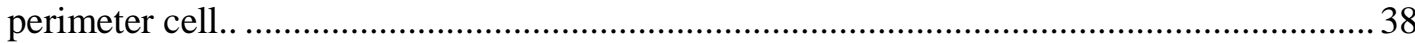

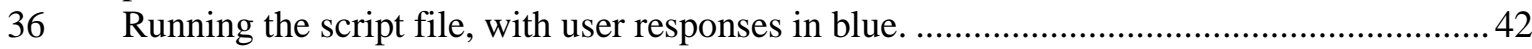

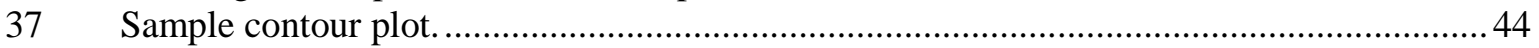

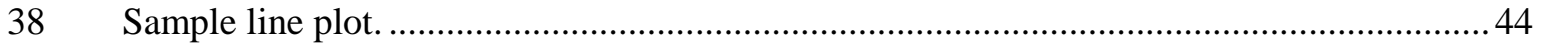

39 Plan (X-Y) view of neutron mesh tally results of the full-power reactor model at a location slightly above the center of the reactor core $(z=18,500 \mathrm{~cm}) . \ldots \ldots \ldots \ldots . . . .46$

40 Close-up plan (X-Y) view within the containment of neutron mesh tally results of the full-power reactor model at a location slightly above the center of the reactor core $(z=18,500 \mathrm{~cm})$..

41 Elevation (Y-Z) view of neutron mesh tally results of the full-power reactor model along the center of the reactor core $(x=122 \mathrm{~cm})$.

42 Elevation $(\mathrm{X}-\mathrm{Z})$ view of neutron mesh tally results of the full-power reactor model along the center of the reactor core $(y=152 \mathrm{~cm})$.

43 Plot of neutron dose rate within the containment along the $Y$-axis at $x=122 \mathrm{~cm}$ (reactor center) and at elevation 18,500 cm (approximate reactor core vertical center)....... 47

44 Plan (X-Y) view of photon mesh tally results of the full-power reactor model at a location slightly above the center of the reactor core $(z=18,500 \mathrm{~cm})$ Close-up plan (X-Y) view within containment of photon mesh tally results of the full-power reactor model at a location slightly above the center of the reactor core $(z=18,500 \mathrm{~cm})$. Elevation (Y-Z) view of photon mesh tally results of the full-power reactor model along the center of the reactor core $(x=122 \mathrm{~cm})$.

47 Elevation (X-Z) view of photon mesh tally results of the full-power reactor model along the center of the reactor core $(y=152 \mathrm{~cm})$.

48 Plot of photon dose rate within the containment along the $X$-axis at $y=152 \mathrm{~cm}$ (reactor center) and at an elevation of 18,500 $\mathrm{cm}$ (approximate reactor core vertical center).

49 Plan (X-Y) view of neutron mesh tally results of the spent fuel source model at a location near the vertical center of the spent fuel racks $(z=18,700 \mathrm{~cm})$

50 Elevation (Y-Z) view of neutron mesh tally results of the spent fuel source model at a location in $\mathrm{X}$ dimension near the center of the spent fuel racks $(x=3600 \mathrm{~cm})$.

51 Plan $(\mathrm{X}-\mathrm{Y})$ view of the modified geometry model at a location slightly above the center of the reactor core $(z=18,900 \mathrm{~cm})$ showing a breach in containment wall.........51

52 Elevation (Y-Z) view along the center of the reactor core $(x=122 \mathrm{~cm})$ of the modified geometry model showing a breach in containment wall.

53 Plan (X-Y) view within containment of neutron mesh tally results of the full-power reactor model at a location slightly above the center of the reactor core $(z=18,900 \mathrm{~cm})$ and with a breach in the containment wall...

54 Elevation (Y-Z) view of neutron mesh tally results of the full-power reactor model along the center of reactor core $(x=122 \mathrm{~cm})$ and with a breach in the containment wall. 


\section{LIST OF FIGURES (continued)}

55 Horizontal plane (plan view) of mesh tally dose rates (in millirems per hour) for coolant loop source.

56 Vertical plane (elevation view) of mesh tally dose rates (in millirems per hour) for coolant loop source.

57 Plot of reactor coolant photon dose rate through center of reactor at elevation $18,850 \mathrm{~cm}$.

58 Simple block model for comparing calculations using different adjoint source locations.

59 ADVANTG neutron dose rates (in rems per hour) using an adjoint source in the first void region and an exterior boundary adjoint source.

60 Relative uncertainties in the neutron dose rates using an adjoint source in the first void region and an exterior boundary adjoint source.

61 ADVANTG photon dose rates (in rems per hour) using an adjoint source in the first void region and an exterior boundary adjoint source.

62 Relative uncertainties in the photon dose rates using an adjoint source in the first void region and an exterior boundary adjoint source.

63 MCNP mesh tally dose rates (in rems per hour) and relative uncertainties from neutron calculation with adjoint source located around periphery of containment for $6 \times 10^{7}$ source particle histories.

64 MCNP mesh tally dose rates (in rems per hour) and relative uncertainties from neutron calculation with adjoint source located in Cell 1 for $8 \times 10^{7}$ source particle histories.

65 MCNP mesh tally dose rates (in millirems per hour) and relative uncertainties from photon calculation with adjoint source located around periphery of containment for $1 \times 10^{8}$ source particle histories.

66 MCNP mesh tally dose rates (in millirems per hour) and relative uncertainties from photon calculation with adjoint source located in Cell 1 (slightly to left of center in above images) for $1 \times 10^{8}$ source particle histories.

67 MCNP mesh tally dose rates (in millirems per hour) and relative uncertainties from calculation of $(n, p)$ photons with adjoint source located around periphery of containment for $1 \times 10^{8}$ source particle histories.

68 MCNP mesh tally dose rates (in millirems per hour) and relative uncertainties from calculation of $(n, p)$ photons with adjoint source located in Cell 1 (slightly to left of center in above images) for $5 \times 10^{7}$ source particle histories.

69 Flowchart for using ADVANTG to implement variance reduction in MCNP through the production of an adjoint source weighted by the reciprocal of the forward response.

70 Plan (X-Y) view of TORT-calculated dose rate (in rems per hour) from reactor source for PWR model at $z \sim 18,500 \mathrm{~cm}$.

71 Elevation (Y-Z) view of TORT-calculated dose rate (in rems per hour) from reactor source for PWR model at plane through center of reactor $(x=122 \mathrm{~cm})$.

72 Plan (X-Y) views of MCNP neutron dose rate (in rems per hour) from the reactor source for the PWR model at $z \sim 18,500 \mathrm{~cm}$ using weight windows obtained from a boundary-based adjoint source and from a forward-weighted global adjoint source.

73 Plan (X-Y) views of MCNP neutron dose uncertainties from the reactor source for the PWR model at $z \sim 18500 \mathrm{~cm}$ using weight windows obtained from a boundary-based adjoint source and from a forward-weighted global adjoint source. 


\section{LIST OF FIGURES (continued)}

Figure

Page

74 Elevation (Y-Z) views of MCNP-calculated neutron dose rate (in rems per hour) from the reactor source for the PWR model on a plane through the reactor center $(x \sim 122 \mathrm{~cm})$ using weight windows obtained from a boundary-based adjoint source and from a forward-weighted global adjoint source.

75 Elevation (Y-Z) views of MCNP-calculated neutron dose uncertainties from the reactor source for the PWR model on a plane through the reactor center $(x \sim 122 \mathrm{~cm})$ using weight windows obtained from a boundary-based adjoint source and from a forward-weighted global adjoint source. White spaces show regions in which neutrons were not transported. 


\section{LIST OF TABLES}

\section{Table}

Page

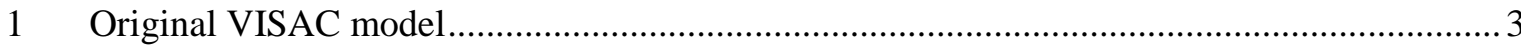

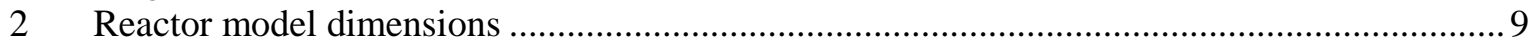

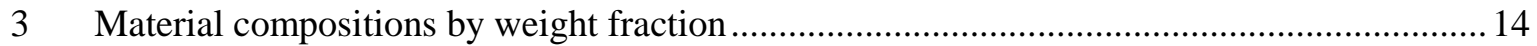

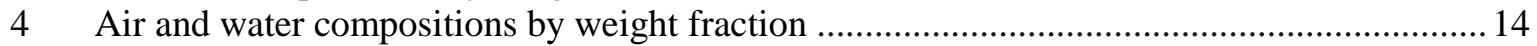

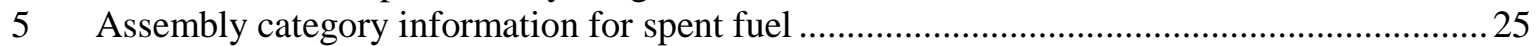

6 Activities (in microcuries per gram) in the coolant calculated using ANSI/ANS 18.1 .........27

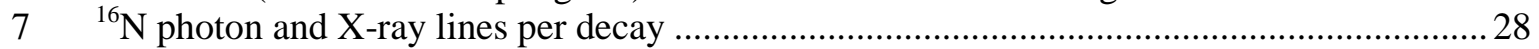

8 Summary of coolant component volumes and source strengths........................................... 31

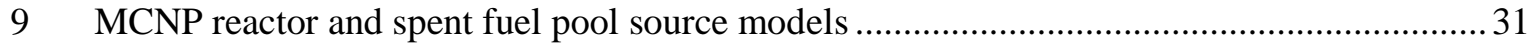

10 Energy group boundaries and flux-to-dose-rate conversion factors ..................................... 32

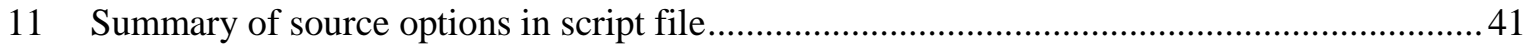

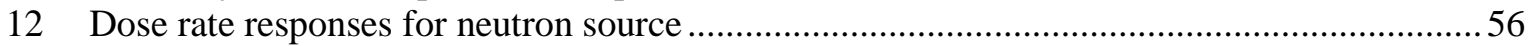

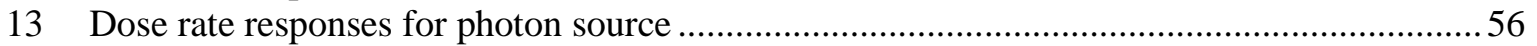

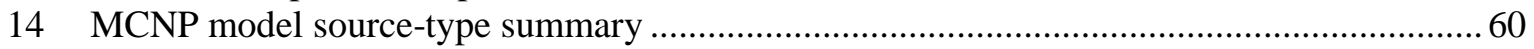

15 Neutron dose rates and relative uncertainties in tally cells for reactor neutron source ...........61

16 Photon dose rates and relative uncertainties in tally cells for reactor photon source ..............61 61

$17(\mathrm{n}, \gamma)$ Photon dose rates and relative uncertainties in tally cells for reactor neutron source...... 62

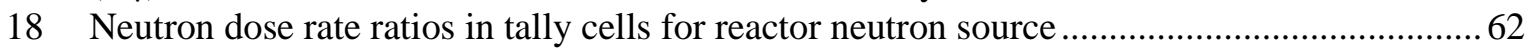

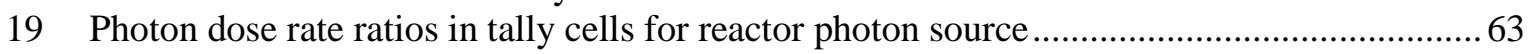

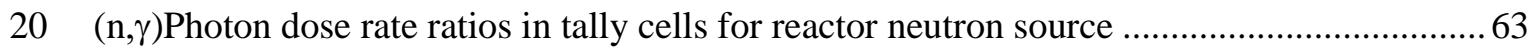

21 Average Cell 1 energy-dependent neutron dose rates and uncertainties for Runs A and B .... 65 



\section{ACKNOWLEDGMENTS}

The authors wish to acknowledge the sponsorship and support of Lt. Col. Todd Hann (ret.) and others of the Defense Threat Reduction Agency (DTRA), Research and Development Enterprise, Nuclear Technologies Directorate.

We also extend appreciation to Marsha K. Savage for editorial comments and Deborah J. Weaver for her preparation and formatting of the final report. 



\begin{abstract}
The feasibility of modeling a pressurized-water-reactor (PWR) facility and calculating dose rates at all locations within the containment and adjoining structures using MCNP5 with mesh tallies is presented. Calculations of dose rates resulting from neutron and photon sources from the reactor (operating and shut down for various periods) and the spent fuel pool, as well as for the photon source from the primary coolant loop, were all of interest. Identification of the PWR facility, development of the MCNP-based model and automation of the run process, calculation of the various sources, and development of methods for visually examining mesh tally files and extracting dose rates were all a significant part of the project. Advanced variance reduction, which was required because of the size of the model and the large amount of shielding, was performed via the CADIS/ADVANTG approach. This methodology uses an automatically generated three-dimensional discrete ordinates model to calculate adjoint fluxes from which MCNP weight windows and source bias parameters are generated. Investigative calculations were performed using a simple block model and a simplified full-scale model of the PWR containment, in which the adjoint source was placed in various regions. In general, it was shown that placement of the adjoint source on the periphery of the model provided adequate results for regions reasonably close to the source (e.g., within the containment structure for the reactor source). A modification to the CADIS/ADVANTG methodology was also studied in which a global adjoint source is weighted by the reciprocal of the dose response calculated by an earlier forward discrete ordinates calculation. This method showed improved results over those using the standard CADIS/ADVANTG approach, and its further investigation is recommended for future efforts.
\end{abstract}





\section{INTRODUCTION}

The purpose of this project was to develop and demonstrate the models to assess radiation dose rates to personnel within a reactor facility using the MCNP5 Monte Carlo (X5 Monte Carlo Team, 2003) code. Dose rates at different locations inside the power plant from various neutron or photon sources (reactor, spent fuel, activated coolant, etc.) were to be part of the final model.

The specific technical tasks discussed in this report are identified as follows:

1. Develop specifications of a typical pressurized-water-reactor (PWR) facility (operating conditions, structure, and configuration) from a current database set of reactors. Identify candidate locations of interest to calculate dose rates.

2. Develop an MCNP* geometry (or geometries) required to represent major facility structures and components using design information for the PWR selected in Task 1 at an appropriate level of detail.

3. Compute reactor-core source terms, coolant-activity source terms, and spent-fuel-pool source terms for approximately four different operating conditions determined in Task 1. Develop sources for specific MCNP models.

4. Determine necessary variance-reduction techniques to obtain acceptable results at dose locations determined in Task 1 and incorporate into facility models.

5. Develop methods and approaches for extracting dose rates from MCNP5 output and visualization of geometry. Evaluate and, if necessary, develop user scripts to aid in the use of the MCNP models.

6. Provide validation of the overall methodologies.

Tasks 1 and 2 are discussed in Section 2. A midsized PWR plant was chosen as the representative facility. Candidate dose calculation points within this plant were not determined because of the use of the MCNP5 mesh tally capability to calculate dose rates everywhere on a grid overlaying the plant geometry.

Task 3 is discussed in Section 3. Source models were created for four different operating conditions: (1) an operating reactor at full power (midcycle), (2) 1 day after shutdown following full-power operation, (3) 1 week after shutdown following full-power operation, and (4) 1 month after shutdown following full-power operation. A source model for the spent fuel held in the spent fuel pool was also created. Both neutron and photon source models have been created for each of the above, for a total of ten source models. In addition, a photon source model was created for the primary coolant loop because of activation from core neutrons.

The focus of Task 4, discussed in Section 4, was to demonstrate that this very difficult calculation could be performed by MCNP5. To our knowledge, this type of calculation has never been successfully attempted before. Because of the large amount of shielding material in this problem, it was known that advanced variance-reduction methods would be required. A methodology that allows for successful calculation of dose rates throughout the PWR facility was found-the CADIS methodology implemented

\footnotetext{
* The term "MCNP" is used in this report as a general reference to models/geometries that are applicable to and can be run by versions of MCNP earlier than MCNP5. However, all runs were performed using MCNP5.
} 
by the ADVANTG code, which automatically generates a biased source distribution and weight windows as a function of position and particle energy for an MCNP input. A more advanced variance-reduction methodology that uses a forward-weighted adjoint source was also examined and is discussed in this report in Section 7.

Tasks 5 and 6 are discussed in Sections 5 and 6, respectively. Examples of the various source types are presented in Section 5. In addition to a description of each sample model, the simplification of model setup using a script file and dose extraction using utility codes are described. In Section 6, a simple block model and a simplified version of the PWR containment model are used to examine the effects of placing the adjoint source in different locations.

A summary of the overall project is presented in Section 8. 


\section{GEOMETRY MODEL}

VISAC, the Visual Interactive Site Analysis Code (Peplow et al., 2004), previously developed at Oak Ridge National Laboratory (ORNL) for the sponsor, is used to analyze nuclear power plants or other facilities for vulnerability to blasts. The code works by coupling a detailed geometry model of the plant components and an event/fault tree logic model of the plant safety systems connectivity. VISAC has a library of nearly 20 plants, consisting mostly of rough building descriptions but containing a few facilities with detailed information about internal walls and plant components. These models are in a format that can be read by the BRL-CAD solid modeling code-the regions are described as Boolean operations of simple solid shapes (boxes, cylinders, wedges, etc.). Since VISAC is designed for blast analysis, the models contain only the large concrete walls of the plant, not the smaller details.

\subsection{ORIGINAL VISAC MODEL}

The most detailed of the VISAC models is the west560 plant, a typical Westinghouse two-loop PWR. The model consists of five separate buildings, detailed in Table 1 and shown in Figs. 1-3. Most of the geometry regions describe the exterior and interior concrete walls, and 170 of the regions describe critical components that are linked into the VISAC fault tree analysis. These critical component regions do not contain any information about material or mass—only the approximate size.

Table 1. Original VISAC model

\begin{tabular}{lcc}
\hline \multicolumn{1}{c}{ Building } & Solids & Regions \\
\hline Containment & 87 & 60 \\
Auxiliary & 261 & 194 \\
Turbine/administration & 173 & 125 \\
Transformer & 27 & 20 \\
Screenhouse/service water & 146 & 82 \\
\hline
\end{tabular}

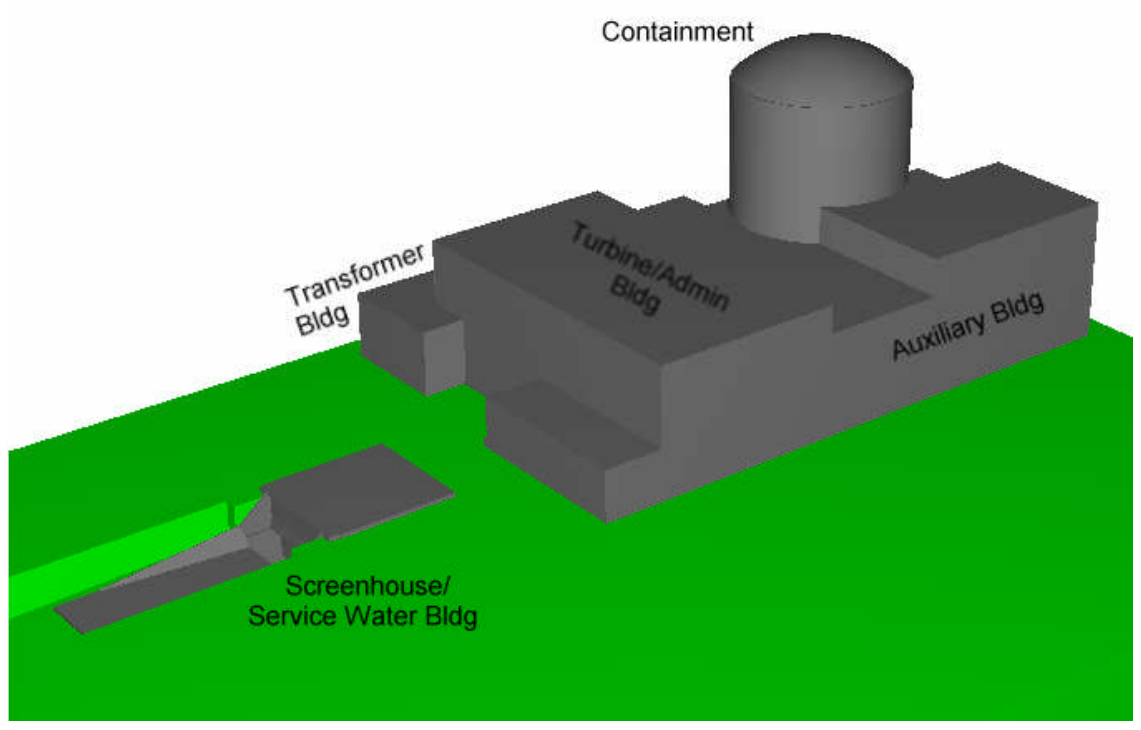

Fig. 1. Original VISAC model, consisting of five buildings. 

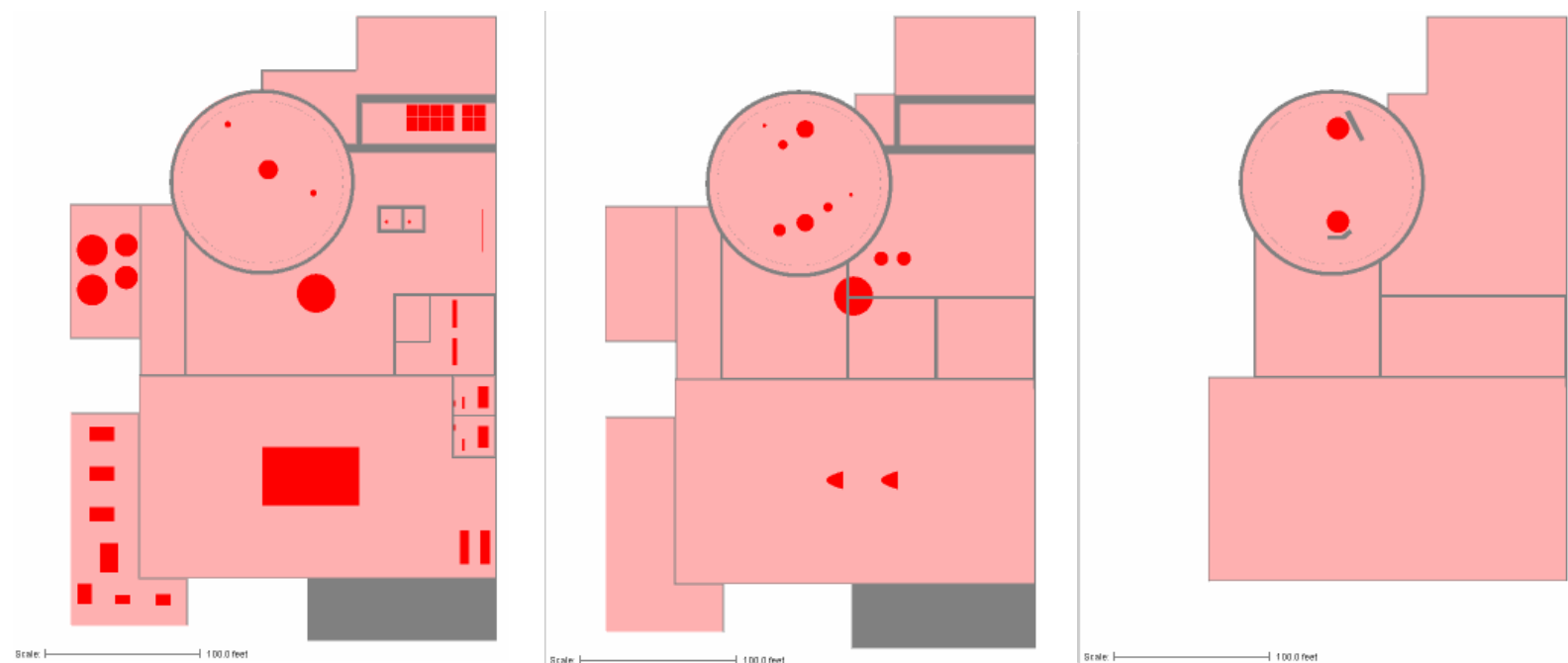

Fig. 2. Original VISAC model at elevations of 610, 640, and $670 \mathrm{ft}$. Ground level is at $605 \mathrm{ft}$ above sea level.

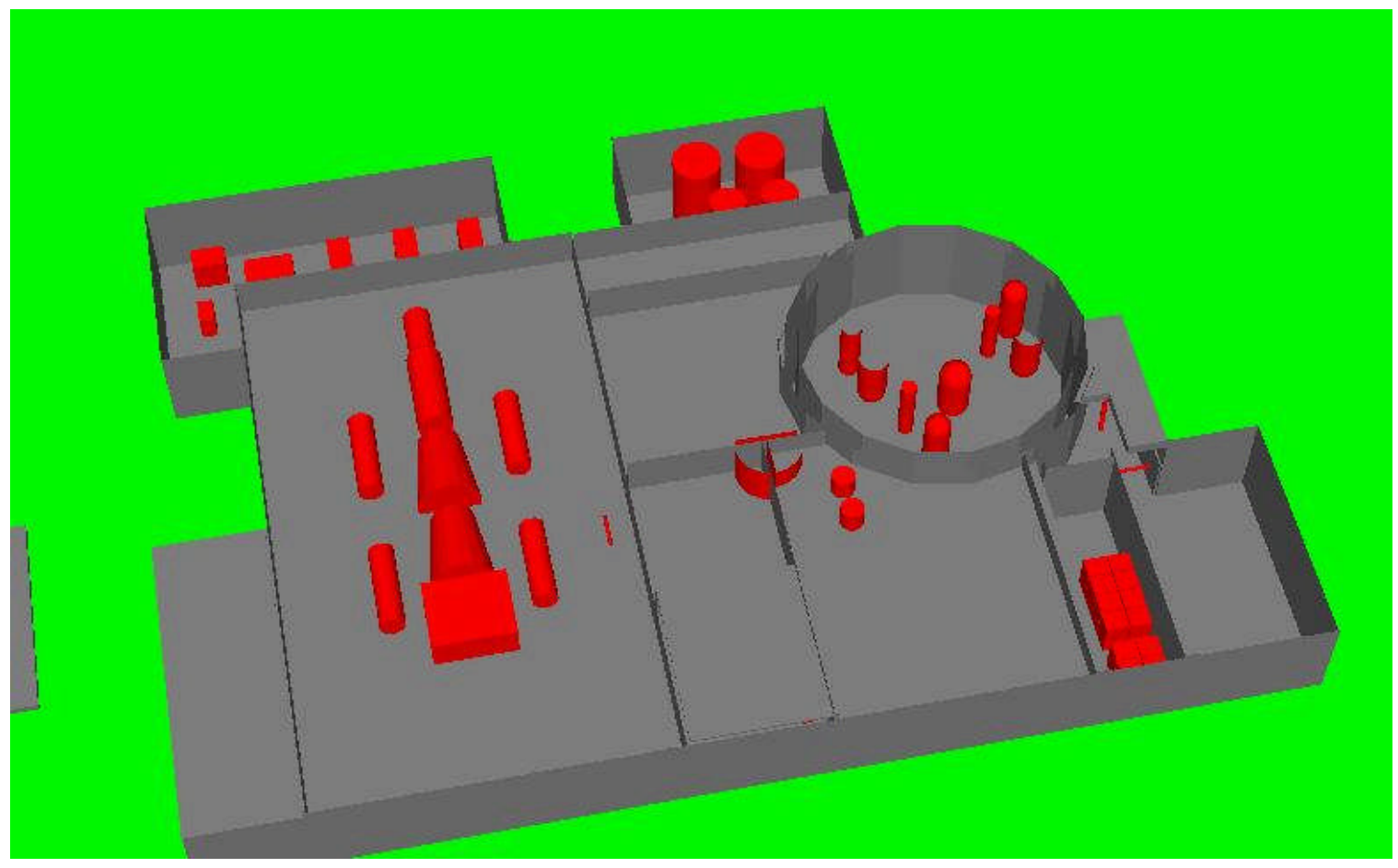

Fig. 3. Cutaway view showing internal walls and critical components. 


\subsection{CONVERSION OF GEOMETRY FROM BRL-CAD TO MCNP}

VISAC's automatic conversion program was used to convert the geometry models of the four main buildings (containment, auxiliary, turbine, and transformer buildings) from BRL-CAD format to MCNP format. Special code was written to convert the units from feet to centimeters. A significant effort was also required to combine the four models into a single facility model because sections of one building could, in general, intersect another building. (In the process, however, potentially useful partial facility MCNP models of the containment, auxiliary, turbine, and transformer buildings were developed.) This process required the removal of redundant cells (i.e., the same adjoining walls might appear in two models, requiring the removal of one in the combined models) and the redefining of global cells. Substantial modifications were then made to the overall "converted" MCNP plant model:

(1) addition of biological reactor shielding and the refueling cavity section to the containment model section;

(2) relocation and revision of several components;

(3) addition of borated water to the spent fuel pool and spent fuel composite material to the spent fuel racks;

(4) removal of many redundant model surfaces;

(5) simplification of a number of geometry constructions (without compromising the final geometry definitions);

(6) subdivision of the air regions of the model into more and simpler cells (to simplify future model modifications and to increase calculation efficiency); and

(7) addition of a moderately more detailed reactor model, replacing the simplistic model in the VISAC design.

The overall philosophy in the above process was to incorporate, insofar as practical, major structures that would significantly attenuate neutron and photon radiation. It is well beyond practical limitations and even existing technology to reproduce in an MCNP model all the design details of a PWR facility. Furthermore, excessive detail in a Monte Carlo model would tend to slow down the transport process. (The calculation must constantly assess particle locations and boundary crossings.) Thus, walls, floors, large tanks, turbines, etc., are included in the facility model, while, in general, smaller structures such as pipes, valves, stairwells, and cranes were not included.

\subsection{FINAL MCNP GEOMETRY MODEL}

The final MCNP facility model combines the four primary buildings and contains 426 MCNP cells and roughly 5000 surfaces. However, a significant number $(\sim 2000)$ of the surfaces are redundant. This is a remnant of the VISAC design and the process of generating the MCNP model, in which each cell is assigned unique surfaces even if some of them are identical to surfaces of other components. Although many of the redundant surfaces were removed, the remaining ones were retained to facilitate model flexibility (e.g., a cell described with unique surfaces can be relocated without affecting other cells).

The MCNP model views, as well as contour color plots of data, are presented as "plan" and "elevation" views, where a plan view is a horizontal plane slice of the model, which will be represented by the $\mathrm{X}$ and $\mathrm{Y}$ axes in a standard format. ( $\mathrm{X}$ is left to right, and $\mathrm{Y}$ is bottom to top.) Thus, a plan view can also be referred to as an "X-Y" view. Assuming a right-handed coordinate system, the $Z$ axis is in the vertical (i.e., "up") direction. Elevation-view plots are geometry slices at a specified X or Y location and represented by either the $\mathrm{Y}$ or the $\mathrm{X}$ axis and the $\mathrm{Z}$ axis. Thus, elevation views are either " $\mathrm{X}-\mathrm{Z}$ " or "Y-Z" views. 
Figures 4-6 show full views of the facility MCNP model. Figures 4 and 5 are plan views at the approximate vertical midplane of the reactor core and at the top of the reactor, respectively. Both figures show the four primary buildings and the primary components. Figure 6 shows an elevation view of the facility and is a cross-section view through the center of the reactor core. Again, primary components can be seen.

Z-plane values in the actual MCNP model have been transformed downward by 10,000 $\mathrm{cm}$ as a result of a data-handling issue. ${ }^{*}$ For example, elevations of $18,600 \mathrm{~cm}(610.2 \mathrm{ft})$ appear in the model as $z=8600$.

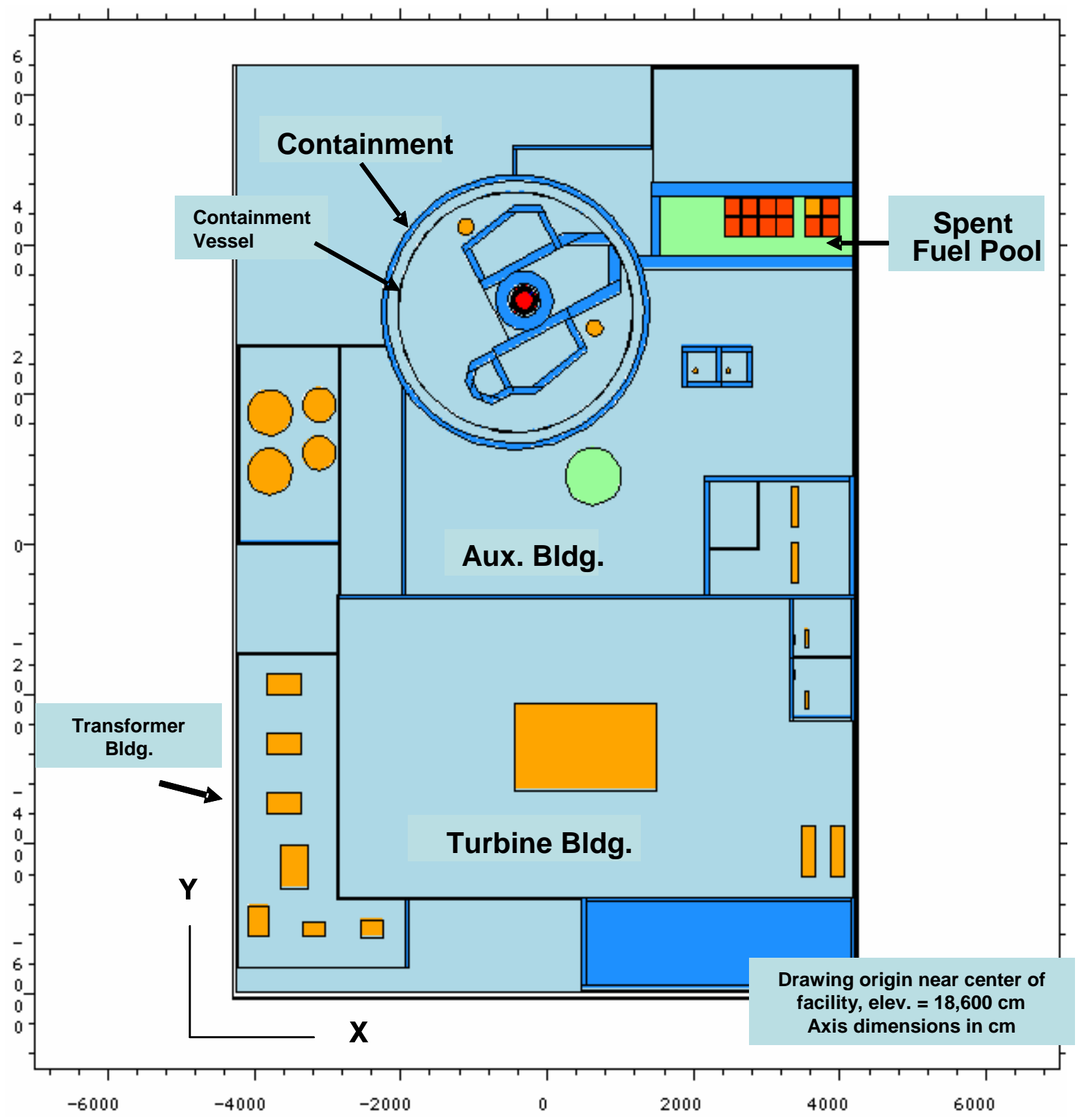

Fig. 4. Plan (X-Y) view of PWR facility at elevation $18,600 \mathrm{~cm}(610.2 \mathrm{ft})$ slightly above core center, showing four primary buildings. Model origin: $x=433 \mathrm{~cm}, y=-3100 \mathrm{~cm}, z=8600 \mathrm{~cm}$.

\footnotetext{
${ }^{*}$ This issue was later resolved, and it is intended that future models be revised to remove this offset.
} 


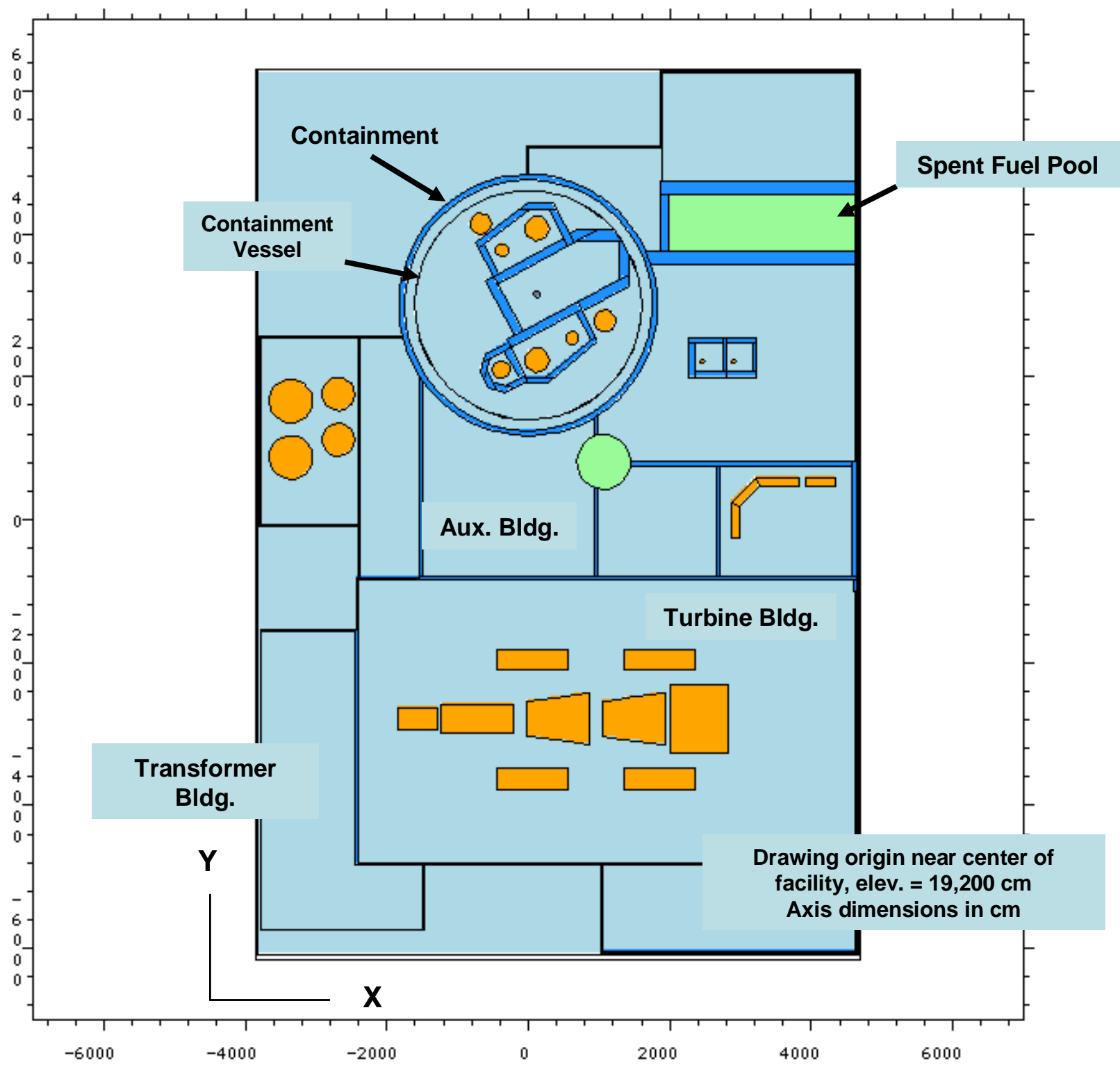

Fig. 5. Plan (X-Y) view of PWR facility at elevation $19,200 \mathrm{~cm}(630 \mathrm{ft})$ at top of core, showing four primary buildings. Model origin: $x=0 \mathrm{~cm}, y=-3000 \mathrm{~cm}, z=9200 \mathrm{~cm}$. 


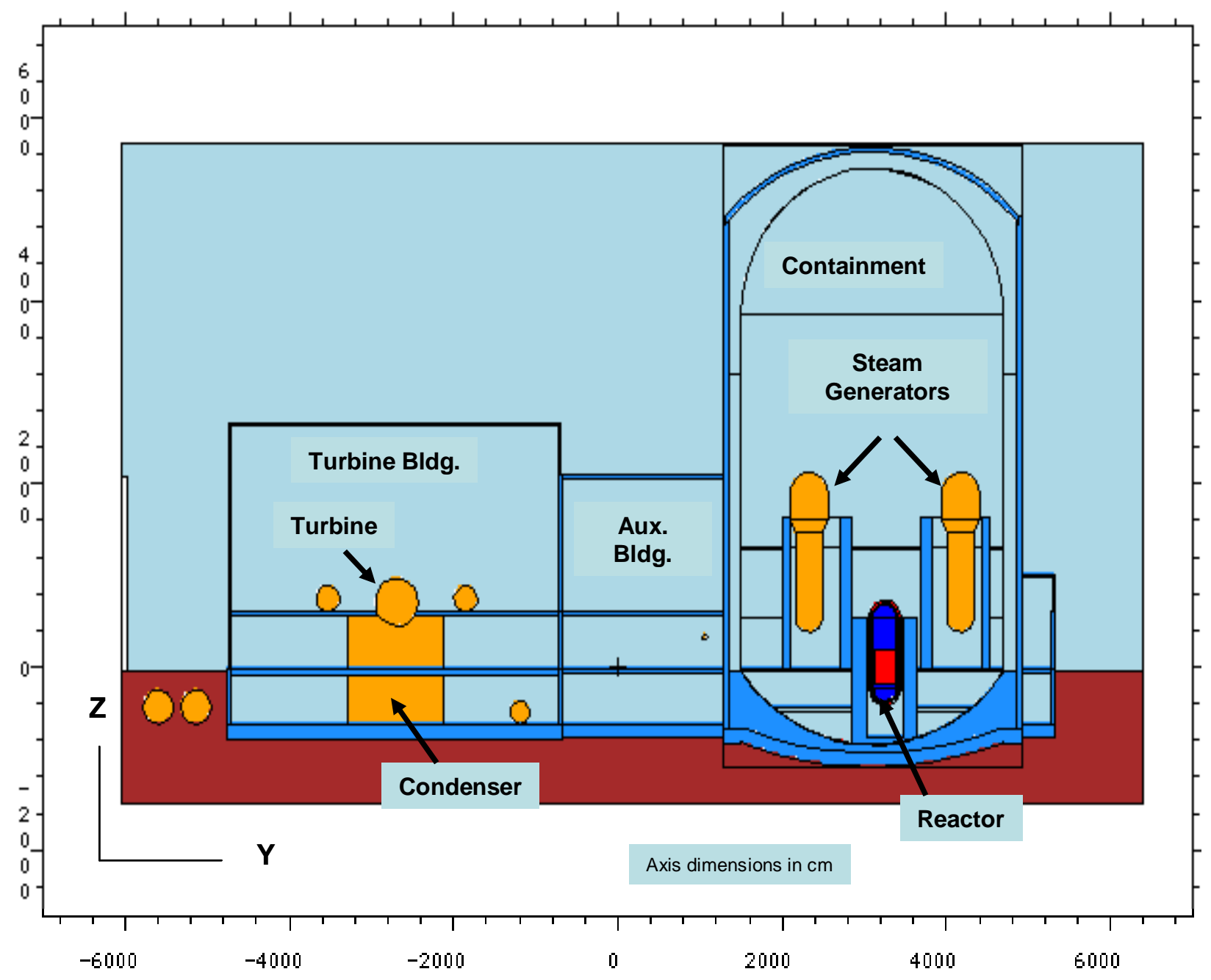

Fig. 6. Elevation (Y-Z) view of PWR facility through the center of the reactor, showing the containment, auxiliary, and turbine buildings, as well as major components. Model origin: $x=122 \mathrm{~cm}, y=-3100 \mathrm{~cm}$, $z=8483 \mathrm{~cm}$. 


\subsubsection{Reactor Core}

Plan and elevation views of a simplified reactor-core MCNP model are shown in Fig. 7. The model contains the primary radial components including the core, coolant channels, core blanket, thermal shield, and vessel structure. Pipes and other smaller features are omitted. The core was represented by a homogenized material (made of uranium dioxide, zirconium, and water). Table 2 includes reactor model dimensions.
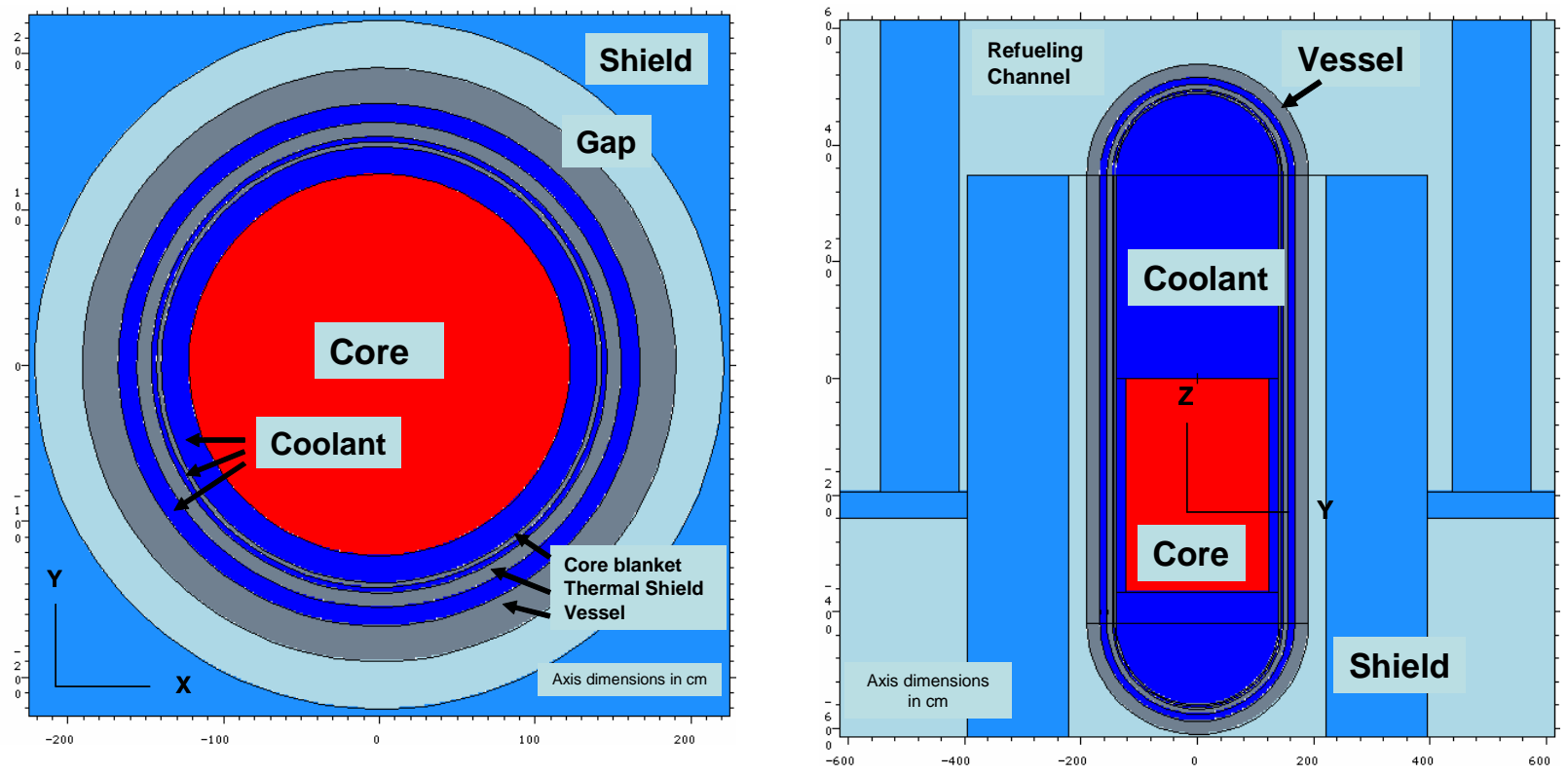

Fig. 7. Plan (X-Y) (left) and elevation (Y-Z) (right) views of the homogenized reactor design. Model origin (left): $x=122 \mathrm{~cm}, y=152 \mathrm{~cm}, z=8500 \mathrm{~cm}$. Origin (right): $x=122 \mathrm{~cm}, y=152 \mathrm{~cm}, z=8666 \mathrm{~cm}$.

Table 2. Reactor model dimensions

\begin{tabular}{lc}
\hline Reactor dimension & Size (cm) \\
\hline Core radius & 122.50 \\
Core blanket radius (inner) & 139.88 \\
Core blanket radius (outer) & 142.88 \\
Thermal shield radius (inner) & 146.43 \\
Thermal shield radius (outer) & 155.58 \\
Vessel radius (inner) & 167.64 \\
Vessel radius (outer) & 190.50 \\
Core length & 366.00 \\
Reactor length & 1150.62 \\
\hline
\end{tabular}




\subsubsection{Biological Shielding around Reactor Core}

Figure 7 also shows the cylindrical biological shield around the reactor and a portion of the refueling channel walls. The biological shield is $175 \mathrm{~cm}$ thick and is offset from the reactor by a gap of $30.5 \mathrm{~cm}$. The shield is constructed of concrete and extends vertically to the top of the cylindrical section of the reactor vessel.

\subsubsection{Remainder of Containment Building}

The majority of modeling efforts for this phase of the project were expended on changes and refinements to the VISAC-based containment building model section and the addition of biological shielding and walls required to define the refueling channel. In addition, the basement floor and the lower section of the containment vessel were added. The model was also improved and simplified somewhat by subdividing air-region cells into smaller cells that had far less complexity. It was also noted that large structures such as the reactor and steam generators that spanned more than one floor level were modeled as two sections, with the floor continuous through the component. This was evidently a reasonable approach for the use of the VISAC model. However, it was not suitable here and was therefore changed. Also, numerous small surface mismatches (which lead to excessive "lost" particles in the MCNP calculations) were corrected. Figures 8 and 9 show elevation and plan views, respectively, of the final containment building model section. The three main floors can be seen in Fig. 8, including the elevation perspective of the reactor with regard to the shielding, walls, and steam generators. It can be seen that the floor of the refueling cavity is located at the top of the cylindrical reactor shield. In Fig. 9, the view is from a cut through the top section of the reactor slightly above the cylindrical biological shielding and between the mezzanine and refueling floors. In this figure, the bottom sections of the steam generators, as well as the reactor coolant pumps, accumulators, and pressurizer can be seen. The containment components are surrounded by the steel containment vessel. The containment vessel is $3.81 \mathrm{~cm}$ thick and has an inner radius of $1600.2 \mathrm{~cm}$. The containment inner radius is $1752.6 \mathrm{~cm}$, and the $76.2-\mathrm{cm}$-thick walls are constructed of concrete.

\subsubsection{Auxiliary Building}

Relatively minor changes were made to the auxiliary building from the VISAC model. A homogenized mixture consisting of the spent fuel and structural materials between individual spent fuel assemblies was determined and loaded in the spent fuel racks. The spent fuel pool and refueling tanks were filled with 1000 ppm borated water. Figures 10 and 11 show relevant regions of the auxiliary building.

\subsubsection{Turbine/Administration Building}

Minor changes were made to the VISAC model turbine building, which included removal of redundant surfaces and removal of the floor intersection with turbine and condenser components. Figure 12 shows an elevation view through the axis of a turbine assembly. All components in the turbine building were modeled as steel with a reduced density of $1 \mathrm{~g} / \mathrm{cm}^{3}$.

\subsubsection{Transformer Building}

No appreciable changes were made to the VISAC transformer building model. 


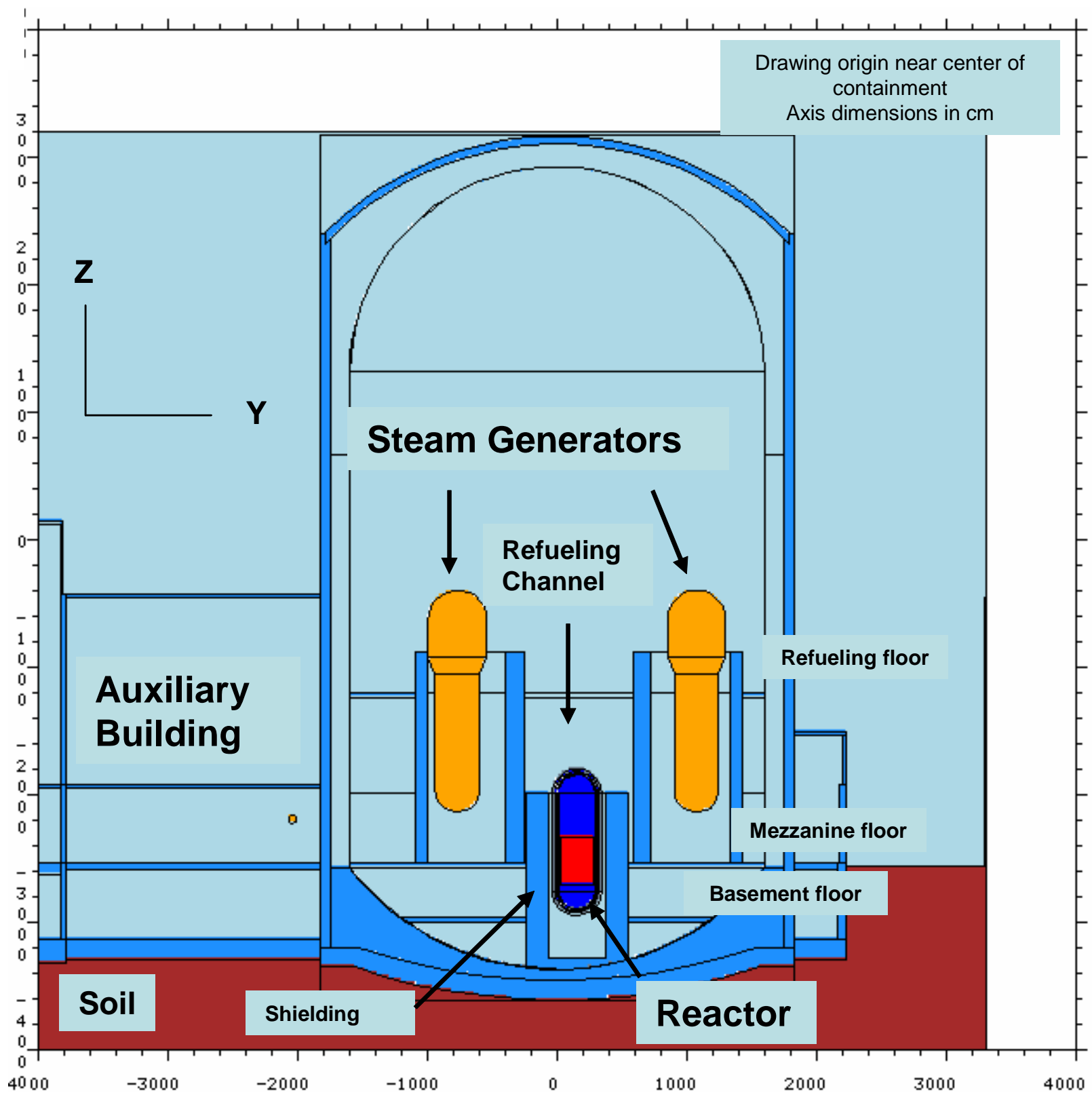

Fig. 8. Elevation $(\mathrm{Y}-\mathrm{Z})$ view of containment building through center of reactor. Model origin: $x=122 \mathrm{~cm}, y=0 \mathrm{~cm}, z=1100 \mathrm{~cm}$. 


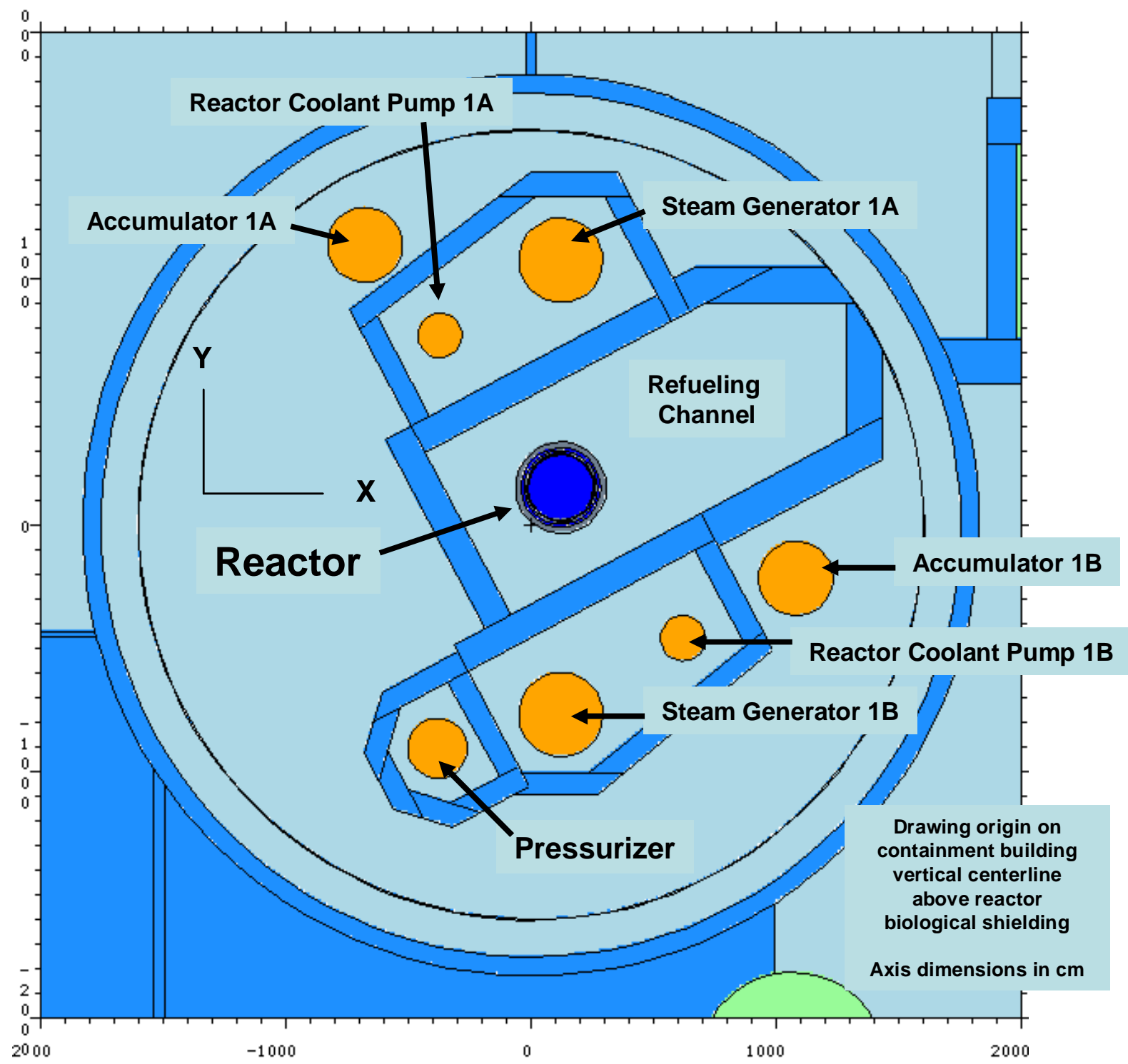

Fig. 9. Plan (X-Y) view of containment building, showing major structural and reactor components. Model origin: $x=0 \mathrm{~cm}, y=0 \mathrm{~cm}, z=9060 \mathrm{~cm}$. 


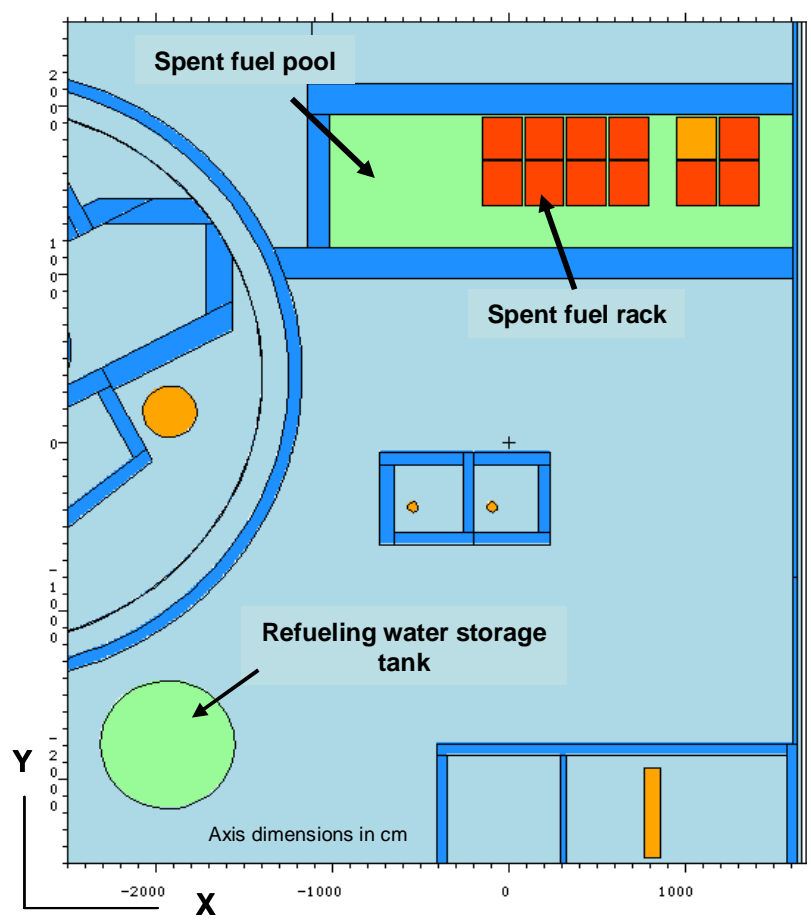

Fig. 10. Plan (X-Y) view of auxiliary building at approximate reactor midplane showing spent fuel pool and refueling water storage tank. Model origin: $x=3000 \mathrm{~cm}, y=-400 \mathrm{~cm}, z=8700 \mathrm{~cm}$.

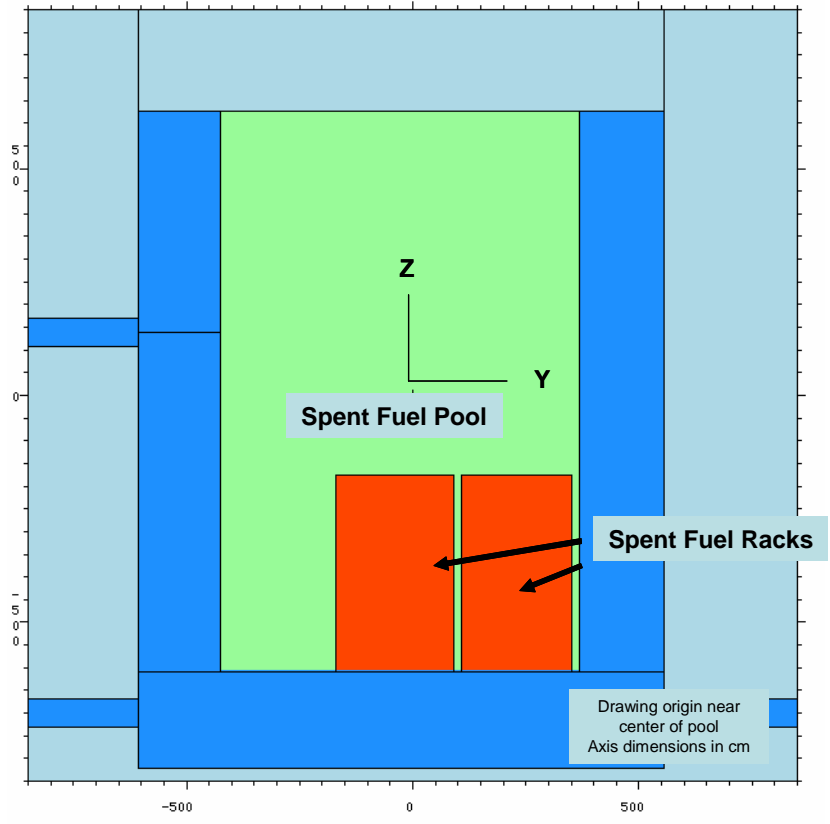

Fig. 11. Elevation (Y-Z) view of the spent fuel pool showing the fuel storage racks. Model origin: $x=3200 \mathrm{~cm}, y=1180 \mathrm{~cm}, z=9140 \mathrm{~cm}$.

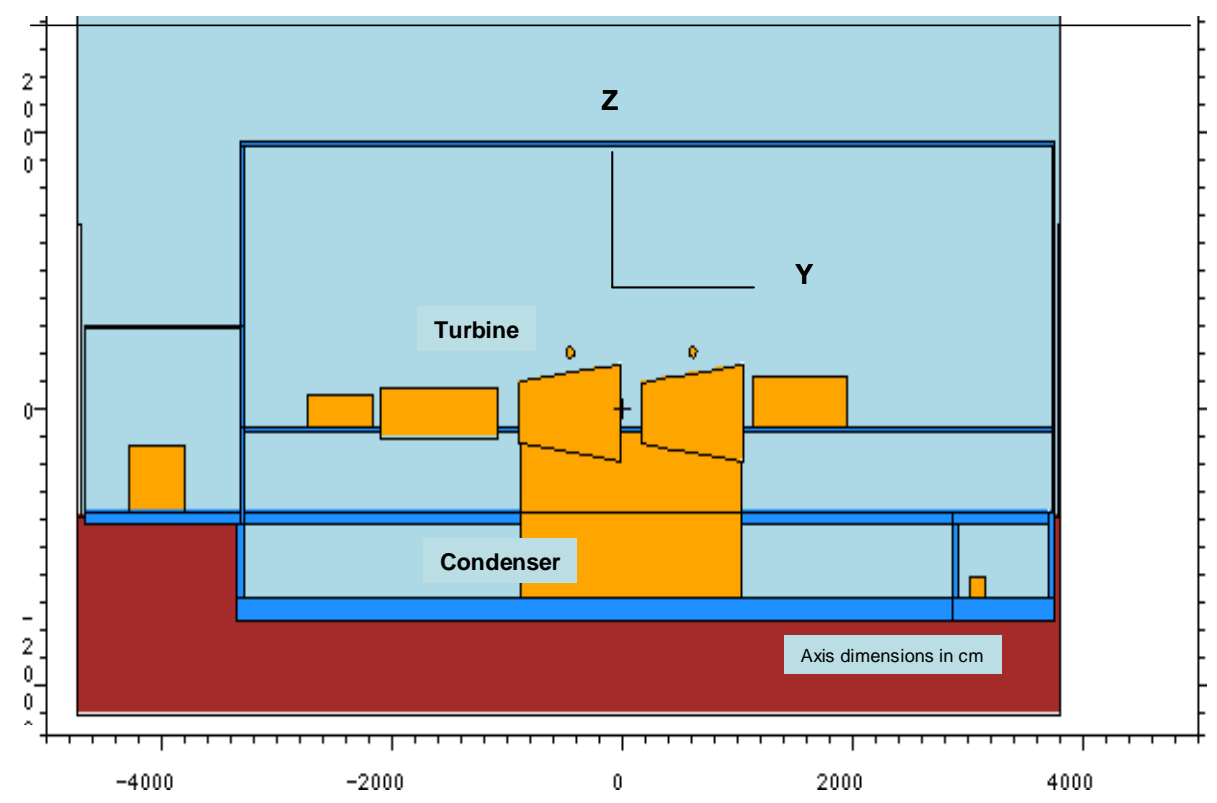

Fig. 12. Elevation $(Y-Z)$ view showing turbine and condenser sections in the turbine building. Model origin: $x=880 \mathrm{~cm}, y=-5890 \mathrm{~cm}, z=9220 \mathrm{~cm}$. 


\subsection{MATERIALS}

Materials used for the model include air, soil, a homogenized core mixture ( $\mathrm{UO}_{2}$, water, and zirconium), water, borated water, concrete, a spent fuel composite material, and steel. Except for the spent fuel composite material, the material components and densities are typical handbook values. The steel was used for two mixtures-a full-density $\left(7.92-\mathrm{g} / \mathrm{cm}^{3}\right)$ mixture to be used for solid-steel components and a reduced-density $\left(1-\mathrm{g} / \mathrm{cm}^{3}\right)$ mixture to be used as a simplified material for most large components (turbines, condensers, etc.). The spent fuel composite material is comprised of a combination of the spent fuel assemblies and structural materials in the spent fuel racks separating the individual spent fuel assemblies. This composite material includes steel and $\mathrm{B}_{4} \mathrm{C}$. Material compositions by weight fraction are shown in Tables 3 and 4.

Table 3. Material compositions by weight fraction ${ }^{a}$

\begin{tabular}{|c|c|c|c|c|c|c|}
\hline Element & $\begin{array}{l}\text { MCNP } \\
\text { identifier }\end{array}$ & $\begin{array}{c}\text { Soil } \\
200 \\
1.02 \mathrm{~g} / \mathrm{cm}^{3}\end{array}$ & $\begin{array}{c}\text { Fuel } \\
300 \\
4.29 \mathrm{~g} / \mathrm{cm}^{3}\end{array}$ & $\begin{array}{c}\text { Concrete } \\
500 \\
2.3 \mathrm{~g} / \mathrm{cm}^{3}\end{array}$ & $\begin{array}{c}\text { ss304 } \\
600 \\
7.94 \mathrm{~g} / \mathrm{cm}^{3}\end{array}$ & $\begin{array}{c}\text { Spent fuel } \\
800 \\
2.06 \mathrm{~g} / \mathrm{cm}^{3}\end{array}$ \\
\hline Hydrogen & 1001 & & $1.29712 \mathrm{E}-02$ & $1.00000 \mathrm{E}-02$ & & \\
\hline Boron & 5010 & & & & & 4.51946E-06 \\
\hline Boron & 5011 & & & & & $1.99976 \mathrm{E}-05$ \\
\hline Carbon & 6000 & & & & $8.00360 \mathrm{E}-04$ & 1.04987E-04 \\
\hline Oxygen & 8016 & 5.22913E-01 & $1.88488 \mathrm{E}-01$ & $5.32000 \mathrm{E}-01$ & & 8.18902E-02 \\
\hline Sodium & 11023 & & & $2.90000 \mathrm{E}-02$ & & \\
\hline Aluminum & 13027 & $9.33530 \mathrm{E}-02$ & & $3.40000 \mathrm{E}-02$ & & \\
\hline Silicon & 14000 & $3.19873 \mathrm{E}-01$ & & $3.37000 \mathrm{E}-01$ & $1.00045 \mathrm{E}-02$ & $1.22985 \mathrm{E}-03$ \\
\hline Calcium & 20000 & & & 4.40000E-02 & & \\
\hline Chromium & 24000 & & & & $1.90086 \mathrm{E}-01$ & 2.32972E-02 \\
\hline Manganese & 25055 & & & & $2.00090 \mathrm{E}-02$ & $2.45971 \mathrm{E}-03$ \\
\hline Iron & 26000 & $6.38612 \mathrm{E}-02$ & & $1.40000 \mathrm{E}-02$ & $6.84058 \mathrm{E}-01$ & 8.39900E-02 \\
\hline Nickel & 28000 & & & & 9.50428E-02 & $1.16986 \mathrm{E}-02$ \\
\hline Zirconium & 40000 & & $1.75652 \mathrm{E}-01$ & & & $1.86978 \mathrm{E}-01$ \\
\hline Uranium & 92235 & & 1.95919E-02 & & & $2.03976 \mathrm{E}-02$ \\
\hline Uranium & 92238 & & $6.03297 \mathrm{E}-01$ & & & 5.87930E-01 \\
\hline
\end{tabular}

Table 4. Air and water compositions by weight fraction ${ }^{a}$

\begin{tabular}{|c|c|c|c|c|}
\hline Element & $\begin{array}{c}\text { MCNP } \\
\text { identifier }\end{array}$ & $\begin{array}{c}\text { Air } \\
100 \\
0.0012 \mathrm{~g} / \mathrm{cm}^{3}\end{array}$ & $\begin{array}{l}\text { Water } \\
400 \\
1 \mathrm{~g} / \mathrm{cm}^{3}\end{array}$ & $\begin{array}{c}\text { Borated water } \\
700 \\
1 \mathrm{~g} / \mathrm{cm}^{3}\end{array}$ \\
\hline Hydrogen & 1001 & $1.11928 \mathrm{E}-03$ & $1.11915 \mathrm{E}-01$ & $1.11706 \mathrm{E}-01$ \\
\hline Boron & 5010 & & & 3.69219E-04 \\
\hline Boron & 5011 & & & $1.63115 \mathrm{E}-03$ \\
\hline Nitrogen & 7014 & $7.80000 \mathrm{E}-01$ & & \\
\hline Oxygen & 8016 & $2.18881 \mathrm{E}-01$ & $8.88085 \mathrm{E}-01$ & 8.86294E-01 \\
\hline
\end{tabular}

${ }^{a}$ Material name, MCNP assigned material number, and density are provided in the heading for each material. Numerical entries under each material are weight fractions. 


\subsection{ADDITION OF PRIMARY COOLANT LOOP}

The base-case PWR geometry model in Section 2.3 was modified to include the piping between the reactor, the steam generators, and the primary coolant pumps, as well as the holdup volumes in these components. (The pressurizer was not modeled.) These changes were made to enable the evaluation of the dose from photons emitted by the primary reactor coolant. Revised model sections that incorporate these components are shown in Figs. 13-15. The source (green volumes in figures) was apportioned between pipe and holdup volumes and is discussed in Section 3.3.

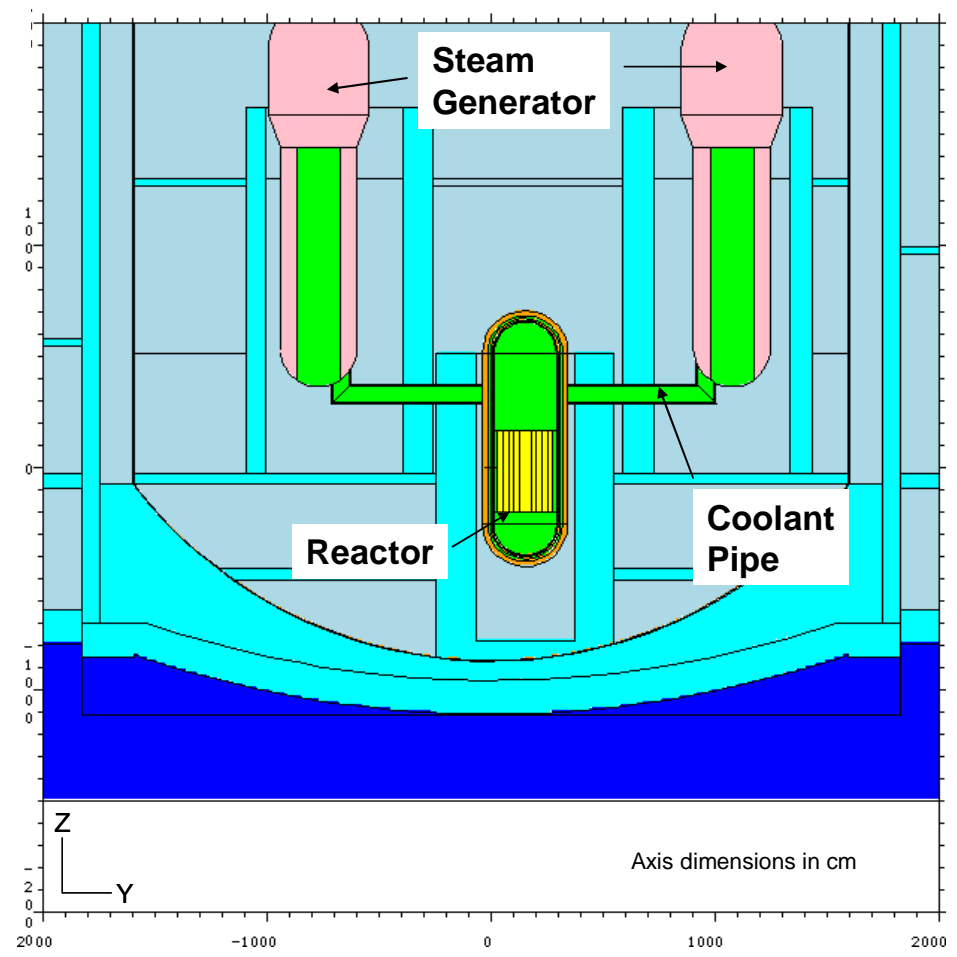

Fig. 13. MCNP model showing coolant pipes from reactor to steam generators (elevation view). 


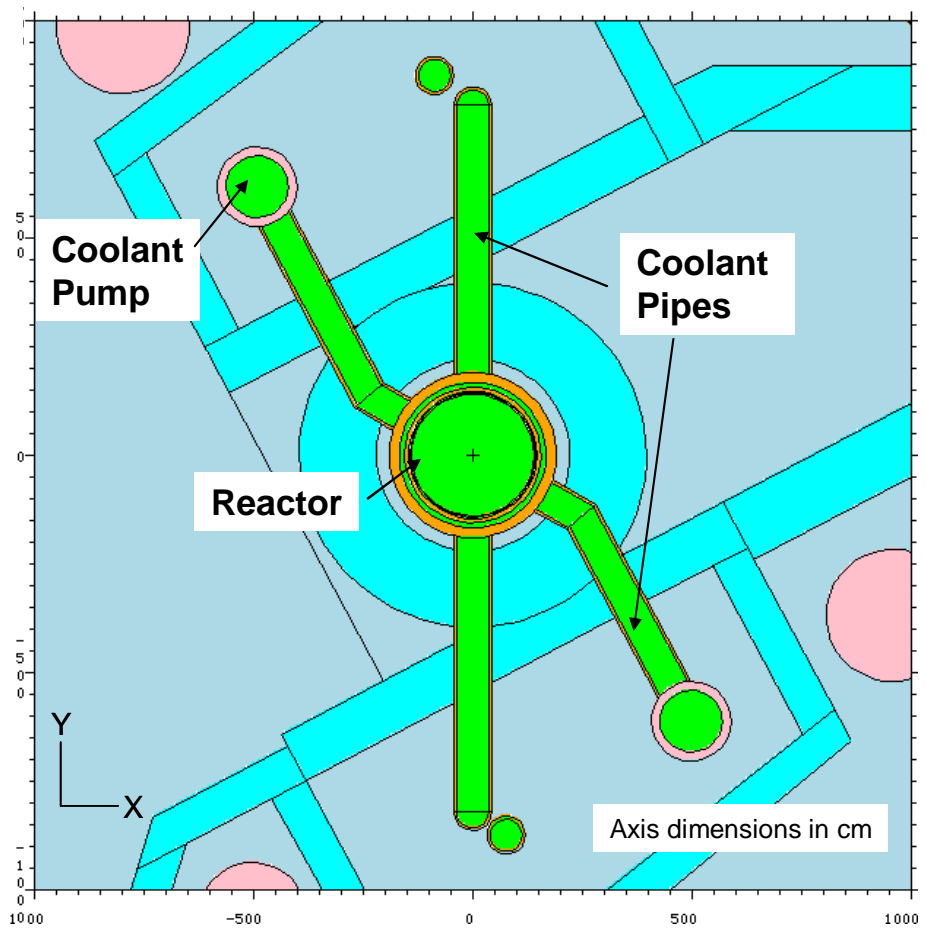

Fig. 14. MCNP model showing coolant pipes from reactor to steam generators and from coolant pumps back to reactor (plan view).

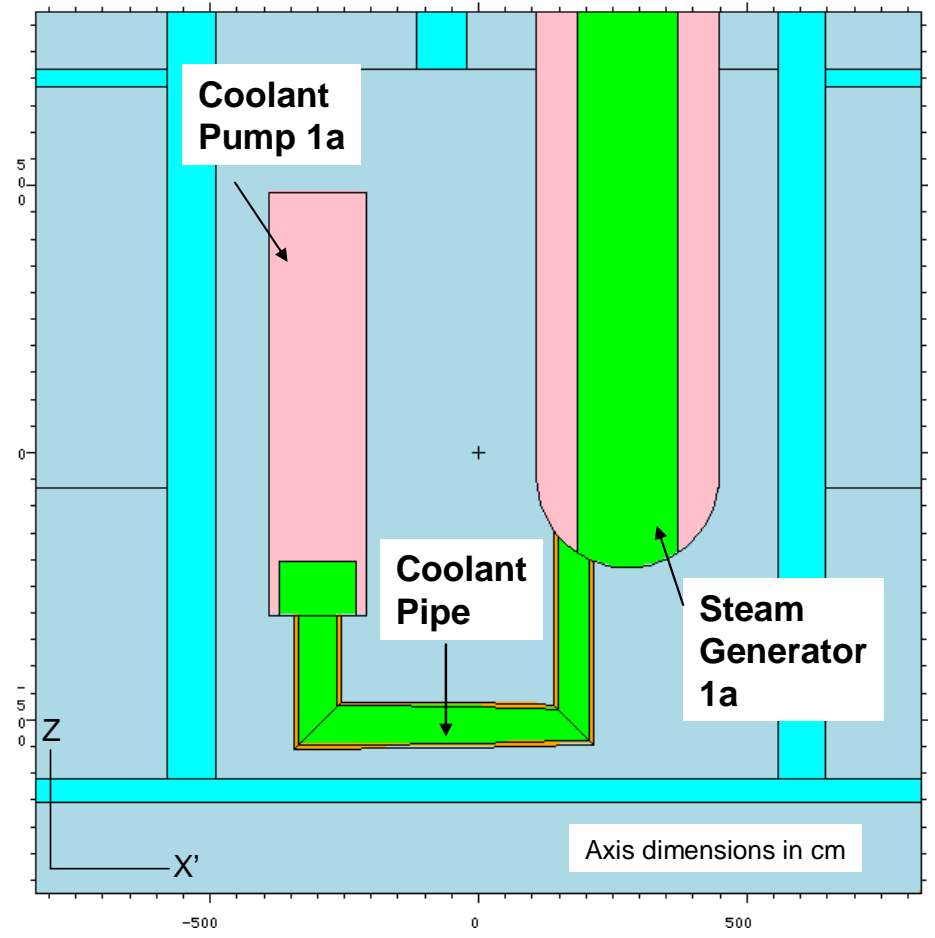

Fig. 15. MCNP model showing coolant pipe from Steam Generator 1a to Coolant Pump 1a (elevation view). Horizontal $\left(\mathrm{X}^{\prime}\right)$ axis is aligned with coolant-pump-to-steam-generator pipe. 


\subsection{SIMPLIFIED CONTAINMENT MODEL}

A simplified PWR containment model was developed to more easily explore the computational issues involved with a large-scale simulation and, in particular, to examine the applicability of the

CADIS/ADVANTG methodology. In addition to being limited to the containment structure, the main features were simplified to geometry representations utilizing rectangular or cylindrical solids, both available in MCNP (referred to as RPPs and RCCs). The geometry was coded without recourse to "union" or "inverse" constructs (represented in MCNP as “:" and “\#”, respectively). This restriction will enable a possible direct rendering of the geometry in the MAVRIC/MONACO (Peplow et al., 2006; Peplow and Wagner, 2006) Monte Carlo code at a later date for possible similar analyses. In addition to simplification and limitation of the model to the containment, the geometry was rotated so that the cooling channel walls were aligned with the horizontal (X-Y) axes, thus making it simpler to describe the model using Monte Carlo constructs as well as a Cartesian mesh for discrete ordinates. Details of the reactor including the source terms were retained from the full PWR model. Otherwise, the dimensions of the model and the approximate amount of shielding (wall thickness and size of water regions) were equivalent to the full unsimplified PWR model described in previous sections. Additional tally cells described below were also added to the model for investigation of calculated results.

Two horizontal cuts (plan view-X-Y plane) and two vertical cuts (elevation views-X-Z and Y-Z planes) of the simplified containment model are shown in Figs. 16-19. Five rectangular solid-shaped cells numbered 1 through 5 (which correspond to Cells 995-999 in the MCNP model) are shown in the figures. These cells are utilized as cell tallies for neutron and photon doses and as adjoint-source locations. Cell number 0 (actual Cell 994 in the model) is an annular-shaped region that surrounds the containment. The figures also show components such as the reactor and steam generators and concrete walls separating the various regions. 


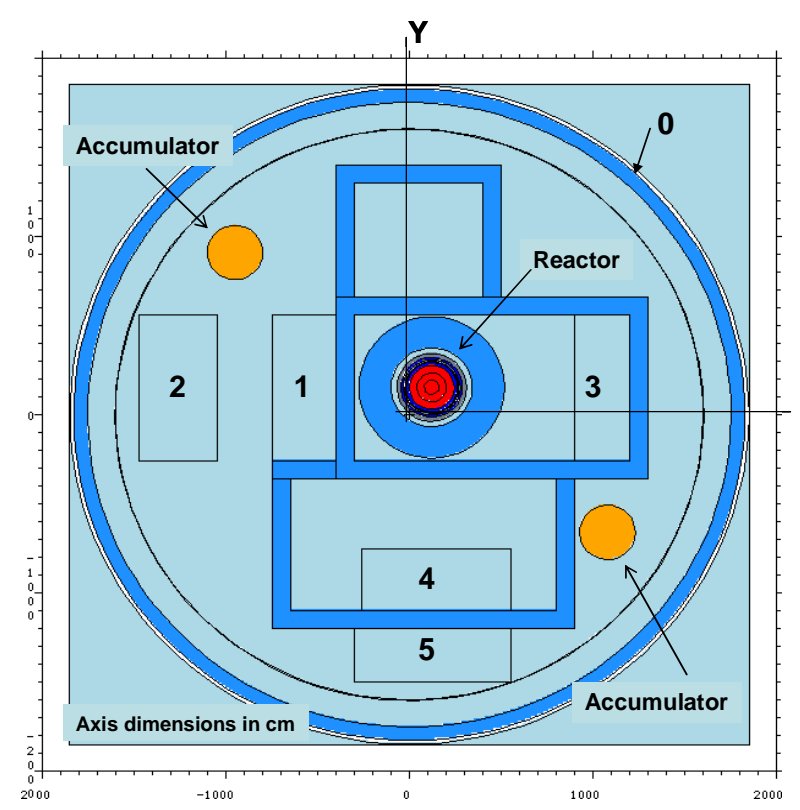

Fig. 16. Plan view of geometry showing $X-Y$ plane with origin at center of containment at approximate vertical center of reactor core. Cells used for tallies and adjoint sources are shown.

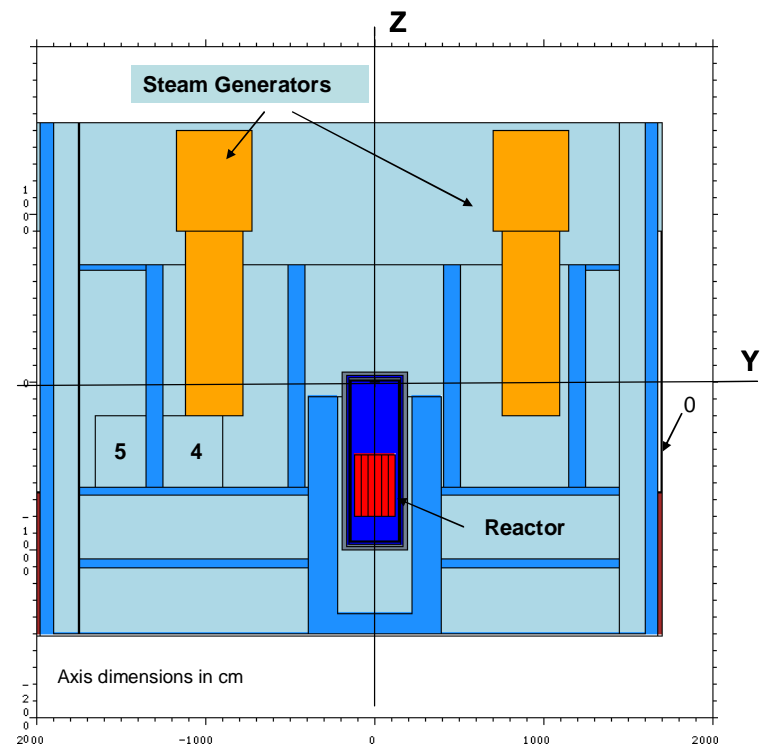

Fig. 18. Elevation view of geometry showing Y-Z plane through center of reactor. Cells used for tallies and adjoint sources are shown.

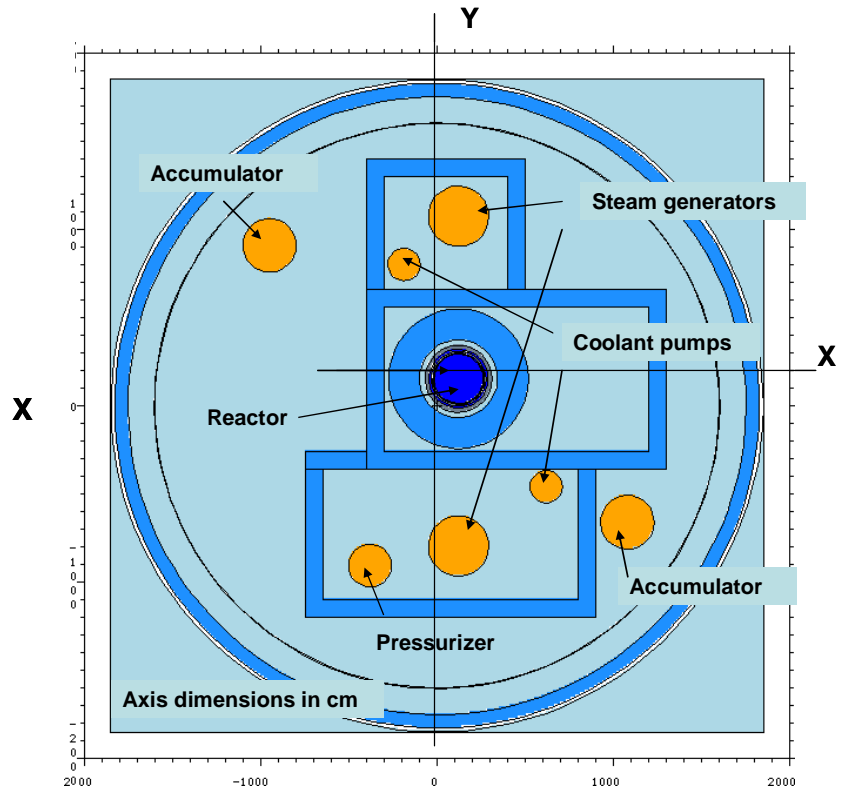

Fig. 17. Plan view of geometry showing X-Y plane with origin at center of containment near top of reactor core and above tally cells. Major components are shown.

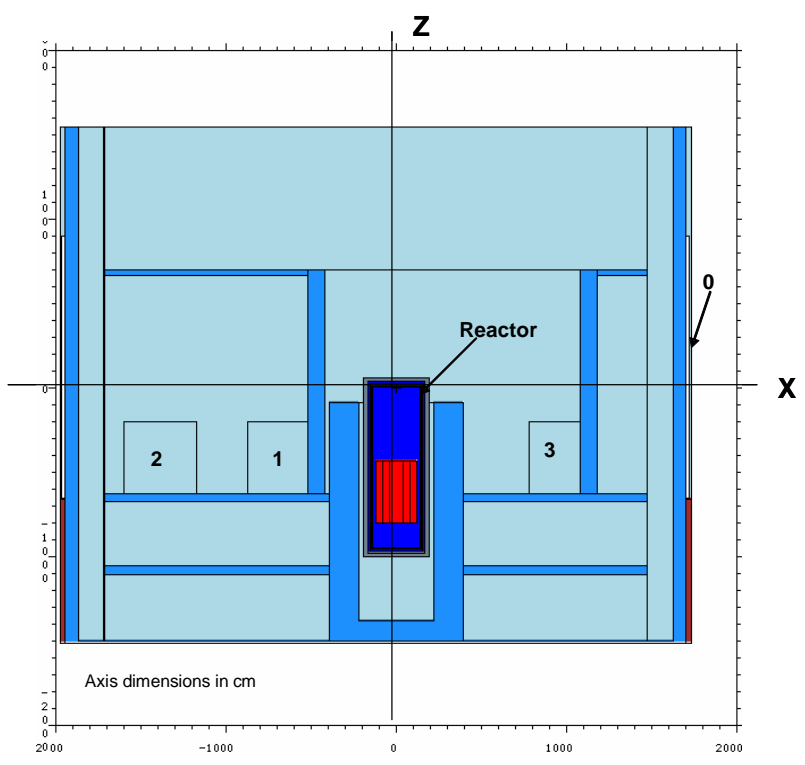

Fig. 19. Elevation view of geometry showing $\mathrm{X}-\mathrm{Z}$ plane through center of reactor. Cells used for tallies and adjoint sources are shown. 


\section{RADIATION SOURCE MODELS}

A nuclear power plant contains many sources of radiation. Chief among them are the reactor itself (operating or not), the stored spent fuel and transfer system, the primary and secondary coolant loops (activated during normal operation), and various filtering systems and resins. Both neutrons and photons contribute to dose in different proportions in different locations within the plant. MCNP models were constructed for the reactor and the spent fuel pool for both neutrons and photons. An additional photonsource model for the activated primary coolant loop was also created.

\subsection{REACTOR SOURCE MODELS}

\subsubsection{Introduction}

MCNP-compatible sources were prepared that represent neutron and photon radiation from a typical PWR core. Source descriptions were prepared that represent conditions while the reactor is at power and also at various times following shutdown. Neutrons and photons that result directly from the fission process (when the reactor is at power) are referred to as "prompt." Decay neutrons and decay photons were also considered. These arise from decay processes in the spent fuel following shutdown. Decay neutrons consist of spontaneous-fission neutrons together with neutrons that arise as a result of $(\alpha, n)$ reactions on oxygen nuclei. By far, the majority of decay neutrons result from spontaneous fission of ${ }^{242} \mathrm{Cm}$ and ${ }^{244} \mathrm{Cm}$. Decay photon radiation results from photon decays following beta decay of the many neutron- rich fission products in the spent fuel.

When considering prompt neutron radiation, it is conventional to consider the associated delayed component also. However, the delayed component was not considered as a separate entity. Its intensity is less than $1 \%$ of that of the prompt and, given that reactor shutdown is not instantaneous, it was assumed that the reactor was at full power until completely shut down. This assumption ensured a conservative approach. In the case of the photon radiation, the first minute or so following shutdown proves difficult to characterize. During this time, the photon intensity is dropping rapidly and cannot be well characterized by either the fission photon spectrum or by the photon decay libraries for spent fuel. Our approach, therefore, was to assume the reactor is at power until such time that the radiation source can be accurately described by the decay photon radiation.

The source characterizations developed in this work refer to a PWR operating at a power level of $1650 \mathrm{MW}(\mathrm{t})$. The total core inventory is $46.1 \mathrm{tHM}$ (tonnes of heavy metal, meaning uranium in this case), and the average maximum burnup is $39 \mathrm{GWd} / \mathrm{MT}$. Therefore, the prompt neutron and photon sources apply to a fission rate that corresponds to $1650 \mathrm{MW}$. For the decay sources, a number of scenarios have been assumed, and in developing the decay sources, it was assumed they would apply to the full-core conditions at midcycle. We assumed there are three separate core loadings present at any time: one-third of the core is in its first cycle, one-third has been irradiated for one cycle and is in its second cycle, and one-third of the core has been irradiated for two cycles and is in its third cycle. Therefore, with $39 \mathrm{GWd} / \mathrm{MT}$ as a maximum burnup and three core loadings at midcycle, one-third of the core experiences burnup at $6.5 \mathrm{GWd} / \mathrm{MT}$, one-third at $19.5 \mathrm{GWd} / \mathrm{MT}$, and one-third at $32.5 \mathrm{GWd} / \mathrm{MT}$.

The ORNL SCALE (SCALE, 2006) Straker/Morrison 22-neutron-energy-group and 18-photon-energygroup structures were used for all sources in this analysis. These are also equivalent to the CASK-81 22and 18-group neutron- and photon-energy structures ("CASK-81," 1983), to which they are often referred. Elsewhere in this document, they will be referred to simply as the "22- and 18-group neutron and photon energy structures." 


\subsubsection{Spatial Arrangement of Source in the PWR Core}

The radiation source is contained in the actinide and fission-product species that are present in the fuel rods. By defining the energy spectra for the neutrons and photons in terms of what is known for fuel in an operating reactor, or for spent fuel as the case may be, and with the surrounding core material properly defined, one obtains a true rendition of the resulting energy spectra outside the core. One possible source definition would be to specify the fuel rods in terms of diameters, lengths, and spacing. Such an arrangement is practical for the case of an individual assembly but is overly cumbersome when an entire reactor core is to be defined. For the core as a whole, it is practical to homogenize the core material and to distribute the source material throughout the core, with the possible addition of zones to allow for radial patterns. In this particular work, however, because of the requirements of a number of codes that were being executed, it was found to be convenient to place a lattice of source points throughout the core. The lattice consisted of horizontal arrays of source points at evenly spaced axial positions. Twenty-five axial positions were chosen with a horizontal array of 164 source points at each one, for a total of 4100 source points within the PWR core.

The source-strength distribution within the core is not uniform: it has axial and radial variations. Figure 20 shows a typical axial profile for the power level for a PWR. This axial profile was employed when defining the source strengths. The profile in Fig. 20 is from a Swedish PWR for which detailed burnup information was available to us in numerical format (SKB, 2003) and is representative of a typical PWR. The profile was fit analytically (sixth-order polynomial using only even-parity terms) and was used in the code that produces the source-definition description.

To account for radial source variations, it was assumed that the source intensity in roughly the outer oneassembly thickness in the radial direction was reduced to $50 \%$ of the central intensity and the intensity in the next inward one-assembly thickness was reduced to about $75 \%$ of the central assembly intensity. Figure 21 shows the resulting radial pattern based on these assumptions (for the array of horizontal points). The active core radius is $122.5 \mathrm{~cm}$. Note that this is an effective value because of the irregular nature of the outer edge of the core.

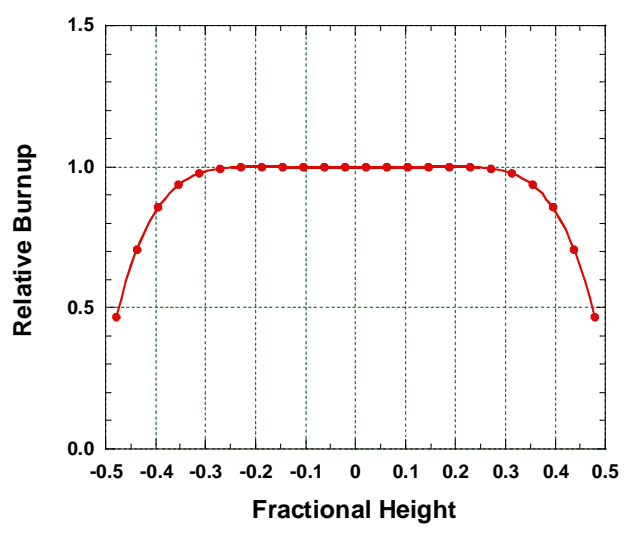

Fig. 20. Axial power profile (proportional to relative burnup) assumed for source definition.

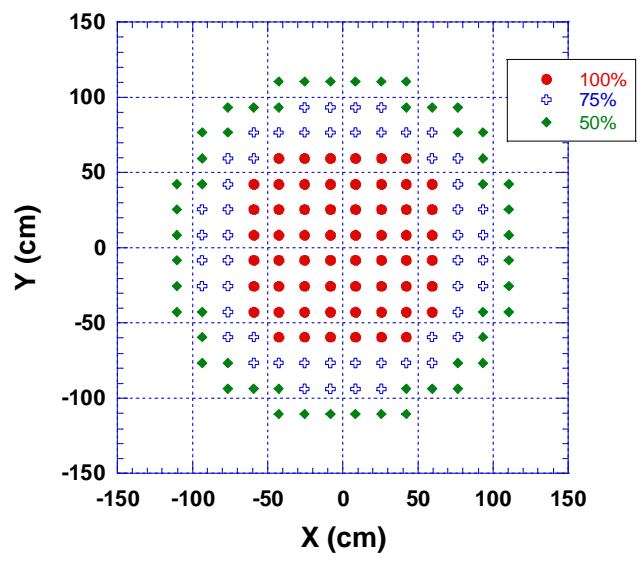

Fig. 21. Radial pattern of source strengths used for the PWR source definition.

\subsubsection{Determination of Neutron Spectra}

Prompt neutron spectra arising directly from fission were determined from the operating power of the reactor and the shape of the spectrum for fission neutrons. Spontaneous-fission decay neutrons were 
determined from the concentrations for spontaneous-fission species, supplemented by the neutron contributions resulting from the alpha decays that cause $(\alpha, n)$ reactions on oxygen isotopes.

\subsubsection{Prompt Neutron Spectra}

Neutrons from the fission process can be characterized by a Maxwellian distribution. However, for shielding purposes, where high-energy neutrons are of importance, a somewhat better representation is obtained using what is generally known as the Watt spectrum (Watt, 1952). A number of researchers seem to have proposed this shape, which was probably first reported in the literature by Watt, when he documented his measurements on fission-neutron spectra. Cranberg et al. (1956), who reported on extended measurements some years later, also discuss this representation of the neutron spectrum. The Watt spectrum can be described by

$$
\chi(E)=0.453 \exp (-1.036 E) \sinh (2.29 E)^{1 / 2},
$$

which gives the probability (per $\mathrm{MeV}$ ) that a neutron is emitted with energy $E(\mathrm{MeV})$. We assume 202.2 MeV/fission $\left({ }^{235} \mathrm{U}\right)$ and 2.5 neutrons per fission. This yields $7.728 \times 10^{16}$ neutrons $\cdot \mathrm{s}^{-1} \cdot \mathrm{MW}^{-1}$.

Thus, using the value of $E$, the effective bin energy, the reactor power in megawatts, and the bin width in $\mathrm{MeV}$, one can use $\chi(E)$ to calculate the number of neutrons per second in the bin. A fission neutron spectrum, calculated using the Watt formula, is shown in Fig. 22. This spectrum was determined using the 22-group neutron energy structure and represents neutron totals from a PWR operating at $1650 \mathrm{MW}$. The Watt spectrum is considered to give a good rendition of the fission neutron energy spectrum. However, it was developed when investigating ${ }^{235} \mathrm{U}$ fission. Thus, the values of the numerical constants will be slightly dependent on the fissioning nuclide. Updated values for the constants have been proposed from time to time. [For an extensive discussion, see Madland and Nix (1982)]. For the purposes of the shielding calculations for which this work is intended, the values used here are considered to be sufficiently accurate. However, two issues need to be mentioned with regard to the accuracy of the calculation of the neutron fission spectrum: firstly, the simple assumption that the bin energy, $E_{b}$, was chosen to be the energy at the bin center and, secondly, that the normalization was done by matching the total neutron count between lowest and highest bin edges to the theoretical total, which applies from zero to infinity. These issues are probably of negligible importance here. However, they can easily be addressed and future calculations will be adjusted accordingly.

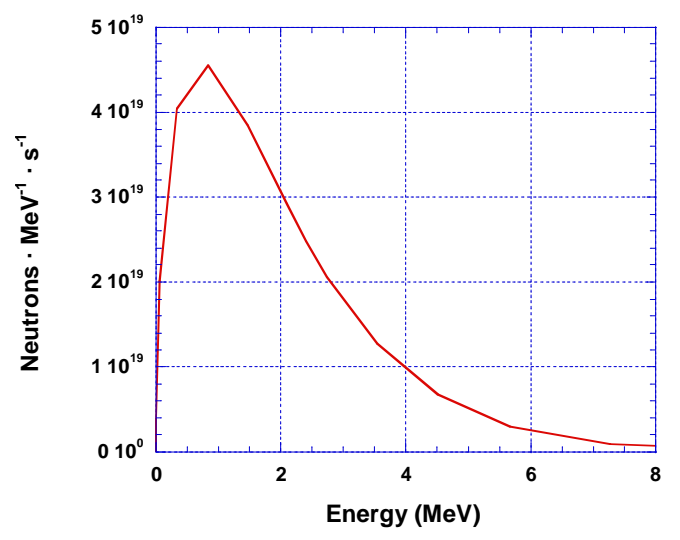

Fig. 22. Fission neutron spectrum for a PWR at $1650 \mathrm{MW}$. 


\subsubsection{Decay Neutron Spectra}

Decay neutrons result from spontaneous fission and $(\alpha, n)$ reactions on ${ }^{17} \mathrm{O}$ and ${ }^{18} \mathrm{O}$ as a result of alpha decay of actinides. Rinard et al. (1981) show examples of calculations that determine such decay neutron spectra for spent PWR fuel. They use a Maxwellian distribution to represent the spontaneous fission neutrons. For the $(\alpha, n)$ neutrons, they use empirical fits to a neutron spectrum resulting from ${ }^{238} \mathrm{Pu}$ alpha decay and conclude that this is also appropriate for the other alpha-decay processes of interest. The Maxwellian distribution gives the normalized neutron intensity as

$$
W(E)=\frac{\sqrt{E}}{0.886227} \frac{e^{-E / T}}{T^{3 / 2}} .
$$

Rinard et al. report that a spectral temperature, $T$, of $1.2 \mathrm{MeV}$ is appropriate for uranium and plutonium nuclides and that $1.5 \mathrm{MeV}$ is appropriate for ${ }^{242} \mathrm{Cm}$ and ${ }^{244} \mathrm{Cm}$. In developing the spectra that are of interest here, spontaneous fission of ${ }^{242} \mathrm{Cm}$ and ${ }^{244} \mathrm{Cm}$ was responsible for about 40 and $50 \%$, respectively, of the decay neutrons. Most of the remainder was from neutrons that result from $(\alpha, n)$ reactions involving ${ }^{238} \mathrm{Pu}$ decay alphas. As indicated for the prompt fission neutrons, the Watt spectrum gives a better representation of the high-energy neutrons than does a Maxwellian. This may also be true for the spontaneous-fission neutrons, and the matter will be considered in future work.

As regards the $(\alpha, n)$ component, the neutron spectrum arising from ${ }^{238} \mathrm{Pu}$ alpha decay was parameterized by Rinard et al. as follows:

$$
N(E)=N_{t o t} F(E)
$$

where the function $F(E)$ is composed of three segments.

$$
\begin{array}{lr}
F(E)=0.2207 E^{6.4} & 0.0<E<0.8 \mathrm{MeV} \\
F(E)=-0.138 E^{2}+0.6448 E+0.3746 & 0.8<E<2.4 \mathrm{MeV} \\
F(E)=0.3803 \exp \left(-[0.77(E-2.31)]^{2}\right) & E>2.4 \mathrm{MeV}
\end{array}
$$

Decay neutron spectra are shown in Fig. 23. Spontaneous-fission and $(\alpha, n)$ neutrons are separately identified. These particular spectra refer to the case of one MT of discharged fuel following burnup to $39 \mathrm{GWd}$. Both the different shapes and the relative importance of the spontaneous-fission and the $(\alpha, n)$ components can clearly be seen.

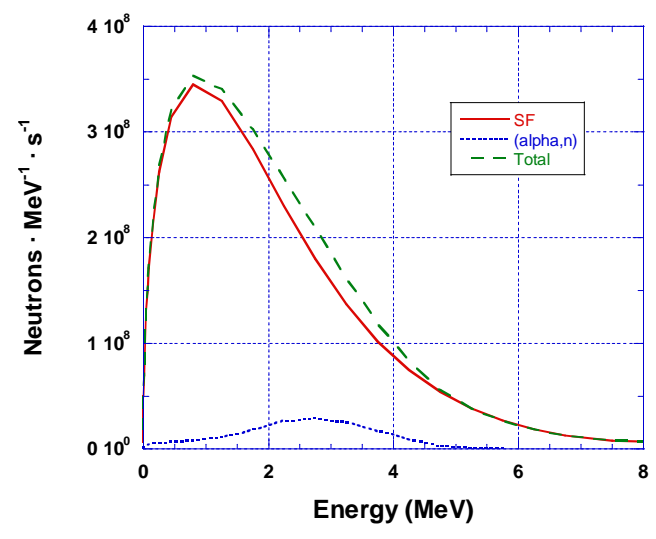

Fig. 23. Spent-fuel decay neutron spectra. 


\subsubsection{Determination of Photon Spectra}

The photon spectrum associated with the prompt photons was calculated using an empirical fit. The decay photon spectrum was calculated using an ORIGEN-S decay case following a TRITON simulation of burnup in a PWR. [ORIGEN-S and TRITON are components of the ORNL SCALE (SCALE, 2006) code system.]

Chilton et al. (1984) discuss the energy spectrum of prompt photons that result from the fission process. They give an empirical fit of the form

$$
N(E)=6.7 \exp (-1.05 E)+30 \exp (-3.8 E)
$$

where $N(E)$ gives the number of photons per $\mathrm{MeV}$ per fission. This empirical fit applies to the range 0.3 to $7 \mathrm{MeV}$. Prompt photon spectra calculated here were determined using this fit. The value at $0.3 \mathrm{MeV}$ was extended to values of $N(E)$ below $0.3 \mathrm{MeV}$, and for all values of $E$ above $7 \mathrm{MeV}, N(E)$ was assigned the 7-MeV value. For our purposes here, photons below $0.3 \mathrm{MeV}$ are probably not of great importance; however, by extending the 7-MeV value upward, we introduce a level of conservatism because we overestimate the flux at higher energies.

An example of a fission photon spectrum calculated with the above formula is shown in Fig. 24. The extension of the $0.3-$ and $7-\mathrm{MeV}$ values can be seen. This calculation refers to a fission rate of $35.8 \mathrm{MW}$ (about one assembly). According to Chilton et al. (1984), the lower part of the spectrum should yield about 10.5 photons $\cdot \mathrm{MeV}^{-1} \cdot$ fission ${ }^{-1}$. The values in this region for Fig. 24 are consistent with this value for the power level used in the calculations.

Decay photon spectra were obtained from ORIGEN-S decay cases. For these purposes the TRITON code was executed to simulate the full course of fuel burnup. Then, from the intermediate burnup steps, the ORIGEN-S decay calculations estimated the photon spectra associated with the fuel mixtures for midcycle conditions. Examples of photon decay spectra are shown in Fig. 25. However, these spectra are not for a midcycle mix of fuel. Rather, they are for the case of 1 MT of fuel irradiated to $39 \mathrm{GWd}$. Nevertheless, they are representative of the types of photon spectra that apply in these kinds of calculations. Spectra are shown at cooling times of 1 day, 1 week, and 1 month.

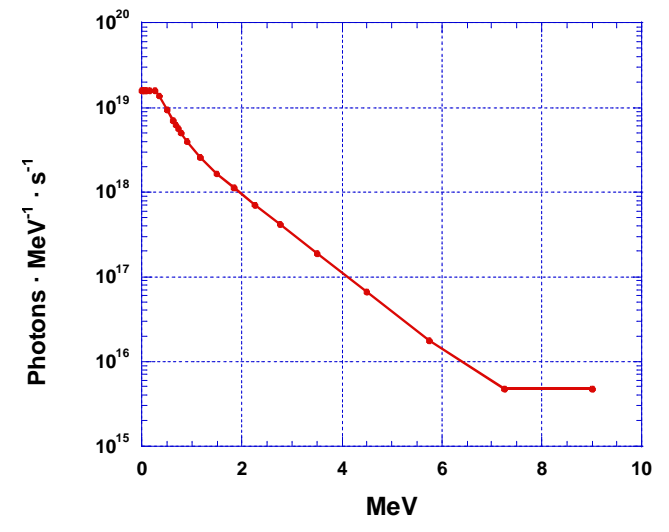

Fig. 24. Fission photon spectrum calculated for a power level of $35.8 \mathrm{MW}$.

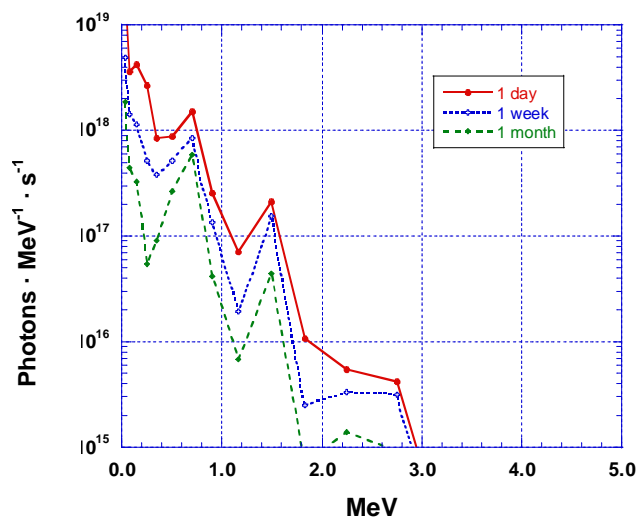

Fig. 25. Decay photon spectra for cooling times of 1 day, 1 week, and 1 month. 


\subsubsection{Details of Source-Preparation Procedures}

The determination of prompt neutron and prompt photon spectra was carried out using the fission-neutron and fission-photon spectral descriptions outlined above. For the required group structure, neutron intensities were calculated for the group midpoints, and counts were then assigned to the groups based on the group width.

All decay sources were determined by running a TRITON case for a total burnup of $39 \mathrm{GWd} / \mathrm{MT}$ and then using ORIGEN-S with the intermediate TRITON output data at 6.5, 19.5, and $32.5 \mathrm{GWd} / \mathrm{MT}$ to produce decay output data for 1 day, 1 week, and 1 month. During the determination of the decay neutron sources, concentrations were obtained for the important spontaneous-fission and $(\alpha, n)$ species. These concentrations were then used to calculate decay neutron spectra [using the technique of Rinard et al. (1980)] for the three values of assembly burnup at each of the decay times. Neutron intensities were calculated for the group midpoints, and group count rates were then determined based on the group width. For each of the three decay times, the 6.5-, 19.5-, and 32.5-GWd/MT neutron spectra were used to produce a core-average spectrum.

The photon source spectra were obtained directly from ORIGEN-S, and for each decay time a coreaveraged source spectrum was again calculated by averaging over the data for the three values of burnup. When one runs ORIGEN-S, one gives the group structure as part of the input and ORIGEN-S determines photon count rates for the groups. It should be mentioned that neutron spectra can also be obtained directly from ORIGEN-S as an alternative to using the approach of Rinard outlined above. A quick comparison of some of the ORIGEN-S output neutron spectra showed good agreement with the corresponding spectra that were calculated as outlined above. The Rinard approach was used here because it was easy to implement. However, future work may use ORIGEN-S in developing the neutron spectra. In our work so far, it is not clear that the two approaches are noticeably different.

We have used averages of decay spectra from fuel irradiated to $6.5,19.5$, and $32.5 \mathrm{GWd} / \mathrm{MT}$ to be representative of the history of the fuel in the PWR core. However, it is not likely that fuel with different irradiation histories would be randomly distributed in the reactor core. It might be more realistic to define separate sources for groups of assemblies with different irradiation histories and to locate these sources more realistically in the core (e.g., in different radial zones). Although this would be likely to provide a more accurate rendition of the reactor's effective source characteristics, it is not clear that it would have a noticeable impact on the intended transport calculations. If time permits, this issue will be addressed at a future date.

\subsection{SPENT-FUEL-POOL SOURCE MODEL}

The goal of this part of the study was to generate neutron and photon source terms for the permanently discharged nuclear fuel of a specific nuclear power plant for use in shielding calculations.

Permanently discharged fuel information for the reactor was extracted from the Form RW-859 Nuclear Fuel Data file obtained from the U.S. Department of Energy (DOE) Energy Information Administration, (DOE, 2002). This data set included permanently discharged fuel through the end of 2002. The database does not include fuel that is expected to be reused. Data from a total of 904 assemblies were extracted and categorized into 16 bins as shown in Table 5. The assembly-specific data used included initial ${ }^{235} \mathrm{U}$ enrichment, initial uranium loading, final burnup, and discharge date. The discharge date was used to calculate the post-shutdown cooling time through 2002. Average parameters calculated for each of the categories were used in SCALE ORIGEN/ARP depletion and decay calculations to generate neutron and photon source terms per assembly for each category. The masses for nonfuel fuel assembly components 
(guide tubes, etc.) were taken from Table 3.11 of NUREG/CR-5625, Technical Support for a Proposed Decay Heat Guide Using SAS2H/ORIGEN-S Data (Hermann et al., 1994). Because the data for the particular reactor selected for this project were not listed, the data for a similar reactor were used.

Table 5. Assembly category information for spent fuel

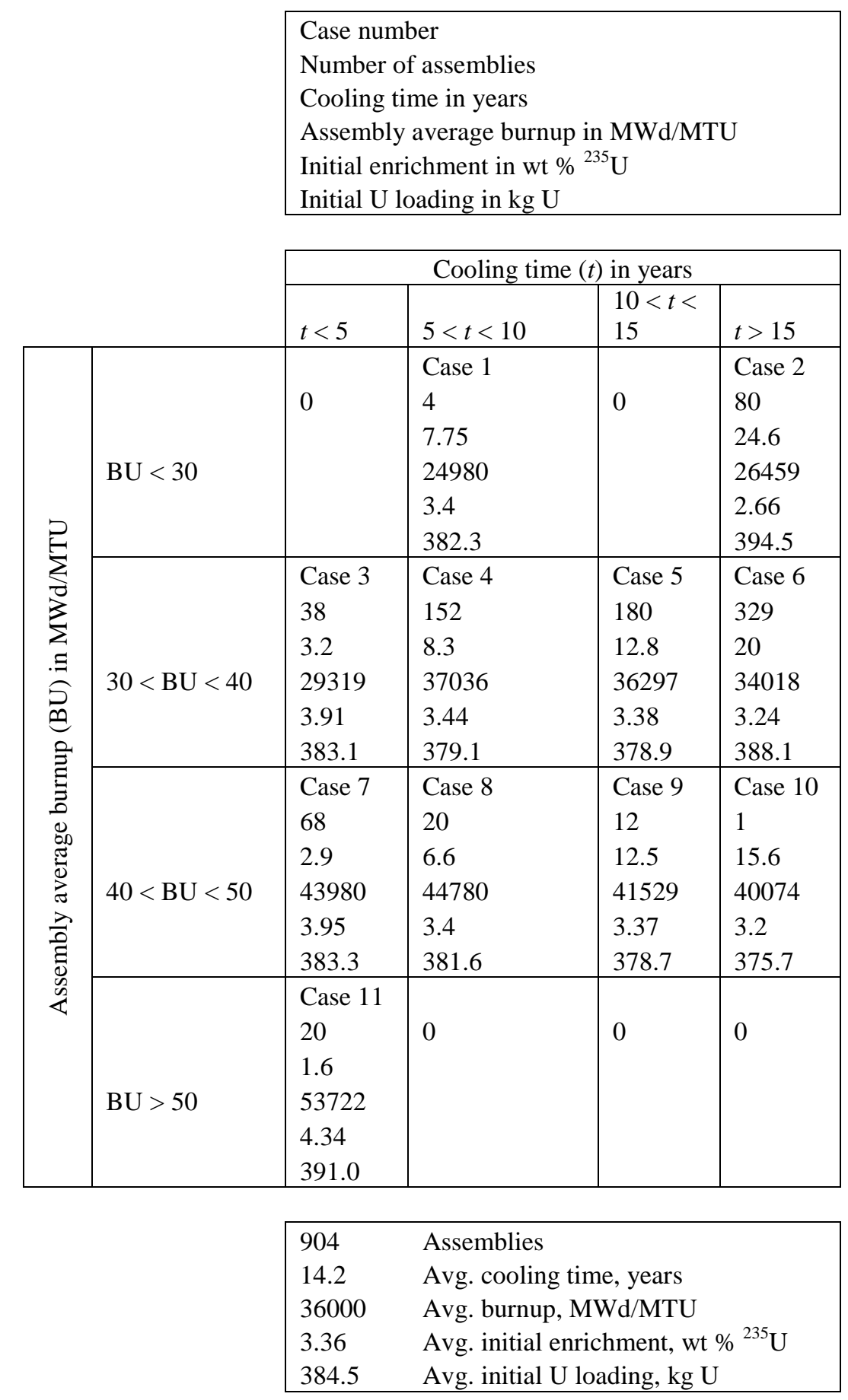


The total source term was then the sum of the source terms for the 904 assemblies. The source terms are provided in 22- and 18-group neutron and photon energy structures. The total neutron and photon source terms are presented in Figs. 26 and 27. Total source strengths are $9.705 \times 10^{10}$ and $2.863 \times 10^{18}$ particles/s for the neutron and photon sources, respectively.

The ORIGEN/ARP depletion/decay calculations used the $14 \times 14$ cross-section library. The list of reactor parameters included a reactor thermal power rating of $1650 \mathrm{MW}$ and an initial uranium loading of 46.1 MTU. The power density is thus calculated to be $35.8 \mathrm{MW} / \mathrm{MTU}$.

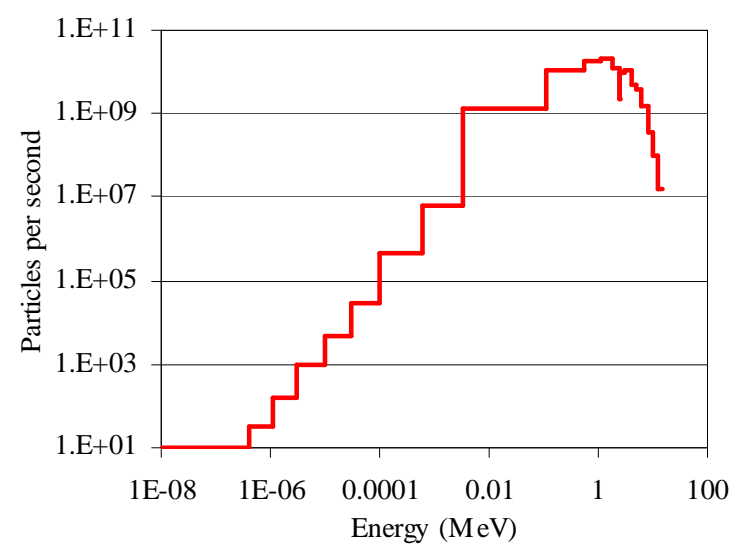

Fig. 26. Neutrons from spent nuclear fuel.

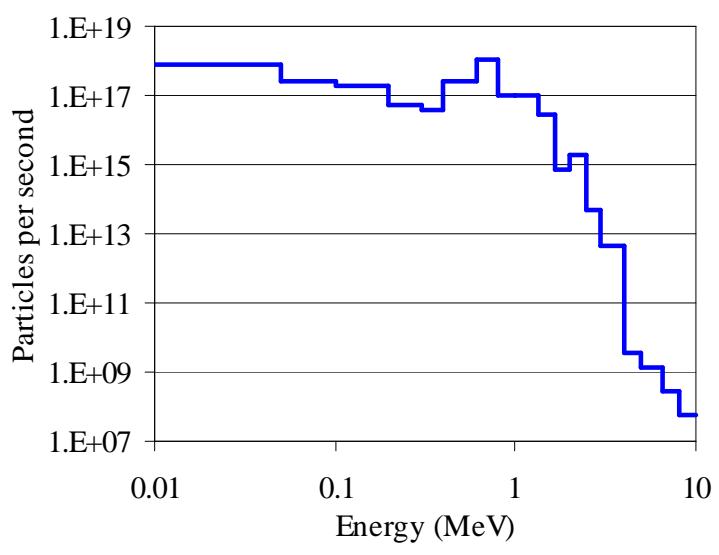

Fig. 27. Photons from spent nuclear fuel.

\subsection{COOLANT ACTIVATION SOURCE MODEL}

For the energies of the emitted photons from the coolant, values from an American Nuclear Society source term standard (ANSI/ANS-18.1-1999, 1999) were used. This standard contains a list of activities for more than 50 isotopes found in the coolant of a typical PWR (entering the letdown line) and scaling factors for a plant's specific operating parameters. Utilizing parameters from a typical PWR U-tube steam generator, we calculated activities for six classes of nuclides and show those values in Table 6 . Two observations are apparent from Table 6: (1) the activity from the primary side vastly exceeds that from the secondary by several orders of magnitude, and $(2){ }^{16} \mathrm{~N}$, with its 7.13 -s half-life, accounts for 94 to $97 \%$ of the activity of the coolant (the higher percentage occurring in regions closest to the core). Photon emission spectra for ${ }^{16} \mathrm{~N}$ are shown in Table 7 and Fig. 28. It is noted that about $92 \%$ of the photons emitted off by ${ }^{16} \mathrm{~N}$ are $6.123 \mathrm{MeV}$ and about $6 \%$ are $7.115 \mathrm{MeV}$. For $40 \mu \mathrm{Ci} / \mathrm{g}$ of ${ }^{16} \mathrm{~N}$, the total strength of photon emitted is

$$
\mathrm{S}=\left(40 \times 10^{-6} \mathrm{Ci} / \mathrm{g}\right)\left(37 \times 10^{9} \text { decays } \cdot \mathrm{s}^{-1} \cdot \mathrm{Ci}^{-1}\right)(0.73127 \text { photons } / \text { decay })=1.082 \times 10^{6} \text { photons } \cdot \mathrm{s}^{-1} \cdot \mathrm{g}^{-1} \text {. }
$$


Table 6. Activities (in microcuries per gram) in the coolant calculated using ANSI/ANS 18.1

\begin{tabular}{|c|c|c|c|c|c|c|c|}
\hline Nuclide & $\begin{array}{l}\text { Reactor } \\
\text { coolant }\end{array}$ & $\begin{array}{c}\text { Secondary } \\
\text { water }\end{array}$ & $\begin{array}{c}\begin{array}{c}\text { Coolant } \\
\text { steam }\end{array} \\
\end{array}$ & Nuclide & $\begin{array}{l}\text { Reactor } \\
\text { coolant }\end{array}$ & $\begin{array}{c}\text { Secondary } \\
\text { water }\end{array}$ & $\begin{array}{c}\text { Coolant } \\
\text { steam }\end{array}$ \\
\hline \multicolumn{4}{|c|}{ Class 1: Noble gases } & \multicolumn{4}{|c|}{ Class 6: Other nuclides } \\
\hline $\mathrm{Kr}-85 m$ & $1.1 \mathrm{E}-02$ & $0.0 \mathrm{E} 00$ & $2.4 \mathrm{E}-09$ & $\mathrm{Na}-24$ & $3.8 \mathrm{E}-02$ & $1.2 \mathrm{E}-06$ & $6.0 \mathrm{E}-09$ \\
\hline $\mathrm{Kr}-85$ & $2.1 \mathrm{E}-01$ & $0.0 \mathrm{E} 00$ & 4.3E-08 & $\mathrm{Cr}-51$ & $2.8 \mathrm{E}-03$ & $1.2 \mathrm{E}-07$ & $5.7 \mathrm{E}-10$ \\
\hline $\mathrm{Kr}-87$ & $1.2 \mathrm{E}-02$ & $0.0 \mathrm{E} 00$ & $6.9 \mathrm{E}-09$ & Mn-54 & $1.5 \mathrm{E}-03$ & $5.9 \mathrm{E}-08$ & $3.0 \mathrm{E}-10$ \\
\hline $\mathrm{Kr}-88$ & $1.2 \mathrm{E}-02$ & $0.0 \mathrm{E} 00$ & $2.6 \mathrm{E}-09$ & $\mathrm{Fe}-55$ & $1.1 \mathrm{E}-03$ & $4.5 \mathrm{E}-08$ & $2.3 \mathrm{E}-10$ \\
\hline $\mathrm{Xe}-131 m$ & $4.5 \mathrm{E}-01$ & $0.0 \mathrm{E} 00$ & 9.3E-08 & $\mathrm{Fe}-59$ & $2.7 \mathrm{E}-04$ & $1.1 \mathrm{E}-08$ & $5.5 \mathrm{E}-11$ \\
\hline $\mathrm{Xe}-133 m$ & 4.7E-02 & $0.0 \mathrm{E} 00$ & $1.0 \mathrm{E}-08$ & Co-58 & $4.2 \mathrm{E}-03$ & $1.7 \mathrm{E}-07$ & $8.5 \mathrm{E}-10$ \\
\hline $\mathrm{Xe}-133$ & $1.9 \mathrm{E}-02$ & $0.0 \mathrm{E} 00$ & 3.9E-09 & Co-60 & $4.8 \mathrm{E}-04$ & $2.0 \mathrm{E}-08$ & $1.0 \mathrm{E}-10$ \\
\hline $\mathrm{Xe}-135 m$ & $9.0 \mathrm{E}-02$ & $0.0 \mathrm{E} 00$ & $1.9 \mathrm{E}-08$ & $\mathrm{Zn}-65$ & 4.6E-04 & $1.9 \mathrm{E}-08$ & $9.1 \mathrm{E}-11$ \\
\hline $\mathrm{Xe}-135$ & 4.6E-02 & $0.0 \mathrm{E} 00$ & 9.7E-09 & Sr-89 & $1.3 \mathrm{E}-04$ & $5.2 \mathrm{E}-09$ & $2.6 \mathrm{E}-11$ \\
\hline Xe-137 & $2.4 \mathrm{E}-02$ & $0.0 \mathrm{E} 00$ & $4.9 \mathrm{E}-08$ & Sr-90 & $1.1 \mathrm{E}-05$ & $4.5 \mathrm{E}-10$ & $2.2 \mathrm{E}-12$ \\
\hline \multirow[t]{3}{*}{ Xe-138 } & $4.2 \mathrm{E}-02$ & $0.0 \mathrm{E} 00$ & $9.0 \mathrm{E}-09$ & Sr-91 & $7.5 \mathrm{E}-04$ & 2.2E-08 & $1.1 \mathrm{E}-10$ \\
\hline & & & & Y-91m & $3.2 \mathrm{E}-04$ & 2.3E-09 & $1.1 \mathrm{E}-11$ \\
\hline & \multicolumn{3}{|c|}{ Class 2: Halogens } & Y-91 & 4.7E-06 & $1.9 \mathrm{E}-10$ & $1.0 \mathrm{E}-12$ \\
\hline $\mathrm{Br}-84$ & $1.1 \mathrm{E}-02$ & 5.3E-08 & $5.3 \mathrm{E}-10$ & Y-93 & 3.3E-03 & 9.4E-09 & $4.8 \mathrm{E}-10$ \\
\hline I-131 & $1.8 \mathrm{E}-03$ & 7.3E-08 & 7.3E-10 & $\mathrm{Zr}-95$ & $3.5 \mathrm{E}-04$ & $1.5 \mathrm{E}-08$ & 7.2E-11 \\
\hline I-132 & 4.3E-02 & $6.5 \mathrm{E}-07$ & $6.5 \mathrm{E}-09$ & $\mathrm{Nb}-95$ & $2.5 \mathrm{E}-04$ & $1.0 \mathrm{E}-08$ & $5.2 \mathrm{E}-11$ \\
\hline I-133 & $2.1 \mathrm{E}-02$ & 7.4E-07 & 7.4E-09 & Mo-99 & $5.6 \mathrm{E}-03$ & $2.2 \mathrm{E}-07$ & $1.0 \mathrm{E}-09$ \\
\hline I-134 & 7.1E-02 & $5.1 \mathrm{E}-07$ & 5.1E-09 & Tc-99m & $3.6 \mathrm{E}-03$ & 8.4E-08 & $4.3 \mathrm{E}-10$ \\
\hline \multirow[t]{3}{*}{$\mathrm{I}-135$} & $4.2 \mathrm{E}-02$ & $1.1 \mathrm{E}-06$ & $1.1 \mathrm{E}-08$ & Ru-103 & $6.8 \mathrm{E}-03$ & $2.8 \mathrm{E}-07$ & $1.5 \mathrm{E}-09$ \\
\hline & \multirow{2}{*}{\multicolumn{3}{|c|}{ lass 3: Cesium, rubidium }} & Ru-106 & $8.2 \mathrm{E}-02$ & $3.4 \mathrm{E}-06$ & $1.6 \mathrm{E}-08$ \\
\hline & & & & $\mathrm{Ag}-110 \mathrm{~m}$ & $1.2 \mathrm{E}-03$ & $4.8 \mathrm{E}-08$ & $2.5 \mathrm{E}-10$ \\
\hline $\mathrm{Rb}-88$ & $1.3 \mathrm{E}-01$ & $3.7 \mathrm{E}-07$ & $1.8 \mathrm{E}-09$ & Te- $129 m$ & $1.7 \mathrm{E}-04$ & 7.1E-09 & $3.5 \mathrm{E}-11$ \\
\hline Cs-134 & $3.1 \mathrm{E}-05$ & $1.4 \mathrm{E}-09$ & $7.6 \mathrm{E}-12$ & Te-129 & $1.7 \mathrm{E}-02$ & $1.6 \mathrm{E}-07$ & $7.8 \mathrm{E}-10$ \\
\hline Cs-136 & 7.2E-04 & 3.3E-08 & $1.7 \mathrm{E}-10$ & Te- $131 m$ & $1.3 \mathrm{E}-03$ & 4.5E-08 & $2.3 \mathrm{E}-10$ \\
\hline Cs-137 & $4.5 \mathrm{E}-05$ & $2.1 \mathrm{E}-09$ & $1.0 \mathrm{E}-11$ & Te-131 & $5.4 \mathrm{E}-03$ & $2.0 \mathrm{E}-08$ & $1.0 \mathrm{E}-10$ \\
\hline \multirow[t]{2}{*}{$\mathrm{Ba}-137 m$} & $3.7 \mathrm{E}-05$ & $1.7 \mathrm{E}-09$ & 8.3E-12 & Тe-132 & $1.5 \mathrm{E}-03$ & $5.8 \mathrm{E}-08$ & $2.9 \mathrm{E}-10$ \\
\hline & & & & Ba-140 & $1.2 \mathrm{E}-02$ & 4.7E-07 & $2.3 \mathrm{E}-09$ \\
\hline \multicolumn{4}{|c|}{ Class 4: Water activation products } & La-140 & 2.1E-02 & 8.0E-07 & 3.9E-09 \\
\hline \multirow[t]{3}{*}{$\mathrm{N}-16$} & 4.0E01 & $1.0 \mathrm{E}-06$ & $1.0 \mathrm{E}-07$ & $\mathrm{Ce}-141$ & $1.4 \mathrm{E}-04$ & $5.5 \mathrm{E}-09$ & $2.8 \mathrm{E}-11$ \\
\hline & & & & Ce-143 & $2.4 \mathrm{E}-03$ & $8.5 \mathrm{E}-08$ & $4.3 \mathrm{E}-10$ \\
\hline & Class 5 & Tritium & & $\mathrm{Ce}-144$ & $3.6 \mathrm{E}-03$ & $1.5 \mathrm{E}-07$ & $7.5 \mathrm{E}-10$ \\
\hline \multirow[t]{2}{*}{$\mathrm{H}-3$} & $1.0 \mathrm{E} 00$ & $1.0 \mathrm{E}-03$ & $1.0 \mathrm{E}-03$ & W-187 & 2.1E-03 & 7.2E-08 & $3.7 \mathrm{E}-10$ \\
\hline & & & & Np-239 & $1.9 \mathrm{E}-03$ & 7.3E-08 & $3.6 \mathrm{E}-10$ \\
\hline
\end{tabular}


Table 7. ${ }^{16} \mathrm{~N}$ photon and $\mathrm{X}$-ray

\begin{tabular}{lc}
\multicolumn{2}{c}{ lines per decay } \\
\hline $\begin{array}{l}\text { Energy } \\
(\mathbf{M e V})\end{array}$ & $\begin{array}{c}\text { Intensity } \\
\text { (photons/decay) }\end{array}$ \\
\hline 0.7872 & $1.50 \mathrm{E}-08$ \\
0.8677 & $2.10 \mathrm{E}-06$ \\
0.98693 & $3.40 \mathrm{E}-05$ \\
1.0675 & $1.50 \mathrm{E}-07$ \\
1.7549 & $1.21 \mathrm{E}-03$ \\
1.9547 & $3.80 \mathrm{E}-04$ \\
2.7415 & $8.20 \mathrm{E}-03$ \\
2.8222 & $1.30 \mathrm{E}-03$ \\
6.12863 & $6.70 \mathrm{E}-01$ \\
6.9155 & $3.80 \mathrm{E}-04$ \\
7.11515 & $4.90 \mathrm{E}-02$ \\
8.8693 & $7.60 \mathrm{E}-04$ \\
\hline
\end{tabular}

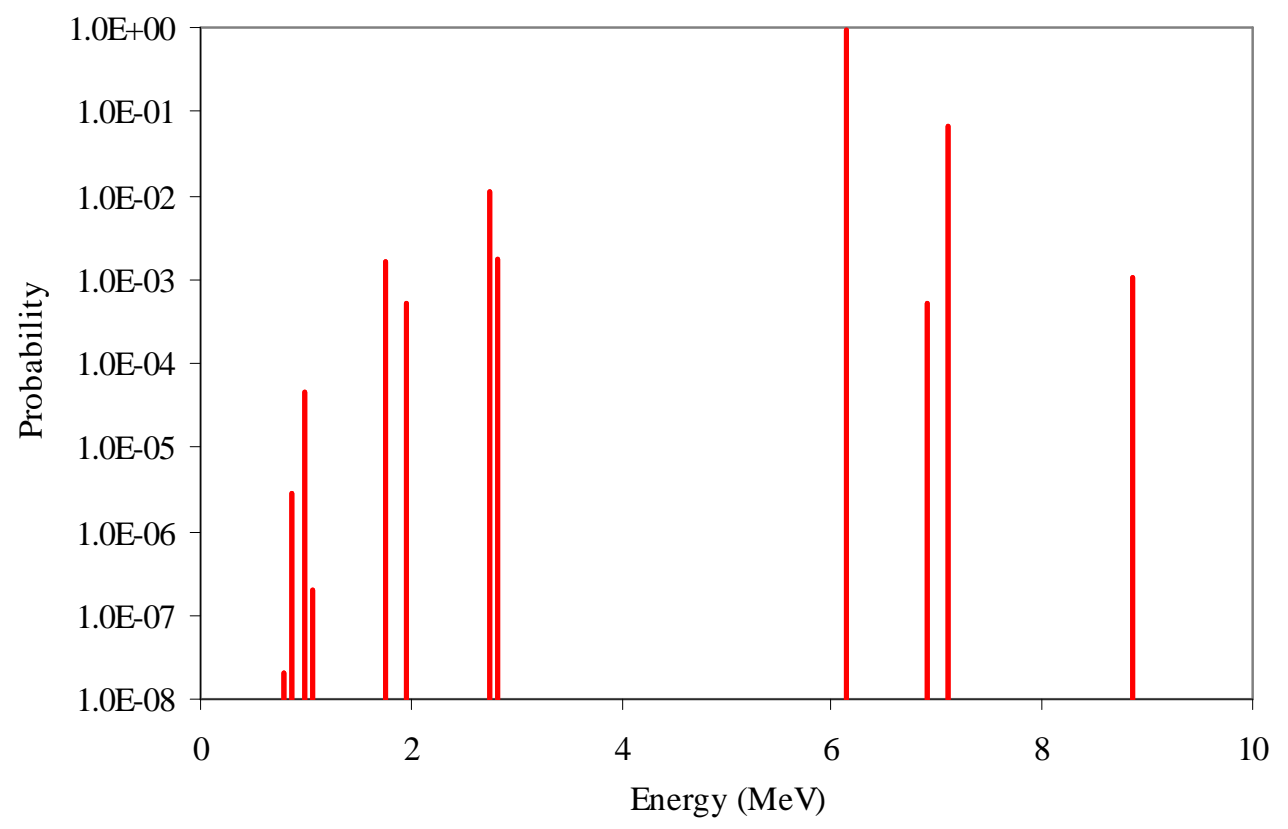

Fig. 28. ${ }^{16} \mathrm{~N}$ photon and $\mathrm{X}$-ray line probabilities per emission.

The other nuclides were combined with SCALE data for their photon emission energies and intensities and then grouped into the 18-group energy-bin structure. The total photon emission rate from all the other nuclides in the coolant is $3.309 \times 10^{4}$ photons $\cdot \mathrm{s}^{-1} \cdot \mathrm{g}^{-1}$ and is shown in Fig. 29. 


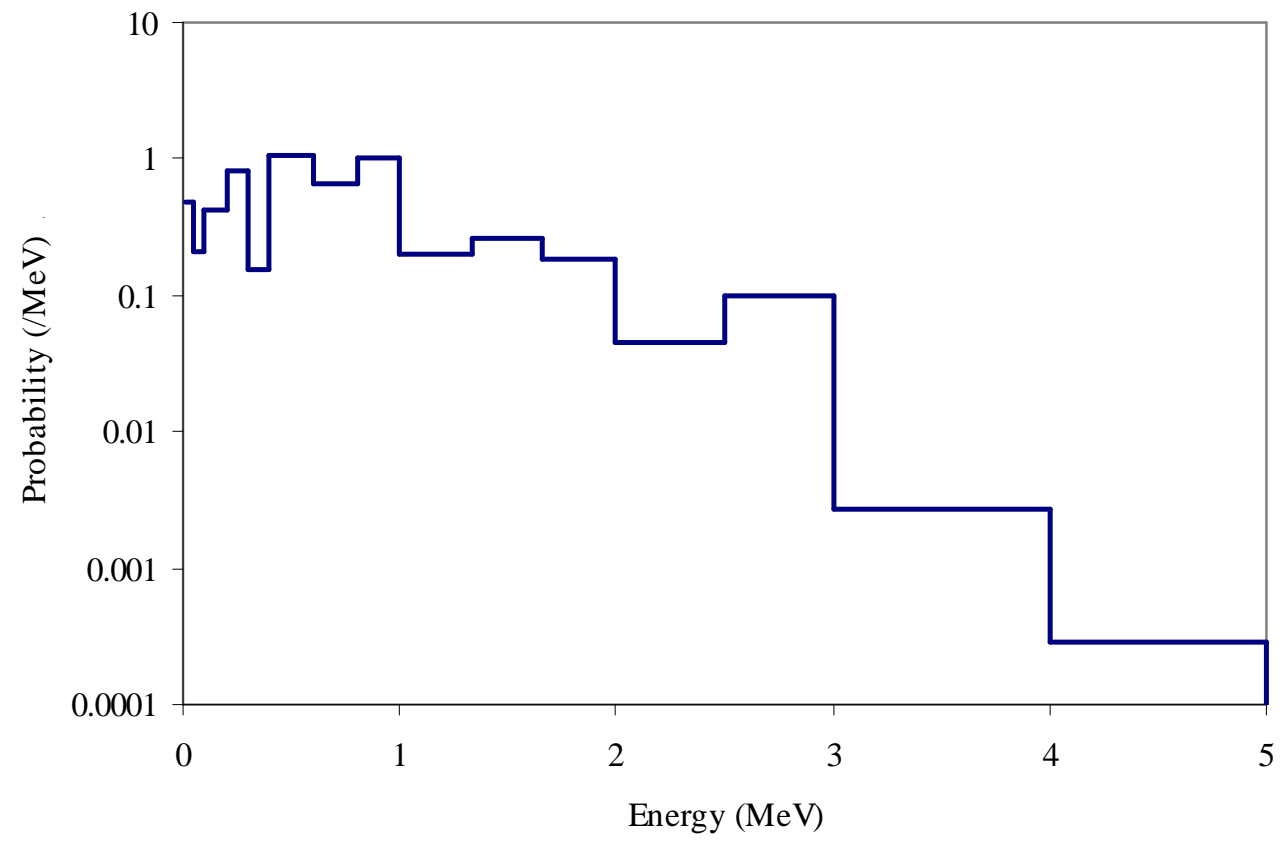

Fig. 29. All other nuclides in a multi-energy-group distribution.

For use with ADVANTG, a single energy probability distribution function was required, which combined the activities from the ${ }^{16} \mathrm{~N}$ with that from all the other nuclides. The calculated activities are for the reactor coolant entering the letdown line. Because of the short half-life of ${ }^{16} \mathrm{~N}$, it was necessary to modify the above value to account for nuclide decay and consequent reduction of the activity during the time of transit around the coolant loop. The coolant spends about $7 \mathrm{~s}$ in the steam generator, which is about 1 half-life of ${ }^{16} \mathrm{~N}$ and requires about 2 half-lives to traverse the cooling loop back to the reactor. On this basis, the average activity of ${ }^{16} \mathrm{~N}$ around the loop was estimated to be $75 \%$ of the value calculated above for the letdown line. Upon combining $75 \%$ of the ${ }^{16} \mathrm{~N}$ activity with the long-term activity of the other nuclides, the total source strength for the entire coolant loop was determined to be $8.4584 \times 10^{5}$ photons $\cdot \mathrm{s}^{-1} \cdot \mathrm{g}^{-1}$. The final source to be used in ADVANTG was the combined source in the 18-group energy-bin structure.

Also for use in ADVANTG, sources must be described spatially as a set of point sources, all sharing one energy distribution. Source points were therefore distributed throughout the primary coolant loop in major components, including the reactor vessel (above and below the core), the steam generators, and the coolant pumps, as well as in pipes between these components. This was accomplished by embedding a cylinder within each component and locating the source points according to a mesh spacing individually assigned to each component cylinder. Each cylinder was aligned with the component longitudinal axis and was sized to nearly fill the component (if a pipe leg), or to approximate the holdup volume. A total of 3158 points were generated. The result of this point source allocation is graphically shown in Figs. 30 and 31. The source strengths from all the reactor coolant components are summarized in Table 8, which also includes the number of point sources within each component. Probabilities assigned to each point were determined by the amount of coolant mass represented by the point as a fraction of the total coolant mass. This is calculated on a relative basis by dividing the volume of the component by the number of point sources allocated to that component. It has been assumed for this analysis that the coolant density is $1 \mathrm{~g} / \mathrm{cm}^{3}$ throughout the coolant loop. 


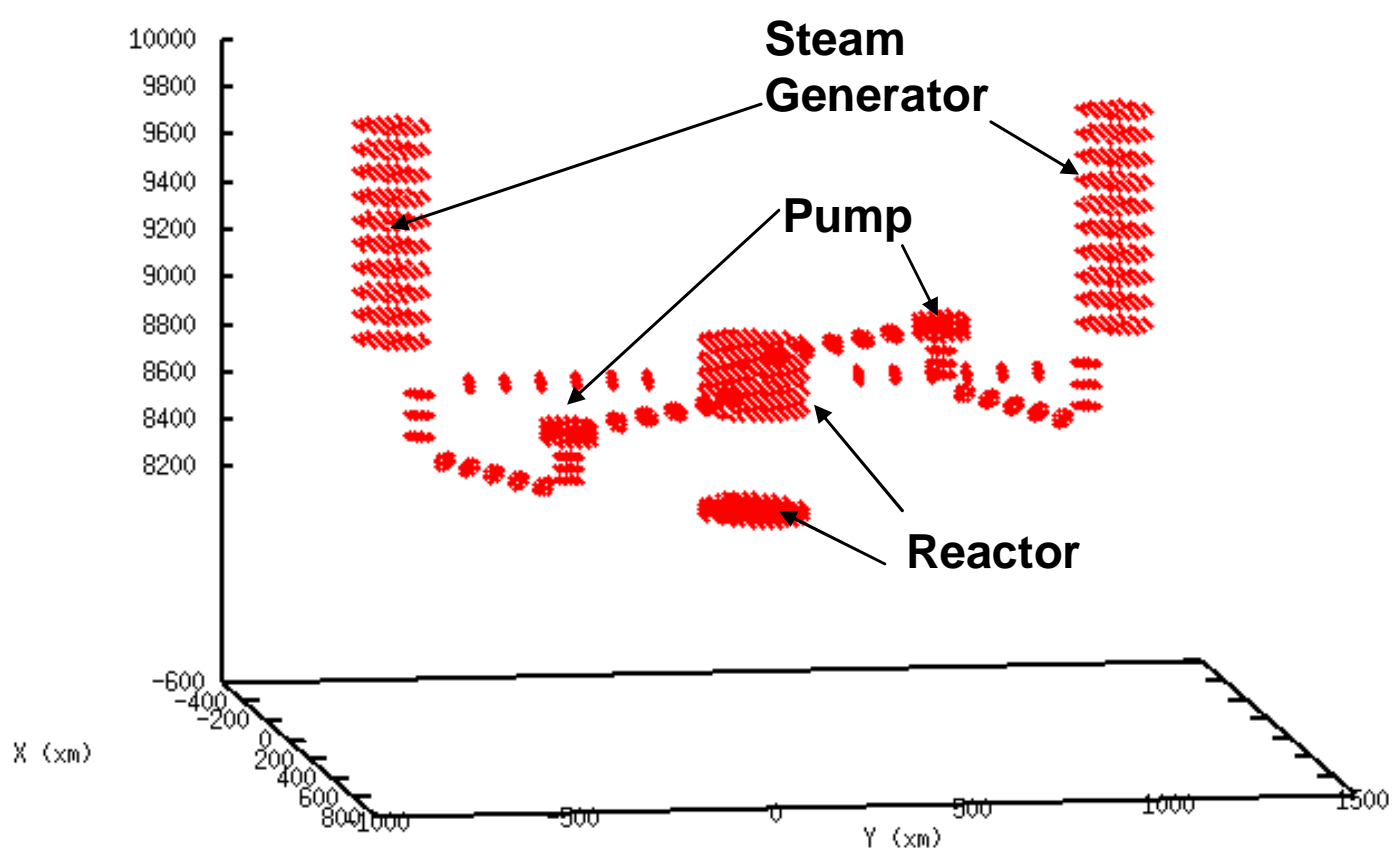

Fig. 30. Plot showing 3158 point source locations for reactor coolant system.

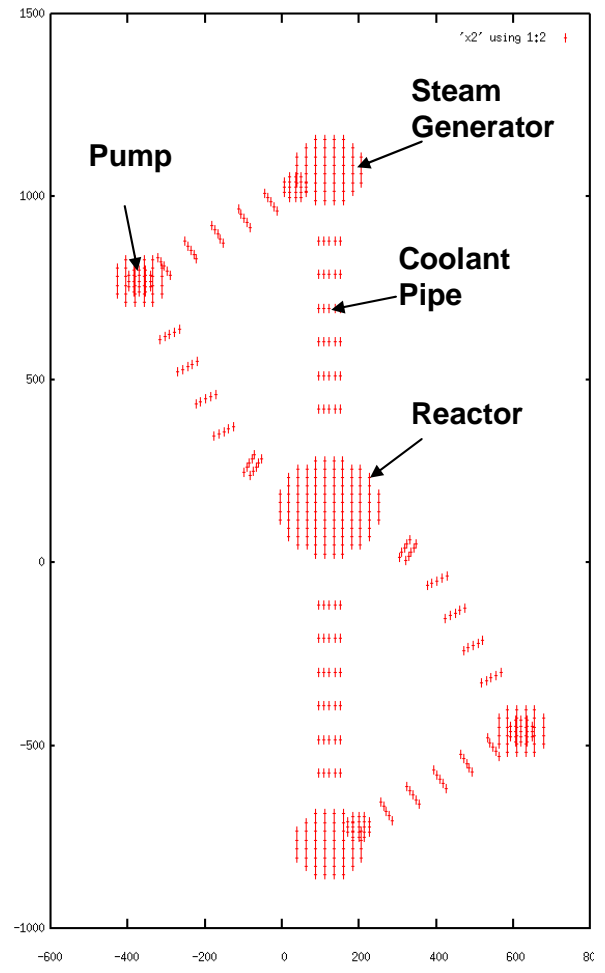

Fig. 31. Two-dimensional representation of source points for the reactor coolant loop, showing points in reactor, steam generators, coolant pumps, and connecting lines. 
Table 8. Summary of coolant component volumes and source strengths

\begin{tabular}{|c|c|c|c|c|c|}
\hline \multicolumn{4}{|c|}{ Coolant component description } & \multicolumn{2}{|c|}{ Source description } \\
\hline Number & Type and location & $\begin{array}{c}\text { Volume } \\
\left(\mathrm{cm}^{3}\right)\end{array}$ & $\begin{array}{l}\text { Volume } \\
\text { fraction }\end{array}$ & $\begin{array}{l}\text { No. } \\
\text { points }\end{array}$ & $\begin{array}{c}\text { Strength } \\
(\text { photons } / \mathbf{s})^{a}\end{array}$ \\
\hline 1,2 & Pipe: Reactor to Steam Gen. 1A, Legs 1 and $2^{b}$ & $2.949 \mathrm{E}+06$ & 0.0193 & 126 & $2.494 \mathrm{E}+12$ \\
\hline 3 & Pipe: Steam Gen. A to Pump 1A, Leg 1 & $1.406 \mathrm{E}+06$ & 0.0092 & 63 & $1.189 \mathrm{E}+12$ \\
\hline 4 & Pipe: Steam Gen. A to Pump 1A, Leg 2 & $2.037 \mathrm{E}+06$ & 0.0133 & 105 & $1.723 \mathrm{E}+12$ \\
\hline 5 & Pipe: Steam Gen. A to Pump 1A, Leg 3 & $8.779 \mathrm{E}+05$ & 0.0057 & 63 & $7.425 \mathrm{E}+11$ \\
\hline 6 & Pipe: Pump 1A to Reactor, Leg 1 & $1.747 \mathrm{E}+06$ & 0.0114 & 84 & $1.478 \mathrm{E}+12$ \\
\hline 7 & Pipe: Pump 1A to Reactor, Leg 2 & $3.295 \mathrm{E}+05$ & & 42 & $2.787 \mathrm{E}+11$ \\
\hline 8 & Holdup: Steam Gen. 1A & $3.060 \mathrm{E}+07$ & 0.1999 & 520 & $2.588 \mathrm{E}+13$ \\
\hline 9 & Holdup: Pump 1A & $1.586 \mathrm{E}+06$ & 0.0104 & 128 & $1.341 \mathrm{E}+12$ \\
\hline $10-18$ & Same as 1 to 9 for Coolant Loop B & & & & \\
\hline 19 & Holdup: Vessel bottom & $1.750 \mathrm{E}+07$ & 0.1143 & 336 & $1.480 \mathrm{E}+13$ \\
\hline 20 & Holdup: Vessel top & $5.250 \mathrm{E}+07$ & 0.3430 & 560 & $4.441 \mathrm{E}+13$ \\
\hline & Total (includes Loops A and B) & $1.531 \mathrm{E}+08$ & 1.0000 & 3158 & $1.295 \mathrm{E}+14$ \\
\hline
\end{tabular}

${ }^{a}$ Average source strength $=8.4584 \times 10^{5}$ photons $\cdot \mathrm{s}^{-1} \cdot \mathrm{g}^{-1}$.

${ }^{b}$ Source for Leg 2 pipe from reactor to steam generator included in Leg 1 source.

\subsection{MCNP SOURCE MODEL SUMMARY}

MCNP source inputs were constructed for the reactor and spent fuel sources discussed in the previous three sections. Each source was described by a spectrum and a large number of source points approximating the volumetric source distribution. For the reactor, 4100 source points were used and are discussed in Section 3.1. For the spent fuel pool, the source was distributed over 10 vertical locations and a 25-point horizontal grid for each of the 11 racks holding spent fuel, resulting in a total of 2750 source points. The distribution was assumed to be flat; therefore, the relative weighting of each point was set to 1.0. For the reactor, four conditions were assumed: operating at full power and shut down for 1 day, 1 week, and 1 month. An additional source and model for the primary coolant are discussed in the previous section. Sources were developed using the 22- and 18-group neutron and photon energy structures. Therefore, the total number of sources, including neutrons and photons from the spent fuel and the photons from the coolant was 11 . Table 9 summarizes the sources and gives the total strength in particles per second for each source. The total source strength is used by MCNP to properly normalize calculated tally values (i.e., dose rate). Table 10 shows the energy group boundaries used for the 22- and 18-group neutron and photon sources. Table 10 also conveniently lists the dose rate multipliers for these group structures to be used in MCNP dose-rate-detector tallies (ANS 6.1.1 Working Group, 1977).

Table 9. MCNP reactor and spent fuel pool source models

\begin{tabular}{llcc}
\hline \multirow{2}{*}{ Source type } & \multicolumn{2}{c}{ Conditions } & \multicolumn{2}{c}{ Source strength (particles/s) } \\
\cline { 3 - 4 } & & Neutron & Photon \\
\hline Reactor & Operating-full power & $1.280 \mathrm{E}+20$ & $5.767 \mathrm{E}+20$ \\
& Shutdown-1 day & $1.058 \mathrm{E}+10$ & $9.340 \mathrm{E}+19$ \\
& Shutdown-1 week & $1.047 \mathrm{E}+10$ & $3.618 \mathrm{E}+19$ \\
& Shutdown-1 month & $9.981 \mathrm{E}+09$ & $1.446 \mathrm{E}+19$ \\
\hline Spent fuel & & $9.705 \mathrm{E}+10$ & $2.863 \mathrm{E}+18$ \\
\hline Coolant & Operating-full power & ---------- & $1.295 \mathrm{E}+14$ \\
\hline
\end{tabular}


Table 10. Energy group boundaries and flux-to-dose-rate conversion factors [Units are in $(\mathrm{rem} / \mathrm{h}) /\left(\right.$ particle $\left./ \mathrm{cm}^{2} / \mathrm{s}\right)$, for neutrons and $(\mathrm{mrem} / \mathrm{h}) /\left(\right.$ particle $\left./ \mathrm{cm}^{2} / \mathrm{s}\right)$ for photons]

\begin{tabular}{|c|c|c|c|c|c|}
\hline \multicolumn{3}{|c|}{ Neutron } & \multicolumn{3}{|c|}{ Photon } \\
\hline Group & $\begin{array}{c}\text { Upper energy } \\
(\mathrm{MeV})\end{array}$ & Factor & Group & $\begin{array}{c}\text { Upper energy } \\
(\mathrm{MeV})\end{array}$ & Factor \\
\hline 1 & 14.9 & $2.27 \mathrm{E}-04$ & 1 & 10 & $9.792 \mathrm{E}-03$ \\
\hline 2 & 12.2 & $2.08 \mathrm{E}-04$ & 2 & 8 & $8.280 \mathrm{E}-03$ \\
\hline 3 & 10 & $1.47 \mathrm{E}-04$ & 3 & 6.5 & $6.840 \mathrm{E}-03$ \\
\hline 4 & 8.18 & $1.47 \mathrm{E}-04$ & 4 & 5 & $5.760 \mathrm{E}-03$ \\
\hline 5 & 6.36 & $1.47 \mathrm{E}-04$ & 5 & 4 & $4.752 \mathrm{E}-03$ \\
\hline 6 & 4.96 & $1.56 \mathrm{E}-04$ & 6 & 3 & $3.960 \mathrm{E}-03$ \\
\hline 7 & 4.06 & $1.56 \mathrm{E}-04$ & 7 & 2.5 & $3.492 \mathrm{E}-03$ \\
\hline 8 & 3.01 & $1.56 \mathrm{E}-04$ & 8 & 2 & $2.988 \mathrm{E}-03$ \\
\hline 9 & 2.46 & $1.25 \mathrm{E}-04$ & 9 & 1.66 & $2.412 \mathrm{E}-03$ \\
\hline 10 & 2.35 & $1.25 \mathrm{E}-04$ & 10 & 1.33 & $1.908 \mathrm{E}-03$ \\
\hline 11 & 1.83 & $1.25 \mathrm{E}-04$ & 11 & 1 & $1.602 \mathrm{E}-03$ \\
\hline 12 & 1.11 & $1.25 \mathrm{E}-04$ & 12 & 0.8 & $1.260 \mathrm{E}-03$ \\
\hline 13 & 0.55 & $1.32 \mathrm{E}-04$ & 13 & 0.6 & $9.216 \mathrm{E}-04$ \\
\hline 14 & 0.111 & $9.26 \mathrm{E}-05$ & 14 & 0.4 & $6.372 \mathrm{E}-04$ \\
\hline 15 & $3.35 \mathrm{E}-03$ & $3.56 \mathrm{E}-06$ & 15 & 0.3 & $4.392 \mathrm{E}-04$ \\
\hline 16 & $5.83 \mathrm{E}-04$ & $3.76 \mathrm{E}-06$ & 16 & 0.2 & $2.376 \mathrm{E}-04$ \\
\hline 17 & $1.01 \mathrm{E}-04$ & $3.76 \mathrm{E}-06$ & 17 & 0.1 & $1.404 \mathrm{E}-04$ \\
\hline 18 & $2.90 \mathrm{E}-05$ & $4.18 \mathrm{E}-06$ & 18 & 0.05 & $3.024 \mathrm{E}-04$ \\
\hline 19 & $1.07 \mathrm{E}-05$ & $4.18 \mathrm{E}-06$ & Lowest & 0.01 & \\
\hline 20 & $3.06 \mathrm{E}-06$ & 4.54E-06 & & & \\
\hline 21 & $1.12 \mathrm{E}-06$ & $4.54 \mathrm{E}-06$ & & & \\
\hline 22 & 4.14E-07 & $4.46 \mathrm{E}-06$ & & & \\
\hline Lowest & $1.00 \mathrm{E}-08$ & & & & \\
\hline
\end{tabular}




\section{VARIANCE REDUCTION}

\subsection{OVERVIEW}

In addition to a more accurate geometry rendition, a perceived advantage of the Monte Carlo method over mesh-based methods (e.g., discrete ordinates) is that the Monte Carlo approach simulates the actual transport of individual particles. Thus, the actual physics of individual particles is simulated. This approach is intuitively more direct than the discrete ordinates approach, in which a large set of coupled transport equations are solved simultaneously by iterative means. In general, the Monte Carlo approach is less subject to various numerical instabilities that can otherwise lead to nonphysical outcomes such as negative flux values. However, this so-called advantage is severely mitigated by the fact that for large shielding problems, it is not possible to simulate a sufficient number of source particles to achieve statistically meaningful results unless variance-reduction methods, as discussed in the next paragraph, are used. An example based on the model in this report points this out dramatically. In the PWR plant considered, the reactor produces $\sim 10^{20}$ neutrons/s at full-power operation. However, an MCNP fixedsource simulation of a large geometry is typically limited to $\sim 10^{9}$ neutron or photon source histories. Thus, a direct simulation of the facility limited to $\sim 10^{9}$ neutron source histories can reproduce operation of the reactor for only $\sim 10^{-11} \mathrm{~s}$ ! If it is hypothetically assumed that the facility could be operated for such a brief instant only, common sense would indicate that any efforts to detect particles due to reactor operation anywhere in the plant remote from the reactor core would be completely futile. Similarly, an equivalent "analog" simulation (i.e., with no variance reduction applied) would be equally futile. As results presented later will show, there are many orders of magnitude of attenuation from the reactor to locations outside the containment (and some inside). Therefore, for an analog simulation in which a "mere" $10^{9}$ source histories are produced, the probability of transporting even one particle to a location outside the containment is extremely low.

Although it is known a priori from the above discussion that an analog Monte Carlo calculation would not produce acceptable results, a sample calculation was nevertheless performed to convincingly demonstrate this assumption. Plan and elevation views of neutron mesh tally dose-rate results are shown in Figs. 32 and 33 for a neutron source calculation of the PWR model for a total of $1 \times 10^{10}$ histories, requiring a time of $\sim 30,000 \mathrm{~min}$ ( $\sim 21$ days) on a Linux-cluster PC. Although the calculation was performed for the full PWR model, no neutrons were transported beyond the vicinity of the reactor. Thus, only the applicable results are shown. These results for so large a calculation dramatically point out the futility of an analog calculation for this geometry and, in general, for any geometry with very large amounts of shielding. In summary, the problem addressed in this analysis is entirely dependent on successful variance-reduction implementation and cannot be solved by analog simulation no matter how much computing power is available.

Variance-reduction methods are modifications to the transport process such that particle populations are enhanced within geometric locations and at specific energies in which they have a relatively high probability of contributing to the response of interest (e.g., dose rate within the auxiliary building). There are a variety of variance-reduction methods available. A general approach is to establish space- and energy-dependent importance values at all locations in the geometry. "Importance" can be defined as a relative measure of the likelihood of a particle at that location and energy to contribute to the response of interest. When particles are transported into regions of higher importance, they are split into additional particles; conversely, when they move into regions of lower importance, they may be eliminated by a "Russian roulette" process. Both processes are controlled according to a statistical methodology and together enhance the population of particles with high importance. Each particle also carries with it a "weight" that represents the probability of that particle surviving to its current location in an analog 


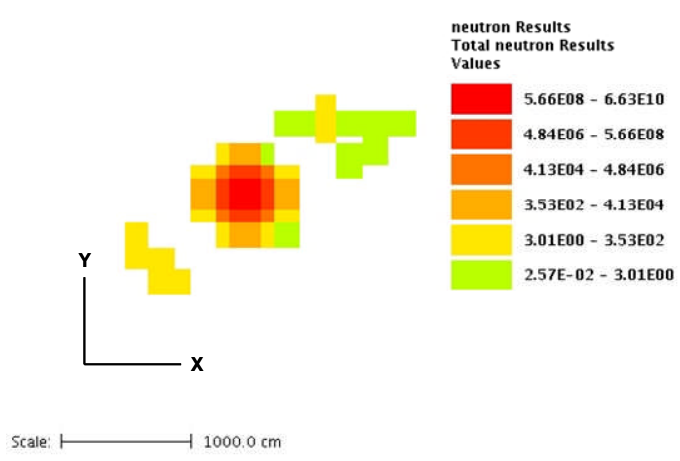

Fig. 32. Close-up plan (X-Y) view of neutron mesh tally analog calculation results of the full-power reactor model at a location slightly above the center of the reactor core. Units are rems per hour.

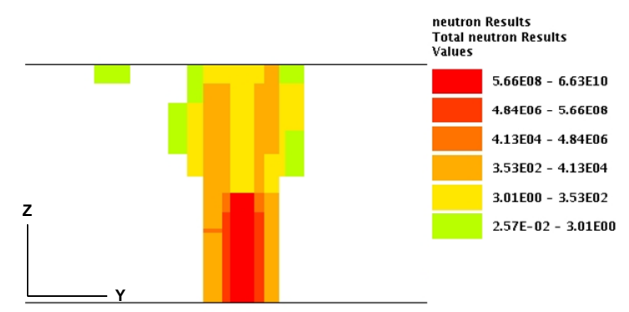

Fig. 33. Elevation (Y-Z) view of neutron mesh tally analog calculation results of the fullpower reactor model along the center of the reactor core $(x=122 \mathrm{~cm})$. Units are rems per hour.

calculation. The contribution that a particle ultimately makes to a response of interest must include multiplication by the weight of the particle at the point of interest. When particles are split into additional particles, the weight of each of the daughter particles is lowered proportionately such that the combined weight of the daughters equals that of the original parent particle. Similarly, when a particle entering a region of lower importance statistically survives the rouletting process, its weight is increased. Weights must also be adjusted for source particles that are preferentially produced at source locations and energies that are of high importance. However, the total weights of all particles must be conserved in order to attain an unbiased solution. In this way, a process known as the "fair game" is implemented such that the final converged result achieved in the variance-reduction-enhanced transport calculation is the same that would ultimately (usually much later) be achieved in the analog calculation.

One approach used to implement the above process is referred to as the "weight windows method." In this methodology a "weight window" consisting of a lower and upper weight limit is employed for every location and energy in the problem geometry. As a particle enters a region, its current weight is compared with the weight window at that location. If the particle weight is above the window upper limit, the particle is split into two or more particles and the corresponding weights of the daughter particles are lowered to fall within the window bounds. If the particle weight is below the window lower bound, it is either eliminated by rouletting or its weight is increased to fall within the window bounds. The weight windows values tend to be proportional to the inverse of importance, as discussed in the previous paragraph. Regions of high importance have low weight windows values. This ensures the desired behavior; that is, as particles move into more important regions, their numbers increase and their weights decrease (due to splitting). Similarly as they move into regions of lesser importance, their numbers decrease and the weights increase (due to rouletting).

The weight windows values can be obtained using either region-based values or an independent mesh superimposed over the geometry model. The drawback of the methodology in either case is the problem of determining the weight windows values for a complex model as a function of both space and energy. Another complication is that the source energy and spatial distribution need to be biased as well and must be consistent with the weight windows values in the source areas. (Otherwise, excessive splitting or particle elimination will occur at the outset of source particle generation.) The determination of appropriate values for the biased source and the weight windows values can be an extremely labor and 
computationally intensive iterative process—especially for large problems such as the ones addressed here.

\subsection{CADIS}

The CADIS (Consistent Adjoint Driven Importance Sampling) methodology was developed in order to quickly and automatically determine the biased source distribution, as well as all of the values for the weight windows over a rectangular mesh and a given energy group structure (Wagner, 1997; Haghighat and Wagner, 2003). The method first determines the approximate adjoint particle flux, usually using a discrete ordinates code. The source for this calculation is the detector energy-group response for the process of interest (e.g., dose rate) at the location(s) of interest. The resulting adjoint flux at each location and energy is equated to the importance of particles and is combined with the source distribution to generate the biased source and weight windows values map that control the splitting and particle elimination at all locations.

In order to make the best use of the adjoint-flux-based importance map, the map must be made consistent with the source biasing. If the source biasing is not consistent with the weight windows that will be used during the transport process, particles will be rouletted or split immediately after birth, wasting computer time.

For a typical problem with the source and detector information defined as follows,

$$
\begin{aligned}
q(\vec{r}, E) & =\text { source emission probability distribution function (pdf), } \\
S & =\text { total source strength, and } \\
\sigma_{d}(\vec{r}, E) & =\text { detector response function, }
\end{aligned}
$$

the total detector response, $R$, is found by integrating the product of the detector response function, $\sigma_{d}(\vec{r}, E)$, and the forward scalar flux, $\phi(\vec{r}, E)$, over the detector volume,

$$
R=\iint_{E V} \sigma_{d}(\vec{r}, E) \phi(\vec{r}, E) d V d E
$$

Alternatively, if the adjoint scalar flux, $\phi^{+}(\vec{r}, E)$, is known, then the total detector response could be found by integrating the product of the forward source and the adjoint flux over the source volume,

$$
R=S \int_{E V} q(\vec{r}, E) \phi^{+}(\vec{r}, E) d V d E
$$

Unfortunately, the exact adjoint flux may be just as difficult to determine as the forward flux. However, an approximation of the adjoint flux, obtained from a mesh-based deterministic calculation, can still be used to form an importance map and a biased source distribution for use in the forward Monte Carlo calculation.

If an approximation to the scalar adjoint flux, $\phi^{+}(\vec{r}, E)$, for a certain detector response function can be found, this approximation can be used as follows: first, the total detector response is computed using Eq. (6); a biased source probability distribution is then formed by 


$$
\hat{q}(\vec{r}, E)=\frac{q(\vec{r}, E) \phi^{+}(\vec{r}, E)}{R / S}
$$

When sampled from this biased distribution, particles would have a starting weight of

$$
w_{0}(\vec{r}, E)=\frac{R / S}{\phi^{+}(\vec{r}, E)} .
$$

For the weight windows used in the transport process, the target weight, $\bar{w}$, as a function of position and energy would be

$$
\bar{w}(\vec{r}, E)=\frac{R / S}{\phi^{+}(\vec{r}, E)}
$$

which is the same as the starting weights for that position and energy. Source particles are born with a weight matching the weight window of the region into which they are born. The size of the weight window is defined by $c$, which is the ratio of the upper weight windows value, $w_{u}$, to the lower weight windows value, $w_{l}$, where the target weight windows value is

$$
\bar{w}=\left(\frac{c+1}{2}\right) w_{l} .
$$

Typical values for the weight windows ratio are $\sim 5$. For weights above the upper weight windows value, splitting is used. For weights below the lower weight windows value, the roulette process is used.

\subsection{ADVANTG}

The Automated Deterministic VAriaNce reducTion Generator (ADVANTG) code (Wagner, 2002) implements the CADIS methodology using the TORT (Rhoades and Childs, 1987) three-dimensional discrete ordinates code for the deterministic adjoint calculation and the MCNP code for the Monte Carlo calculation. The methodology is implemented in three steps as follows:

\section{Step 1: Generation of deterministic adjoint function}

In this step the MCNP geometry file is used in conjunction with a user-supplied three-dimensional mesh to generate and run a TORT discrete ordinates adjoint-source model. Cross sections for the model are generated using the DOORS (DOORS 3.1, 1996) system GIP code for the selected energy-group structure. The 22- and 18-group neutron and photon energy structures were used-both are listed in Table 10. Cross sections and energy boundaries for these structures are from "CASK-81" (1983). The adjoint source for the calculation is the detector response of interest (usually the flux-to-dose rate conversion factors) and is described as a cell tally in the MCNP input file. The result of this calculation is a file (referred to as a "varscl" file) of the adjoint scalar fluxes at all locations and energy group values in the mesh-based model. 


\section{Step 2: Generation of the weight windows and source biasing values}

In this second step, the results of the scalar fluxes from Step 1 are used to produce the weight windows lower bounds and are combined with the MCNP source (described in a separate "sdef" file) to produce a biased source. The biased source values are included in a revision of the MCNP input file. The weight windows values are written to a separate file and linked to the file "wwinp" to be used by MCNP5 along with the MCNP input file.

\section{Step 3: Usage of the weight windows and biased source values in a "standard" MCNP calculation}

The results of Step 2 produce an MCNP input file ready to be run by implementing ADVANTG Step 3. However, the user may alternatively choose to modify the MCNP file to include additional tallies (e.g., mesh tally); change the number of histories; make small changes in the geometry, etc.; and run the case using standard MCNP procedures. The point here is that the MCNP file produced by Step 2 is a standard MCNP file and requires no special procedures to be run.

A flowchart depicting the above-described procedure for implementing the standard CADIS/ADVANTG methodology is shown in Fig. 34. The two columns show program flow (left) and input/output files (right).

\subsection{APPLICATION TO THE PWR DOSE PROBLEM}

The overall goal of this project was to develop a model that would calculate the personnel dose rate anywhere in the facility. Thus, the approach taken in application of the CADIS methodology, at least in this initial phase, was to place the adjoint source along the entire facility perimeter, completely encircling it. This would produce a set of spatial- and energy-dependent importances (adjoint fluxes) and subsequent weight windows map (ADVANTG Step 2) so that the true source particles would be "driven" outward isotropically from the source. Figure 35 shows a conceptual view of this approach (exaggerating the actual thickness of the cell in the horizontal plane). The adjoint source cell surrounding the facility was made thicker at the far end of the facility (from the reactor toward the auxiliary and turbine buildings) to effectively increase the source proportionally in these locales to "encourage" transport in these directions. For this approach, two runs were performed for ADVANTG Step 1-one each to obtain the adjoint neutron and photon fluxes. The TORT cases for each used a mesh consisting of 212, 275, and 84 intervals in the X, Y, and Z coordinates, respectively, for a total of 4,897,200 voxels. This large number of mesh intervals and voxels was necessitated by the fact the facility is quite large and contains dense steel and concrete regions, which require a relatively fine mesh. A relatively low-order $\mathrm{S}_{4}$ angular quadrature was used to help keep the computational demands within reason. Legendre scattering order was limited to the $\mathrm{P}_{3}$ approximation. ( $\mathrm{P}_{5}$ is generally preferred, although $\mathrm{P}_{3}$ is usually adequate.) It should be kept in mind that the TORT discrete ordinates calculation step is intended only to acquire an approximate adjoint flux to be used for weighting the Monte Carlo model, not to provide a solution to the problem. Results from a mediocre TORT calculation will provide a far better variance reduction than the user can provide by hand (usually by assigning importance values to cells) and a vastly improved response over a pure analog calculation. Nevertheless, the more accurate the TORT result, the better the Monte Carlo will be.

The TORT calculation for the above model required $6208 \mathrm{~min}(103 \mathrm{~h})$ for the neutron case and $655 \mathrm{~min}$ $(10.9 \mathrm{~h})$ for the photon case running on a single LINUX-cluster PC processor. 


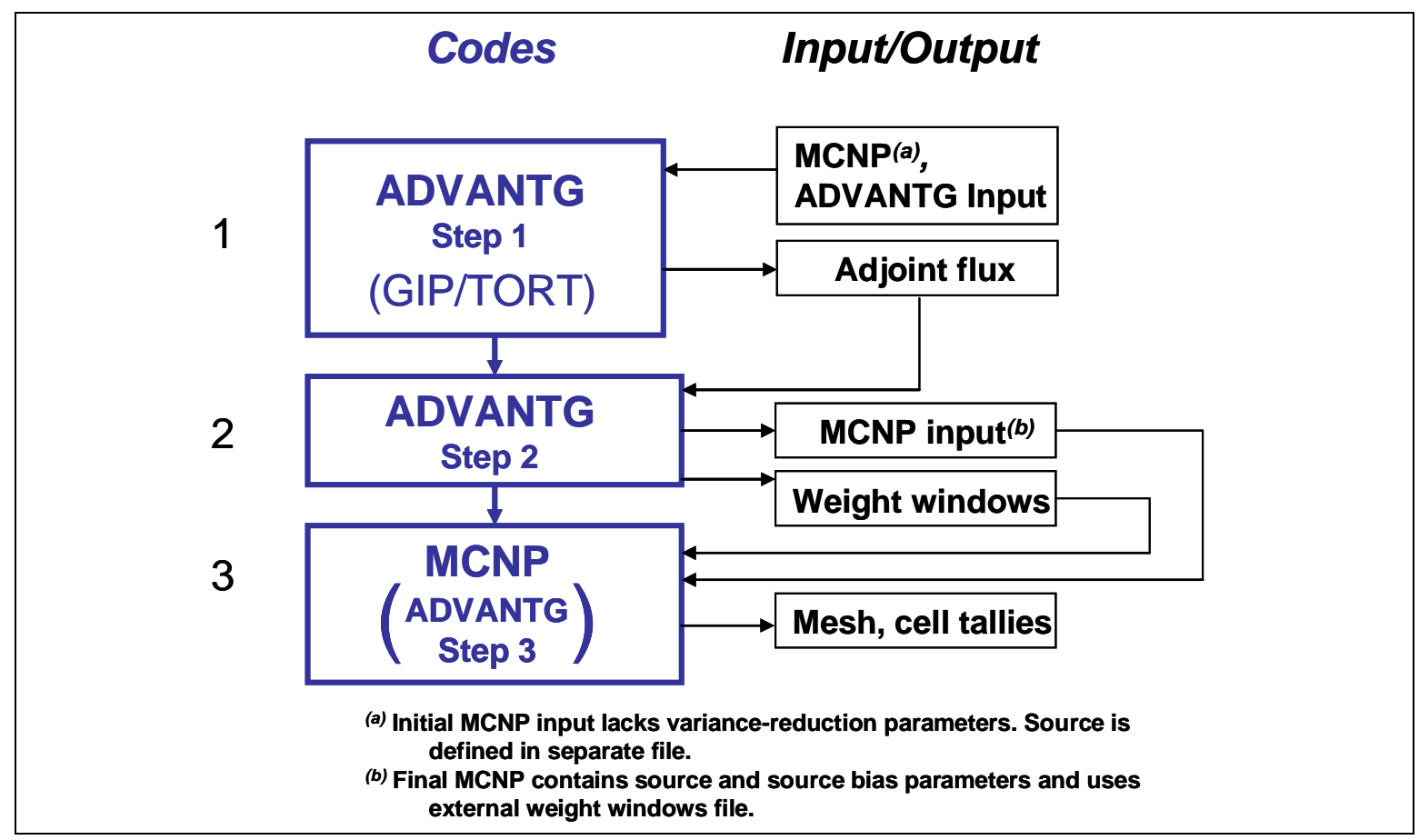

Fig. 34. Flowchart of standard ADVANTG sequence for adjoint-source-based weight windows variance reduction in MCNP.

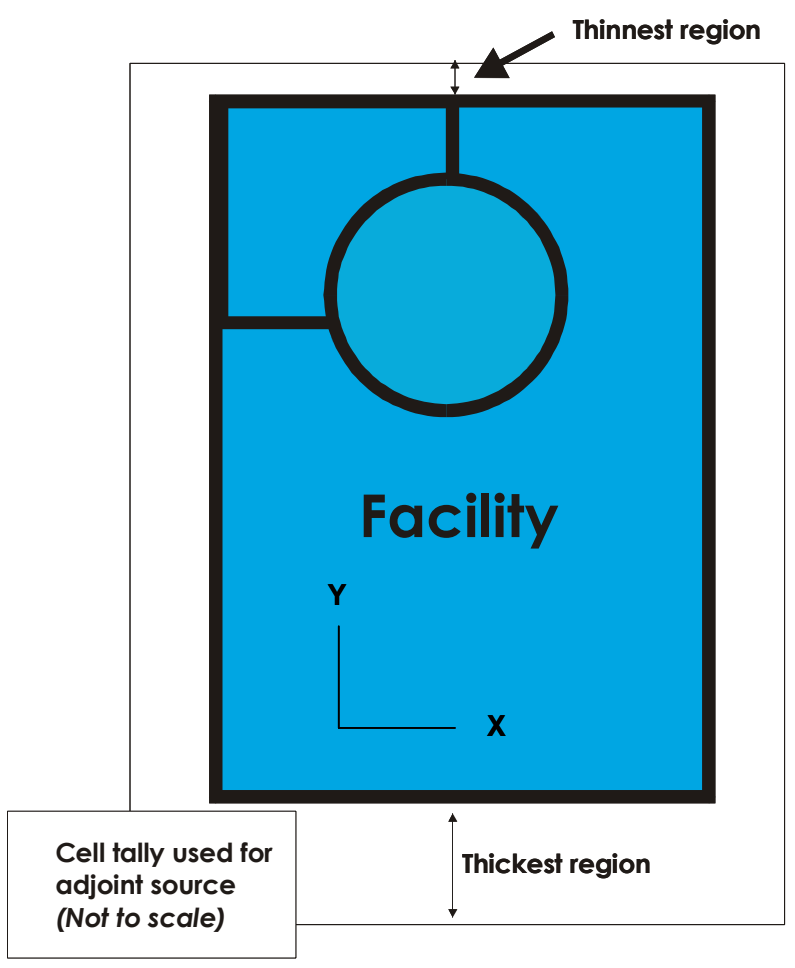

Fig. 35. Conceptual PWR facility model showing adjoint source in surrounding perimeter cell. The cell is thicker in regions further from the reactor to balance transport in all regions. 
Each of the 11 source descriptions was then combined with the appropriate neutron or photon adjoint flux to calculate the following: the biased source spatial distribution, the biased source energy distribution as a function of each spatial point within the source, and the weight windows map (space and energy dependent). The 11 runs of ADVANTG Step 2 required only a few minutes each. 



\section{MCNP MODELS FOR PWR DOSE RATE}

Models and software described in this section have been provided to the sponsor but are not otherwise generally available without sponsor concurrence. They are discussed in this section to ensure completeness.

\subsection{MODELS}

MCNP models have been developed and run incorporating the geometry model discussed in Section 2 and the sources in Section 3 and using the CADIS/ADVANTG adjoint flux, weight windows variancereduction methodology. A script file is discussed in Section 5.2 that enables the construction of an MCNP input file that incorporates the user's selection of particle (neutron or photon) transport and source (operating or shutdown reactor, spent fuel). In order to implement this approach, the base-case MCNP model was "modularized" into components. The first component is the geometry model alone without the source and additional run parameters including the weight windows, number of histories, transport mode (neutron or photon), and tallies. The most significant run distinction is the choice of source, which can be the reactor, either operating or shut down, or the spent fuel pool. The sources were discussed in detail in Section 3. Table 11 summarizes the source options. (The coolant source model was discussed in Section 3.4.5, but its application is not included in the script file discussed in Section 5.2. Therefore, it was not included in Table 11.) A shorthand descriptive name is provided for each of the ten source configurations. These names are used for subdirectories containing weight windows, source bias information, and normalizations for each source.

Section 5.4 provides sample runs.

\subsection{SCRIPT FILE FOR EASY PROCESSING}

A script file was prepared to enable the user to build an MCNP input file, while selecting from the particle and source options. The script file, build.sh, is found in the phaseOne/build subdirectory. Prior to running the script, a simple editing change must be made to ensure that the directory path is correct for the system on which the code is implemented. The line that reads

$$
\text { LIB="/home/edb/phaseOne/build/lib/" }
$$

must be edited to correct the directory structure (above the phaseOne subdirectory).

Table 11. Summary of source options in script file

\begin{tabular}{|c|c|c|c|c|}
\hline & \multirow{2}{*}{\multicolumn{2}{|c|}{ Source option/condition }} & \multicolumn{2}{|c|}{$\begin{array}{c}\text { Shorthand description } \\
\text { (for subdirectory names) }\end{array}$} \\
\hline & & & Neutrons & Photons \\
\hline 1 & Reactor & Full power & On & $\mathrm{Op}$ \\
\hline 2 & Reactor & Shutdown-1 day & SD1dn & SD1dp \\
\hline 3 & Reactor & Shutdown—1 week & SD1wn & SD1wp \\
\hline 4 & Reactor & Shutdown-1 month & $\mathrm{SD} 1 \mathrm{mn}$ & SD1mp \\
\hline 5 & Spent fuel pool & & SFn & SFp \\
\hline
\end{tabular}


Following the above edit, instructions to build and run an MCNP model are as follows. (Typed commands are in bold; <cr> indicates carriage return. Default entries are shown in brackets [ ]).

\subsubsection{Run the Script to Prepare an MCNP Input Deck}

To run the script, simply type

build. sh<cr>

and the code will query the user first for the input geometry file name. Currently, the only choice is "geom01", which includes a few small improvements over the geometry model used to run the examples given in Section 5.4. The geometry model is particle independent and does not include run parameters.

The code next queries for transport mode; either " $n$ " (default) or " $p$ " can be entered.

The code next queries for one of five operating options discussed in Section 3 and 5.1 and summarized in Table 11. The user enters a selection 1 to 5.

The code next queries for a run name (default: "r001") and a number of histories (default: 1e6). An example of the script and the user's responses is shown in Fig. 36.

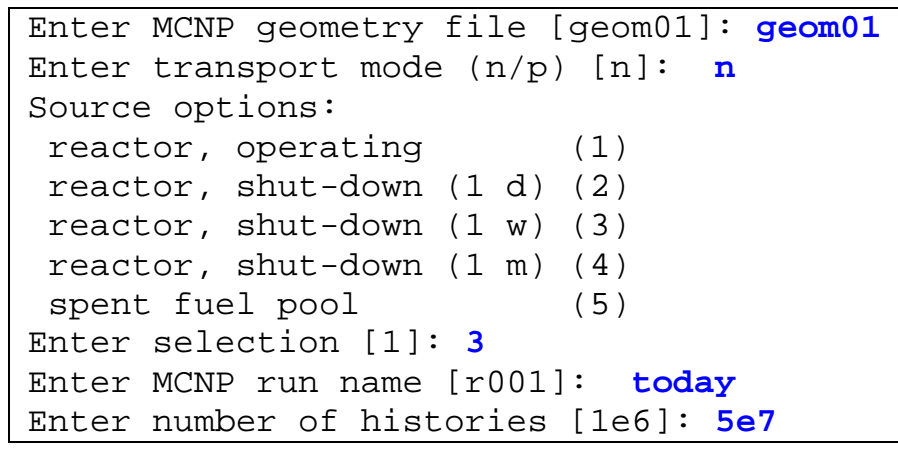

Fig. 36. Running the script file, with user responses in blue.

When the script finishes, two files are generated. One is the MCNP input file, which includes the geometry and all the parameters specific to the run except for the weight values. The weight windows values are included in the second file, "wwinp," which is actually a symbolic link to the appropriate weight windows file. If the "wwinp" file is examined (using the command $1 \mathbf{s}-1$ wwinp<cr>), it is seen that the actual weight windows file name is preceded by a prefix (e.g., "On", "SD1dp", etc.). The prefix refers to the operating condition source of choice as listed in Table 11 and is used to unambiguously identify the file.

It is assumed that the user creates the file from the "build" subdirectory and will probably transfer the file to a separate user directory. The "wwinp" file must also be copied. Because of the large size of the file (>1 gigabyte), it is preferable to copy only the link to the file rather than the file itself. This can be done by typing

cp -1 wwinp user-directory<cr> ,

where user-directory is the desired locale to run the problem. 


\subsubsection{Modify the MCNP Input Deck if Needed}

The MCNP input file produced by "build.sh" is a standard MCNP5 input file and as such can be modified by the user. The file contains a single-mesh tally that provides dose rate information over the entire facility geometry. The mesh for this tally is similar to that used for the discrete ordinates run to produce the source bias and weight windows bias but has been simplified somewhat. In particular, the mesh has been made coarser in the source region (core), where there is little interest in determining the dose rate. (Obviously, the rate is quite high there.) The user may modify the mesh spacing in the tally or add additional cell or point tallies as desired for specific locations, referring to the MCNP5 users' manual if necessary. Also, reasonable changes to the geometry may be made and the weight windows file will still be appropriate. One of the examples discussed in Section 5.4 demonstrates this. A trivial change that the user will almost certainly wish to explore is a variation in the number of histories (i.e., the value assigned to "nps").

Changes to the geometry can be visualized using the MCNP5 geometry viewer, which is also described in the MCNP5 users' manual.

\subsubsection{Run the MCNP Input Deck}

The input file produced from the script file discussed above can be run like any MCNP input file using

monp5 name= today \& ,

where "today" is the name of the input. On some machines, only an "mpi" version of MCNP5 (mcnp5.mpi) that accommodates multiple-processor parallel runs may be available, in which case a single processor run can still be implemented by substituting "mcnp5.mpi" for "mcnp5". On our LINUX cluster we have not as yet been able to run the current model in parallel because of memory constraints. However, we intend to resolve this issue in the near future. Fortunately, the Monte Carlo methodology falls into a class of problems known as "embarrassingly parallel," in which the results of a set of statistically independent problems can be added to yield a single reduced-error result that is the equivalent of a parallel computation. Runs can be made statistically independent by starting each one with a different random number, which alters the random number sequence. A utility code (meshAdder), which performs the result addition, is described in Section 5.3.

\subsubsection{MCNP Results}

The results of the mesh tally are saved to a separate file with the default name "meshtal" and can be viewed with MCNP5 or a utility code (Mesh File Viewer). If the "meshtal" file exists, MCNP5 will write to the file "meshtam". If "meshtam" exists, MCNPS will write to "meshtan", etc.

The results of additional tallies such as cell or point tallies are printed in the MCNP5 output file.

\subsection{UTILITY CODES}

\subsubsection{Mesh File Viewer}

MCNP mesh tally files and TORT "varscl" files can contain enormous quantities of data. A utility application was written to load and display the data contained in these files as contour plots, one slice at a time. This tool was developed for a wide range of projects currently ongoing at ORNL and can show MCNP "meshtal" files and TORT "varscl" files, as well as other mesh-based files used in SCALE. 
For this project, this tool is useful for examining "varscl" files that are used for making the importance maps and biased sources, an example of which is shown in Fig. 37. The mesh file viewer can also be used for viewing the final MCNP mesh tally files. For a mesh tally file, both the dose rate values and the uncertainties can be displayed using the viewer. From the contour, a line of data from any dimension (X, Y, Z, or energy) can be selected and displayed in a traditional two-dimensional line plot, as shown in Fig. 38. Some of the contour plots in this document were created with this viewer.

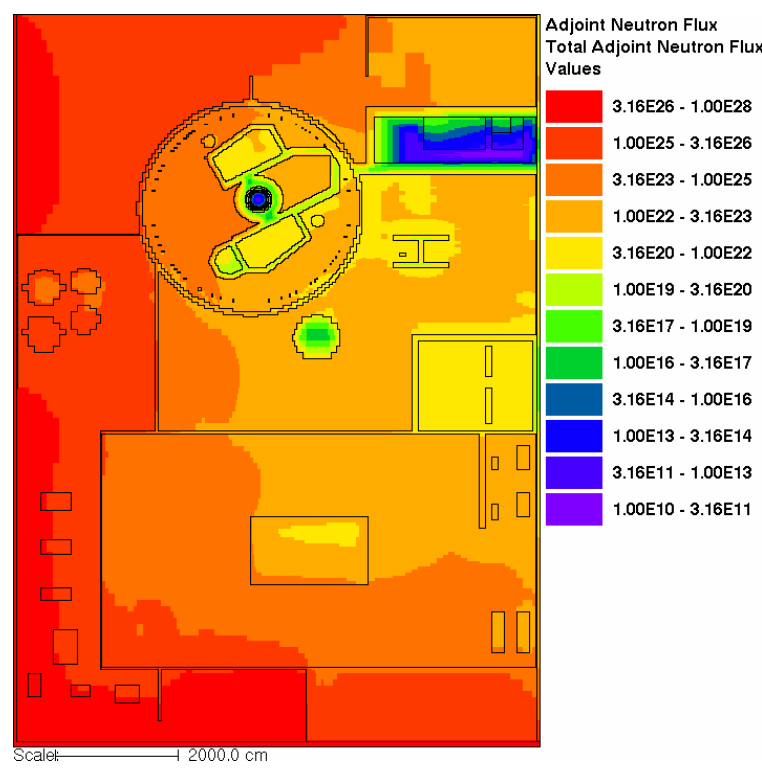

Fig. 37. Sample contour plot.

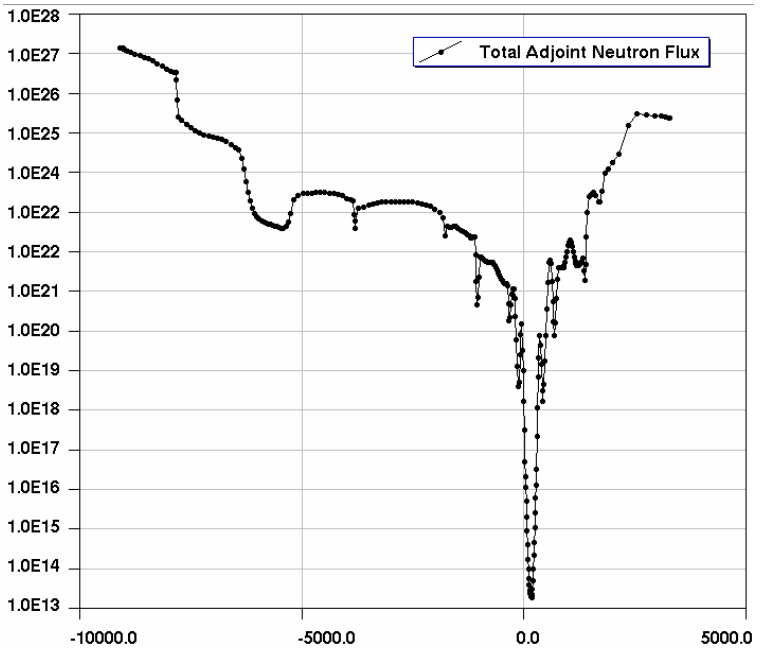

Fig. 38. Sample line plot.

The Mesh File Viewer is a Java application. It is distributed with two files: the executable Java archive file "meshview.jar" and a help file "meshview.pdf". On Windows PCs, simply click on the "meshview.jar" file to start the program. Documentation for the two-dimensional plotter is contained in "plot.pdf". For Windows, UNIX, or LINUX systems, the command line can also be used:

java -jar meshview.jar \&,

For very large files, the memory allocated to the Java Virtual machine can be increased using

java -jar -Xms1500m-Xmx1500m meshview.jar \& ,

where the " $1500 \mathrm{~m}$ " is 1500 megabytes. If the machine has more memory available, higher values may be used.

The latest version of the Java Runtime Environment (JRE) can be downloaded at no cost from Sun at http://java.sun.com/javase/downloads/index.jsp.

\subsection{2 "Meshtal" File Adder}

In some cases, it is desirable to add the mesh tally results from multiple runs of MCNP5. A utility program, meshAdder, has been created to average two or more "meshtal" files, weighting the average by the number of histories used to produce each "meshtal" file. This is a Fortran 95 program and must be compiled on the system where the "meshtal" files are located. A short script file, "compile", has been 
supplied with the source code. It should be modified to use the local Fortran 95 compiler. A short text file, "readme.txt", contains a description of how to run the "meshtal" file adder.

\subsection{3 "Varscl" File Splitter}

For this project, the "varscl" files produced by TORT for the multigroup adjoint fluxes are so large they may not be able to be viewed using the Java mesh file viewer above. A utility program, vsplit, has been created to select one of the Z planes from a given "varscl" file and save it as a separate "varscl" file. This is also a Fortran 95 program, and it too must be compiled on the system where the "varscl" files are located. A short script file, "compile", has been supplied with the source code. It can be modified to use the local Fortran 95 compiler. A description of how to run the "varscl" file splitter is given in the short text file, "readme.txt".

\subsection{EXAMPLES}

\subsubsection{Neutron Dose Rates from the Full-Power Operating Reactor}

A sample calculation was performed using the discrete-ordinates-based weight windows and source biasing variance-reduction methodology discussed in Section 4. Figures 39-42 show mesh tally dose rates for different planar views for a total of $1 \times 10^{9}$ histories. This calculation was performed using multiple runs with averaged results. Total computational time was $\sim 28,000 \mathrm{~min}(\sim 19.5$ days $)$ on a stateof-the-art LINUX-cluster PC. Figure 39 is a plan (X-Y) view. It shows that in spite of the large number of histories and the application of an effective variance-reduction methodology, mesh tally results-other than a few very sparse regions - could not be obtained in the auxiliary and turbine buildings (seen as the primarily white zone below and to the right of the containment). The explanation is that the dose rates in these areas are extremely low because of the massive concrete shielding around the reactor and within the walls surrounding the spent fuel pool and the steam generator and pressurizer regions. Some coloration is seen along the left-hand and bottom boundaries of the figure. This appears to be the remnants of neutrons that penetrate the upper containment walls and thus bypass the massive shielding described above but are still attenuated heavily through the containment walls. Dose rates in these regions outside the containment are calculated to be in the range of $\sim 10^{-7}$ to $10^{-6} \mathrm{rem} / \mathrm{h}$. It can reasonably be assumed that in the "white" areas, where only a scant number of particles were transported, dose rates are even lower. A typical background radiation level from all natural radiation sources is $1 \times 10^{-5}$ to $2 \times 10^{-5} \mathrm{rem} / \mathrm{h}$. Thus, it can be seen that calculated neutron dose rates outside the containment for the normal plant geometry and operating conditions are an order of magnitude below background for all radiation contributors and thus are of absolutely no practical significance. The situation can be different, however, if the geometry is modified. This scenario is discussed later.

Figures 40-42 show close-up views of the containment region along cut-planes passing through or near the center of the reactor core. Rapid attenuation away from the reactor core (red section) can be seen. Overall, values can be seen to vary by over 20 orders of magnitude.

Figure 43 shows a plot of the neutron dose rates across the containment in the Y-direction at a vertical (Z) location of $\sim 18,500 \mathrm{~cm}$ and passing through the center of the core at $x \sim 122 \mathrm{~cm}$ from the center of the containment. Only values within the containment are shown. Outside the containment they either plunge to very low values or are not calculated at all by the MCNP model. Within the containment, values are seen on this plot to vary by $\sim 15$ orders of magnitude. 


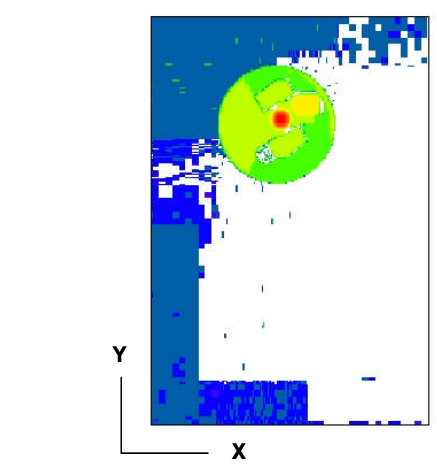

Scale: $\longmapsto 5000.0 \mathrm{~cm}$

Fig. 39. Plan (X-Y) view of neutron mesh tally results of the full-power reactor model at a location slightly above the center of the reactor core $(z=\mathbf{1 8 , 5 0 0} \mathrm{cm})$. Units are rems per hour.

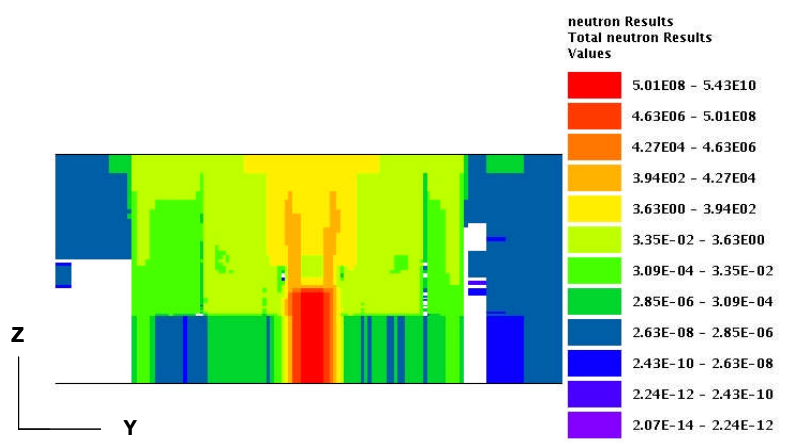

Scale: $\longmapsto 1000.0 \mathrm{~cm}$

Fig. 41. Elevation (Y-Z) view of neutron mesh tally results of the full-power reactor model along the center of the reactor core $(x=122 \mathrm{~cm})$. Units are rems per hour.

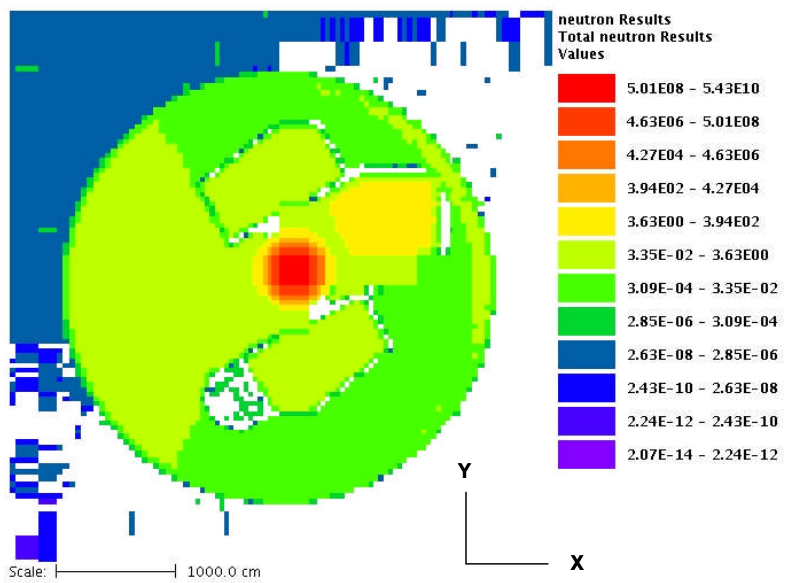

Fig. 40. Close-up plan (X-Y) view within the containment of neutron mesh tally results of the fullpower reactor model at a location slightly above the center of the reactor core $(z=18,500 \mathrm{~cm})$. Units are rems per hour.
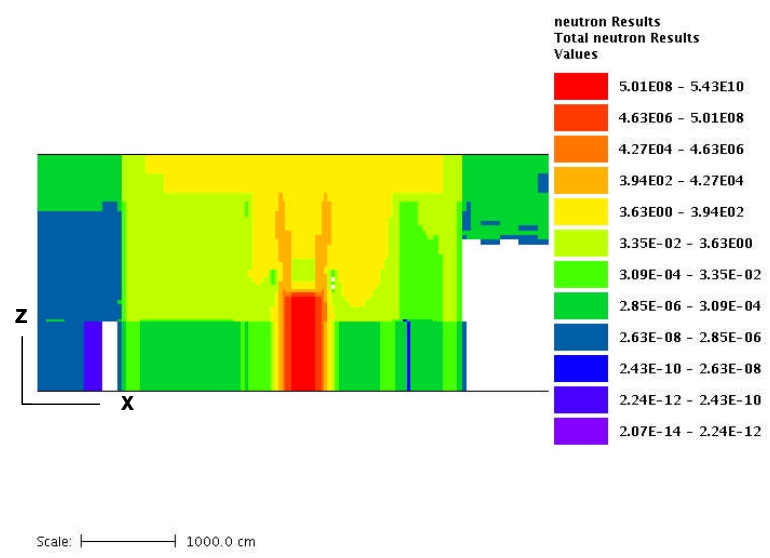

Fig. 42. Elevation (X-Z) view of neutron mesh tally results of the full-power reactor model along the center of the reactor core $(y=152 \mathbf{c m})$. Units are rems per hour. 


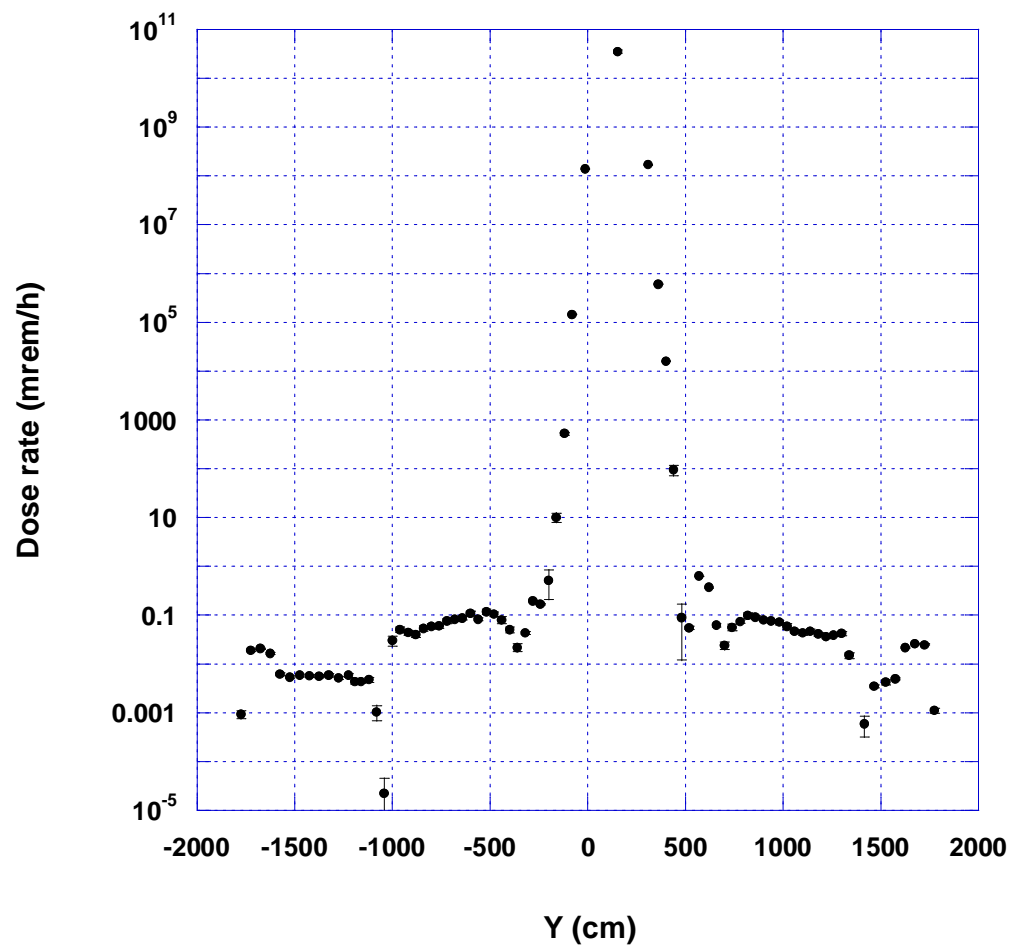

Fig. 43. Plot of neutron dose rate within the containment along the $Y$-axis at $x=122 \mathrm{~cm}$ (reactor center) and at elevation $18,500 \mathrm{~cm}$ (approximate reactor core vertical center).

\subsubsection{Photon Dose Rates from the Full-Power Operating Reactor}

Figures 44-47 show photon transport results for a photon source problem similar to that of the previous section. These results are for $1 \times 10^{10}$ histories (summation of 10 runs of $1 \times 10^{9}$ histories each) and required a total run time of $\sim 6000 \mathrm{~min}(\sim 4.2$ days $)$ on a state-of-the-art LINUX-cluster PC. Results are similar to those of the previous neutron case in that massive shielding around the reactor, refueling channel, and steam generator/pressurizer regions prohibits any particle transport and results in large "white" areas within not only the auxiliary and turbine buildings but also within heavily shielded regions in the containment. It is of interest to note the region in the $-\mathrm{X}$ direction of the $\mathrm{X}-\mathrm{Y}$ plots in which the dose rate is clearly higher.

Figure 48 shows a plot of the photon dose rate within the containment along the X-axis at $y=152 \mathrm{~cm}$ (reactor center) and at an elevation of 18,500 $\mathrm{cm}$ (approximate reactor core vertical center). Note that in this plot, dose rates vary over a range of $\sim 16$ orders of magnitude. Attenuation through the containment wall on the left side of the plot can be readily observed. 

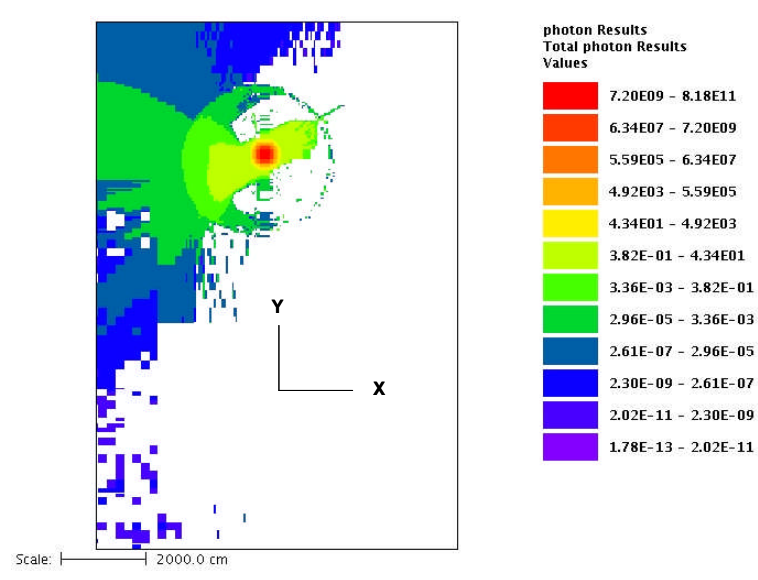

Fig. 44. Plan (X-Y) view of photon mesh tally results of the full-power reactor model at a location slightly above the center of the reactor core $(z=18,500 \mathrm{~cm})$. Units are millirems per hour.

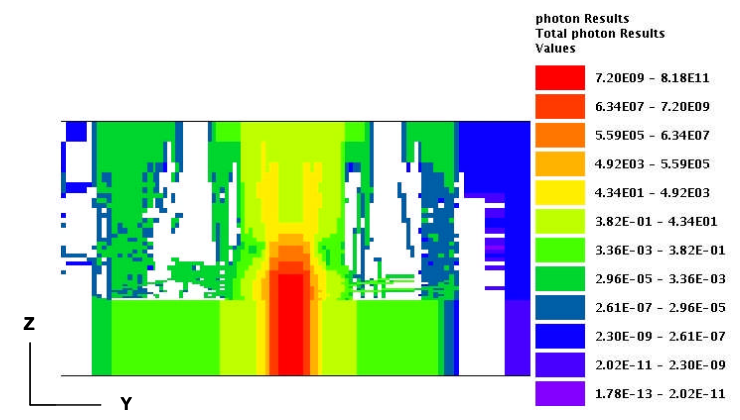

Fig. 46. Elevation (Y-Z) view of photon mesh tally results of the full-power reactor model along the center of the reactor core $(x=122 \mathrm{~cm})$. Units are millirems per hour.

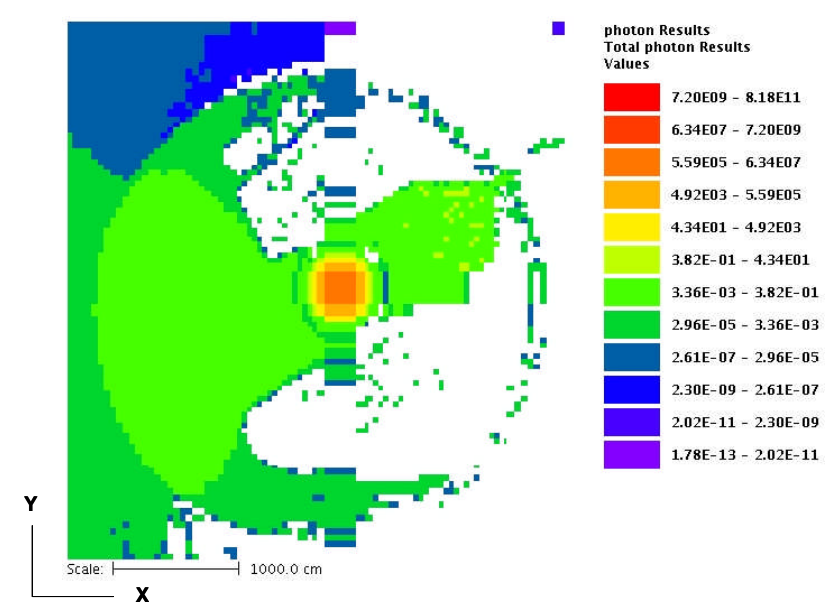

Fig. 45. Close-up plan (X-Y) view within containment of photon mesh tally results of the fullpower reactor model at a location slightly above the center of the reactor core $(z=\mathbf{1 8 , 5 0 0} \mathrm{cm})$. Units are millirems per hour.
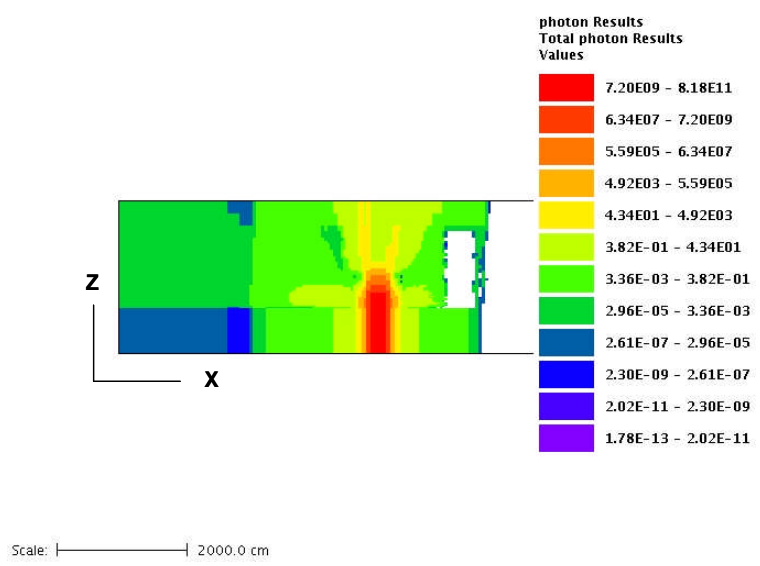

Fig. 47. Elevation $(X-Z)$ view of photon mesh tally results of the full-power reactor model along the center of the reactor core $(y=152 \mathrm{~cm})$. Units are millirems per hour. 


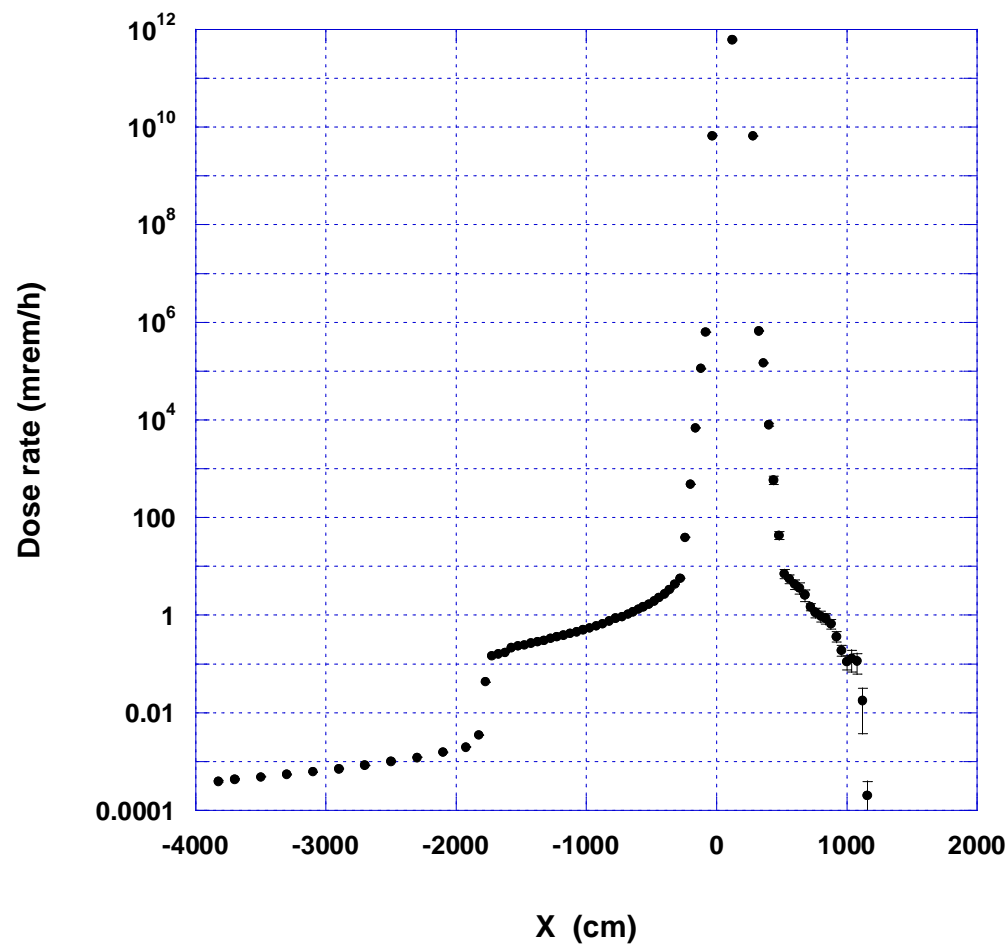

Fig. 48. Plot of photon dose rate within the containment along the $X$-axis at $y=152 \mathrm{~cm}$ (reactor center) and at an elevation of $18,500 \mathrm{~cm}$ (approximate reactor core vertical center).

\subsubsection{Neutron Dose Rates from the Spent Fuel Pool}

Figures 49 and 50 show the results of a neutron calculation with the source distributed within the spent fuel region. These results are for $5 \times 10^{8}$ histories (summation of 10 runs of $5 \times 10^{7}$ histories each) and required $\sim 2400$ min (1.7 days) on a state-of-the-art LINUX-cluster PC. Both X-Y and Y-Z views are shown. The spent fuel racks are surrounded by thick concrete walls on all sides and by water on all sides, except the $+Y$ side since the racks are nearly against the wall. Thus, it should be no surprise that neutrons are not successfully transported to regions of the plant on the other side of the water zones. There is, however, some leakage of particles through the wall not surrounded by water. This radiation, which results in very low dose rates in the $\sim 10^{-7}$ - $\mathrm{mrem} / \mathrm{h}$ range, scatters and is thus responsible for the calculated values seen on the $+\mathrm{Y}$ and $-\mathrm{X}$ side of the containment. It is evident that the huge amount of shielding around the spent fuel pool eliminates essentially all radiation and that no dose rates of concern elsewhere in the facility will be experienced unless the geometry is modified (e.g., water removed, wall breached). 


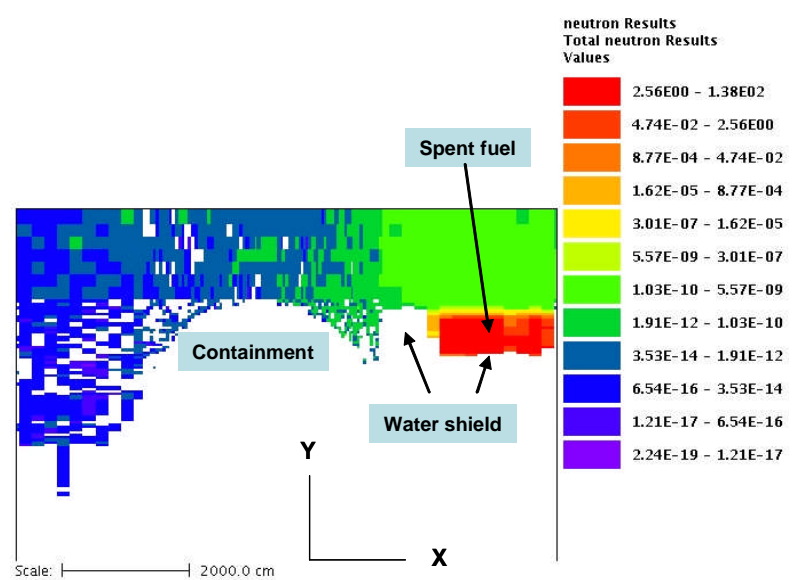

Fig. 49. Plan (X-Y) view of neutron mesh tally results of the spent fuel source model at a location near the vertical center of the spent fuel racks $(z=\mathbf{1 8 , 7 0 0} \mathrm{cm})$. Units are rems per hour.

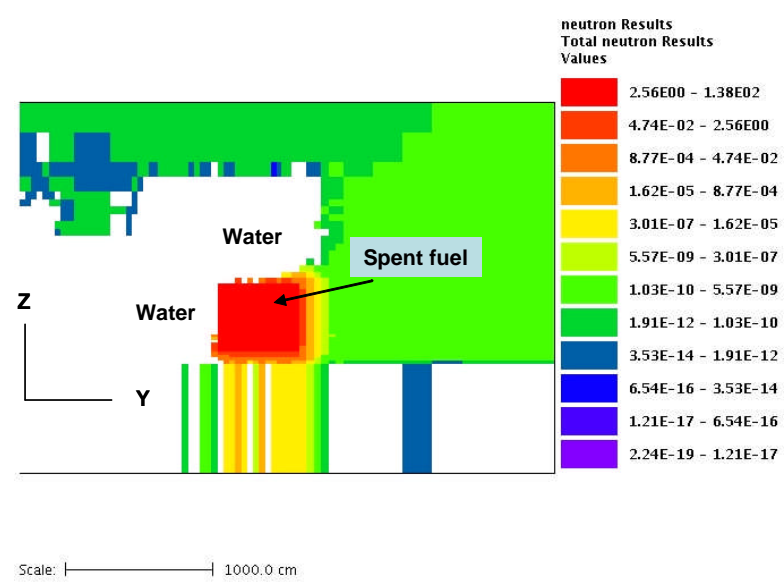

Fig. 50. Elevation (Y-Z) view of neutron mesh tally results of the spent fuel source model at a location in $\mathrm{X}$ dimension near the center of the spent fuel racks $(x=3600 \mathrm{~cm})$. Units are rems per hour.

\subsubsection{Modified Geometry-Neutron Dose Rates from the Full-Power Operating Reactor}

All results shown in the preceding sections are for the facility as-built with no modifications to the geometry. In general, these results have shown that for the sources considered, for locations outside of the containment building and spent fuel areas, the neutron and photon dose rates are small. Moreover, in most locations where a value could be determined, the dose rates are completely negligible (less than U.S. average background). It is of interest, however, to examine the efficacy of the calculation model for situations in which the geometry has been modified such that particle leakage into locations outside the containment occurs and dose rates may no longer be negligible.

Figures 51 and 52 show a modification to the geometry, in which a section of the wall between the containment and auxiliary buildings has been removed, thus allowing streaming between the two structures. In this case, the wall breach was simulated by inserting a void "box" between the two structures at a location slightly above the reactor core. The "box" has dimensions of $200 \times 200 \times 400 \mathrm{~cm}$ $(\mathrm{X}, \mathrm{Y}, \mathrm{Z}$ ) and its center is at elevation $z=19,063 \mathrm{~cm}$. Figures 53 and 54 show the results of calculations using the modified geometry. Radiation streaming through the breach in the wall can clearly be seen. It is interesting to compare the results shown in Fig. 53 with those of Figs. 39-42. It is also noted that the calculations using the modified geometry were performed using the same weight windows and source biasing files that were used for the unmodified geometry. It appears that there is no need to recalculate the weight windows and source bias files (using the ADVANTG Steps 1 and 2) for reasonable but significant changes in the facility geometry. However, we have not fully explored the limitations of this process and should do so in future work. 


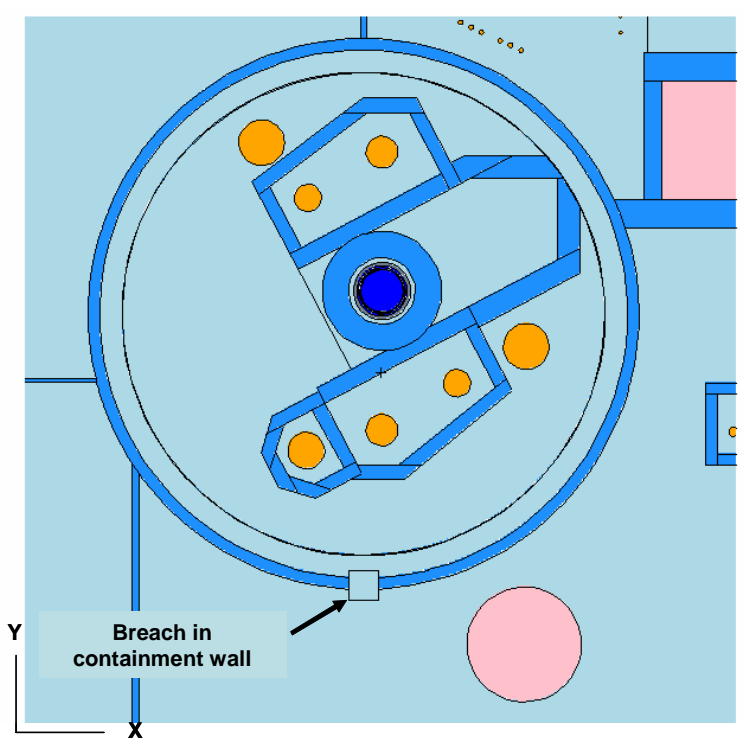

Fig. 51. Plan (X-Y) view of the modified geometry model at a location slightly above the center of the reactor core $(z=18,900 \mathrm{~cm})$ showing a breach in containment wall.

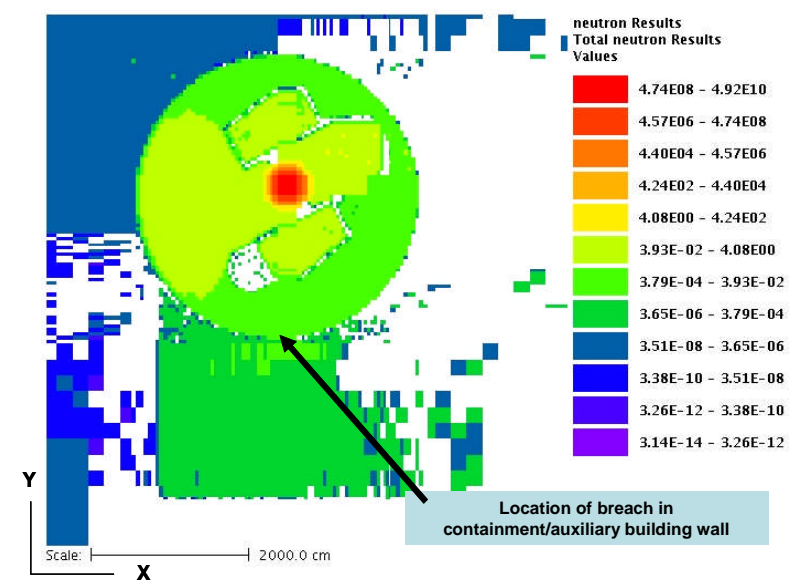

Fig. 53. Plan (X-Y) view within containment of neutron mesh tally results of the full-power reactor model at a location slightly above the center of the reactor core $(z=18,900 \mathrm{~cm})$ and with a breach in the containment wall. Units are rems per hour.

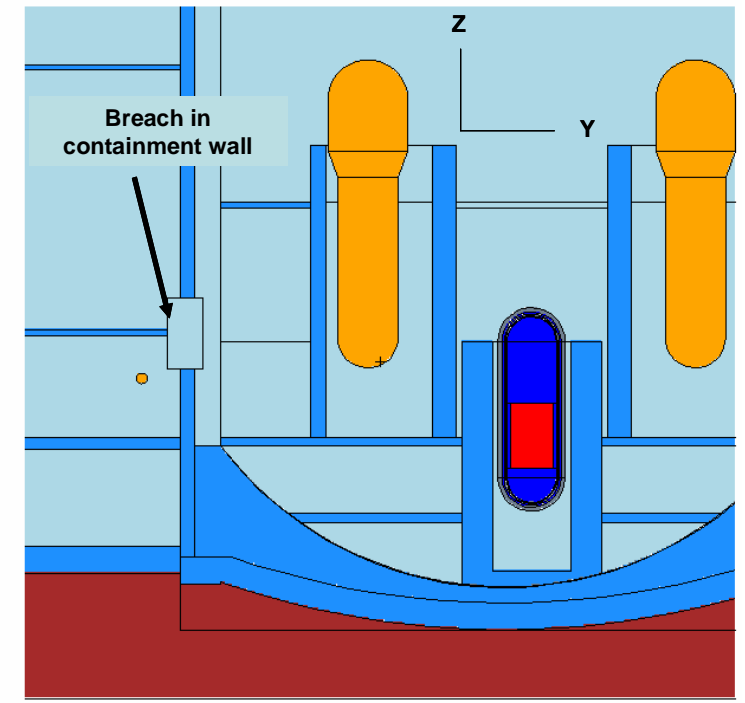

Fig. 52. Elevation (Y-Z) view along the center of the reactor core $(x=122 \mathrm{~cm})$ of the modified geometry model showing a breach in containment wall.

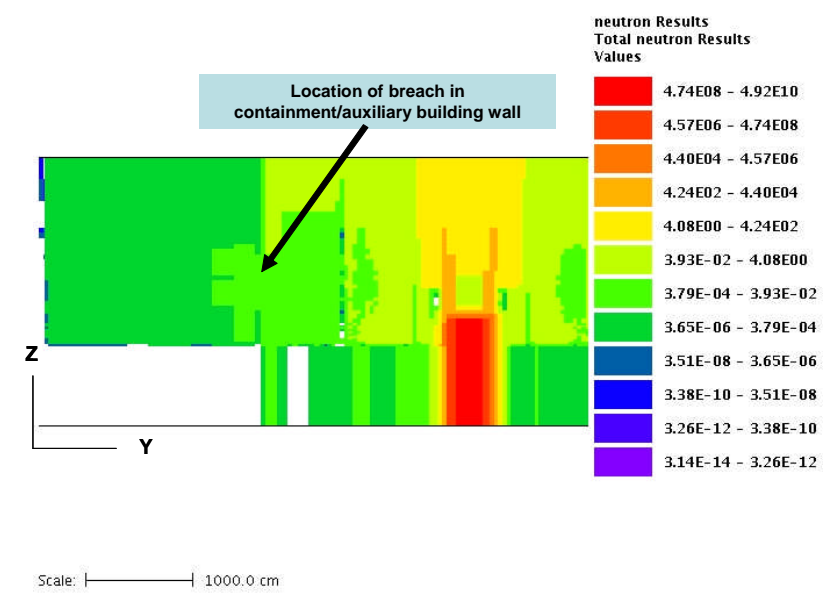

Fig. 54. Elevation (Y-Z) view of neutron mesh tally results of the full-power reactor model along the center of reactor core $(x=122 \mathrm{~cm})$ and with a breach in the containment wall. Units are rems per hour. 


\subsubsection{Photon Dose from Coolant Activation}

The geometry for the PWR model including the primary coolant system loop was discussed in Section 2.5, and the details of the photon source are included in Section 3.3. A

CADIS/ADVANTG/MCNP calculation sequence was performed for $1 \times 10^{9}$ MCNP histories; mesh tally dose rate results are shown in Figs. 55 and 56. A visual correspondence between the components that contain coolant and the highest dose rate regions in the images is quite evident in these figures.

A plot of dose rate values with error bars is also shown in Fig. 57. This plot corresponds to values along the $\mathrm{Y}$-axis in Fig. 55 (bottom to top of figure) at the reactor center along the $\mathrm{X}$-axis (left to right) and at elevation $18,850 \mathrm{~cm}$. Error bars are seen to be small $(<\sim 1 \%)$ for most points in this plot and typically are not large enough to be seen beyond the dimensions of the points as depicted. The oscillations in the values from $\sim-750$ to $\sim 1100 \mathrm{~cm}$ are attributed to the source representation as a set of discrete points.

Results were obtained for most locations within the containment and for some locations outside the containment. Because of the large attenuation, particles were not successfully transported to some regions, as evidenced by the "white" areas. Inside the containment these locations are typically within concrete walls or areas of massive shielding such as the biological shield around the reactor. Outside the containment these areas are concentrated on the right-hand side of the figure. Recall that the transport is based on weight windows produced by an adjoint source located along the periphery of the model. In this case, it is suggested that the right-hand side has greater attenuation between the containment and the adjoint-source location on that side (largely due to the spent fuel pool) and that a larger adjoint source is needed to transport the particles in that locale. 


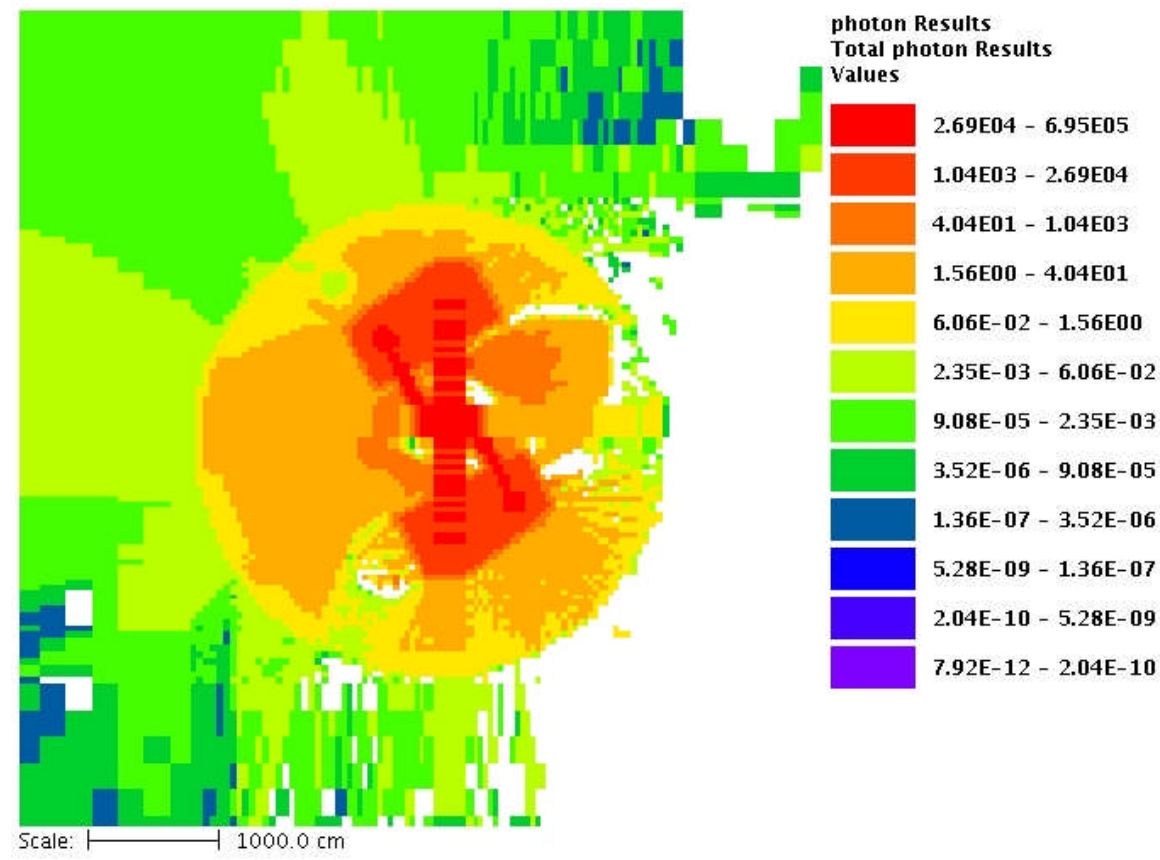

Fig. 55. Horizontal plane (plan view) of mesh tally dose rates (in millirems per hour) for coolant loop source. Plane is at elevation $18,850 \mathrm{~cm}$. The figure is limited to the containment and surrounding area in which a significant fraction of nonzero values are obtained. Components and piping containing coolant stand out as highest-dose regions.
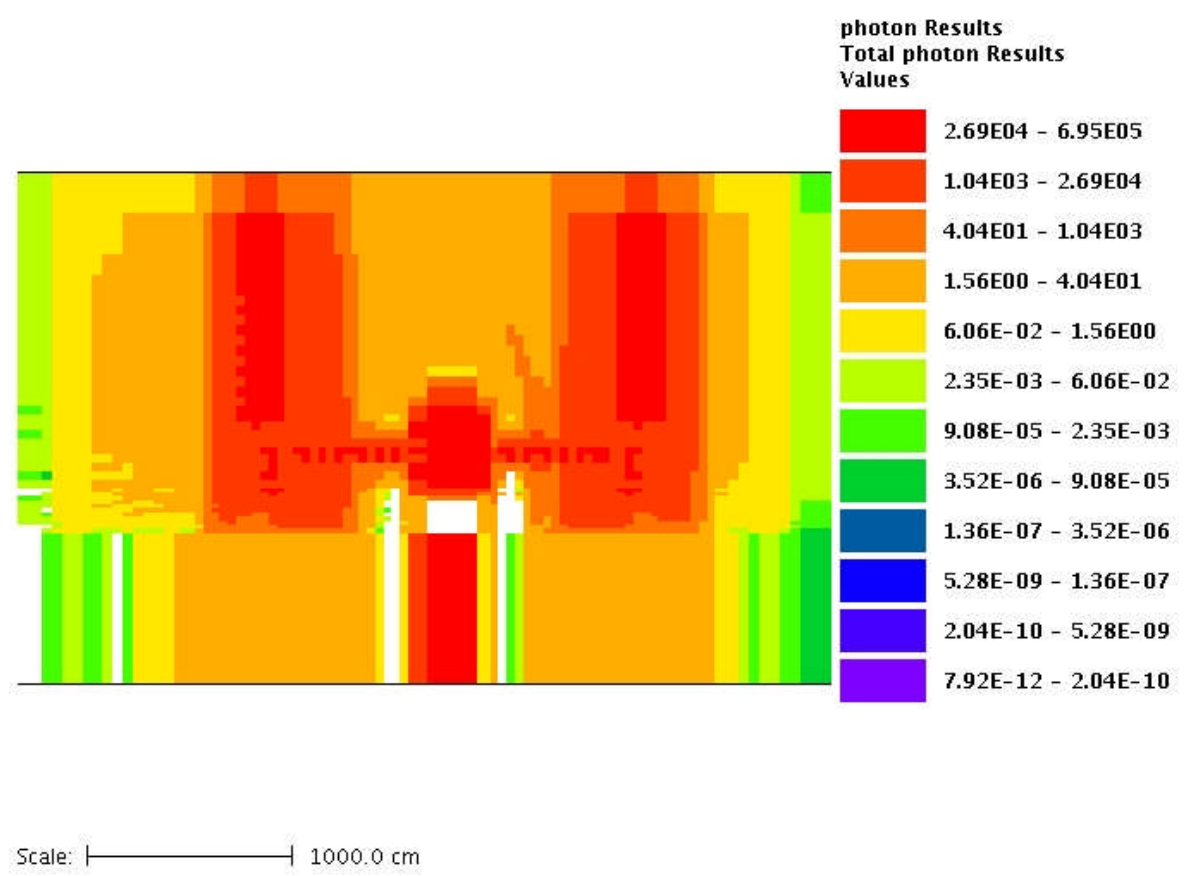

Fig. 56. Vertical plane (elevation view) of mesh tally dose rates (in millirems per hour) for coolant loop source. Plane is through center of the reactor and steam generators. The figure is limited to the containment and surrounding area in which a significant fraction of nonzero values are obtained. Components and piping containing coolant stand out as highest-dose regions. 


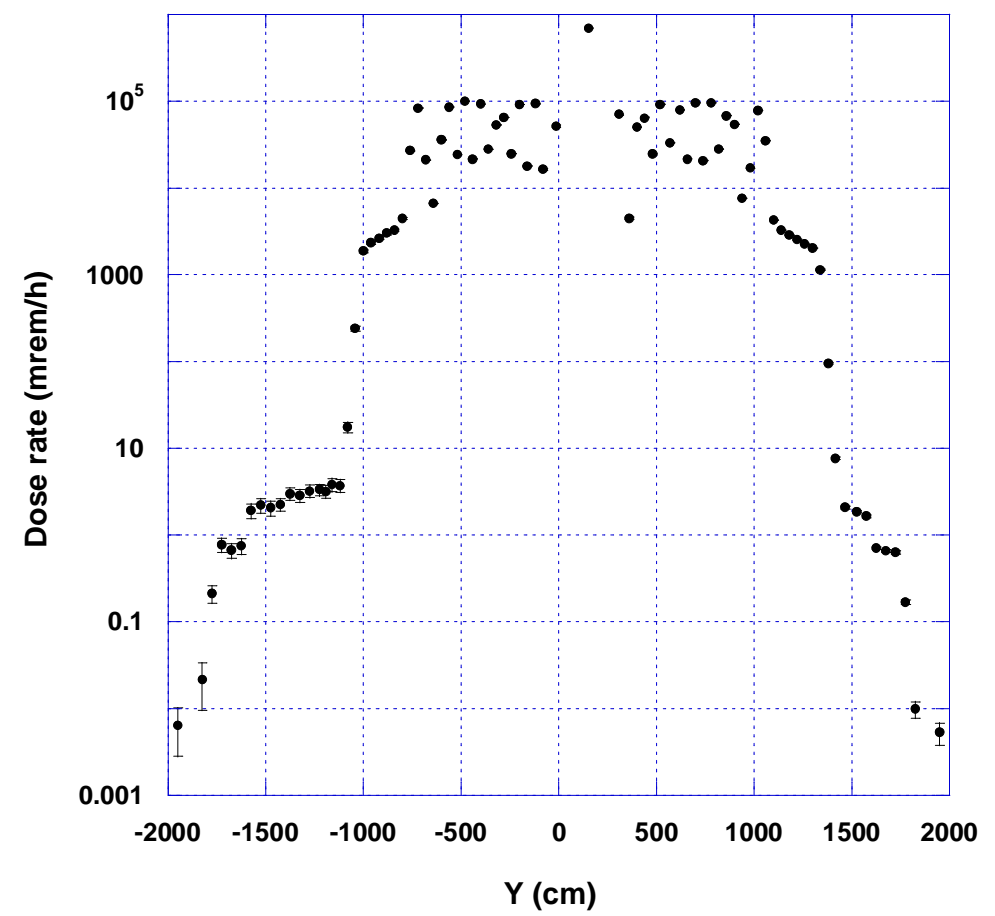

Fig. 57. Plot of reactor coolant photon dose rate through center of reactor at elevation $18,850 \mathrm{~cm}$. 


\section{DOSE VALIDATION AND VERIFICATION}

The PWR model utilized the CADIS/ADVANTG approach in which the adjoint source was located on the periphery of the model. The reasoning for using this approach was to ensure that particles would be transported and distributed through the model at all locations and would thus produce meaningful results at all locations. The concern that arises in this approach, however, is that low-energy particles in the interior of the model that would not ultimately contribute significantly to the dose rate at the adjointsource location would be assigned low importance and would therefore not be transported. This would consequently lead to a reduced dose rate at interior locations. In particular, it could lead to a reduced secondary photon dose rate since the secondary photons are to a large extent produced by capture of lowenergy neutrons. This concern was evaluated using two models and sets of calculations as discussed in the following sections. The first used a simple block model, and the second used the simplified PWR containment model, the geometry of which was discussed in Section 2.6.

\subsection{INVESTIGATION OF ADJOINT-SOURCE LOCATION WITH SIMPLE BLOCK MODEL}

A simple block model shown in Fig. 58 was used to initially test the validity of placing the adjoint source on the periphery of the model (in the air, region 0 ). The model was comprised of a $\mathrm{UO}_{2} / \mathrm{H}_{2} \mathrm{O}$ homogenous mixture fuel region surrounded by stainless steel and concrete. Four air regions (numbered 1 to 4 ) are shown between the concrete walls. Five calculations were performed with the adjoint source located sequentially in regions 1 through 4 and also in the surrounding peripheral region (0). Also, an analog calculation (no adjoint or variance reduction otherwise) was performed. For each of these six calculations, the dose rate was tallied in regions 1 through 4 . In each case except the analog, the weight windows and source bias parameters were calculated using ADVANTG and MCNP5. An equivalent set of calculations were performed for both neutron and photon sources. For convenience, ${ }^{252} \mathrm{Cf}$ spectrum was assumed for the neutron source and a ${ }^{60} \mathrm{Co}$ spectrum for the photon source.

The results of the above-described calculations are presented in Tables 12 and 13. Results are shown for neutron and photon sources uniformly distributed in the fuel region shown in Fig. 58.

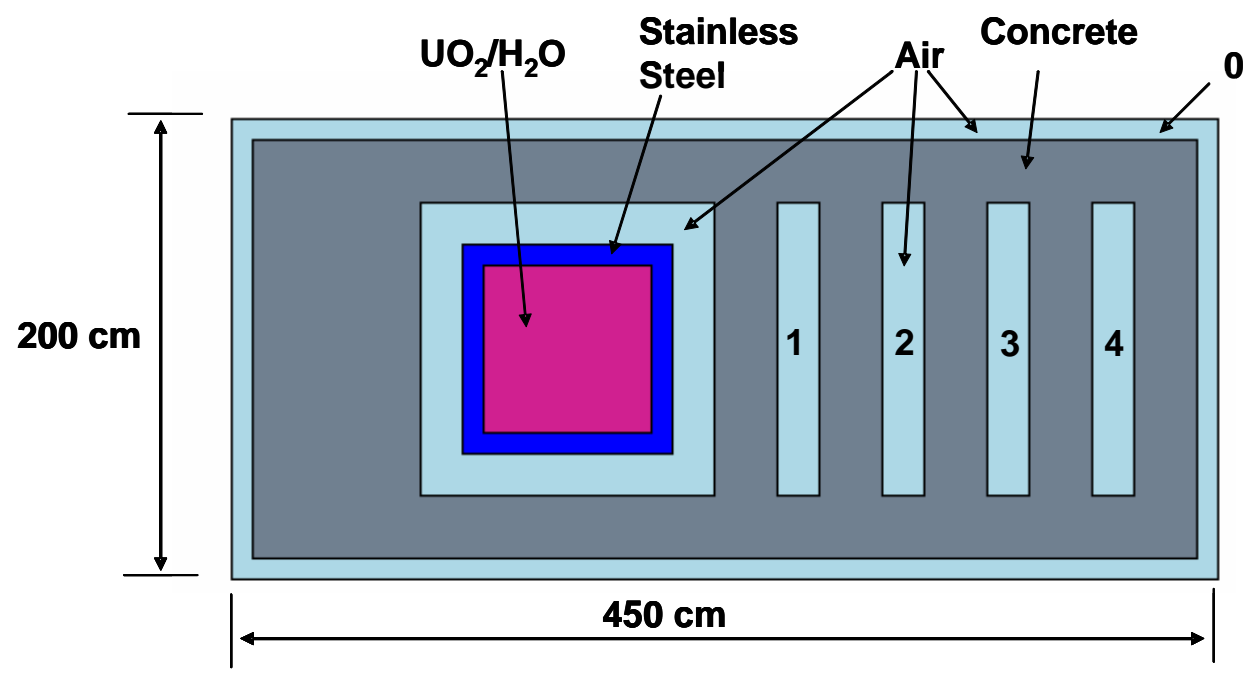

Fig. 58. Simple block model for comparing calculations using different adjoint source locations. 
Table 12. Dose rate responses for neutron source

\begin{tabular}{|c|c|c|c|c|c|c|c|c|}
\hline \multirow{3}{*}{$\begin{array}{l}\text { Adjoint- } \\
\text { source } \\
\text { location }\end{array}$} & \multicolumn{8}{|c|}{ Dose rate and uncertainty by region } \\
\hline & \multicolumn{2}{|c|}{ Region 1} & \multicolumn{2}{|c|}{ Region 2} & \multicolumn{2}{|c|}{ Region 3} & \multicolumn{2}{|c|}{ Region 4} \\
\hline & $\mathrm{rem} / \mathrm{h}$ & Unc. & $\mathrm{rem} / \mathrm{h}$ & Unc. & $\mathrm{rem} / \mathrm{h}$ & Unc. & $\mathrm{rem} / \mathrm{h}$ & Unc. \\
\hline $\begin{array}{c}\text { None } \\
\text { (analog) }\end{array}$ & $1.486 \mathrm{E}-01$ & 0.0061 & $4.534 \mathrm{E}-03$ & 0.0349 & $2.402 \mathrm{E}-04$ & 0.1616 & $1.416 \mathrm{E}-05$ & 0.5208 \\
\hline Region $0^{a}$ & 1.459E-01 & 0.0047 & 4.920E-03 & 0.0211 & $2.091 \mathrm{E}-04$ & 0.0432 & $1.012 \mathrm{E}-05$ & 0.0507 \\
\hline Region 1 & $1.451 \mathrm{E}-01$ & $0.0005^{b}$ & 4.732E-03 & 0.0096 & $2.339 \mathrm{E}-04$ & 0.2356 & $0.000 \mathrm{E}+00$ & 0.0000 \\
\hline Region 2 & $1.451 \mathrm{E}-01$ & 0.0007 & $4.758 \mathrm{E}-03$ & 0.0008 & $2.045 \mathrm{E}-04$ & 0.0074 & $8.124 \mathrm{E}-06$ & 0.1678 \\
\hline Region 3 & $1.451 \mathrm{E}-01$ & 0.0008 & $4.756 \mathrm{E}-03$ & 0.0009 & $2.042 \mathrm{E}-04$ & 0.0011 & $9.456 \mathrm{E}-06$ & 0.0061 \\
\hline Region 4 & $1.453 \mathrm{E}-01$ & 0.0009 & $4.763 \mathrm{E}-03$ & 0.0012 & $2.042 \mathrm{E}-04$ & 0.0013 & $9.516 \mathrm{E}-06$ & 0.0014 \\
\hline
\end{tabular}

${ }^{a}$ Region 0: void surrounding geometry. Regions 1-4: void at increasing distances from source.

${ }^{b}$ Regions in which adjoint source is located are highlighted.

Table 13. Dose rate responses for photon source

\begin{tabular}{|c|c|c|c|c|c|c|c|c|}
\hline \multirow{3}{*}{$\begin{array}{l}\text { Adjoint- } \\
\text { source } \\
\text { location }\end{array}$} & \multicolumn{8}{|c|}{ Dose rate and uncertainty by region } \\
\hline & \multicolumn{2}{|c|}{ Region 1} & \multicolumn{2}{|c|}{ Region 2} & \multicolumn{2}{|c|}{ Region 3} & \multicolumn{2}{|c|}{ Region 4} \\
\hline & $\mathrm{rem} / \mathrm{h}$ & Unc. & $\mathrm{rem} / \mathrm{h}$ & Unc. & $\mathrm{rem} / \mathrm{h}$ & Unc. & $\mathrm{rem} / \mathrm{h}$ & Unc. \\
\hline $\begin{array}{c}\text { None } \\
\text { (analog) }\end{array}$ & $8.334 \mathrm{E}-05$ & 0.0285 & $1.662 \mathrm{E}-06$ & 0.1960 & $1.583 \mathrm{E}-07$ & 0.7339 & $0.000 \mathrm{E}+00$ & 0.0000 \\
\hline Region $0^{a}$ & $8.065 \mathrm{E}-05$ & 0.0266 & $1.745 \mathrm{E}-06$ & 0.1035 & 5.324E-08 & 0.2403 & $1.528 \mathrm{E}-09$ & 0.2643 \\
\hline Region 1 & $8.047 \mathrm{E}-05$ & $0.0014^{b}$ & $1.661 \mathrm{E}-06$ & 0.0308 & 3.999E-09 & 1.0000 & $0.000 \mathrm{E}+00$ & 0.0000 \\
\hline Region 2 & $8.062 \mathrm{E}-05$ & 0.0031 & $1.783 \mathrm{E}-06$ & 0.0019 & 4.211E-08 & 0.0639 & $5.830 \mathrm{E}-10$ & 0.5864 \\
\hline Region 3 & $8.021 \mathrm{E}-05$ & 0.0121 & $1.778 \mathrm{E}-06$ & 0.0024 & $4.042 \mathrm{E}-08$ & 0.0025 & $8.759 \mathrm{E}-10$ & 0.0231 \\
\hline Region 4 & 7.932E-05 & 0.0160 & $1.781 \mathrm{E}-06$ & 0.0074 & $4.028 \mathrm{E}-08$ & 0.0028 & $9.472 \mathrm{E}-10$ & 0.0030 \\
\hline
\end{tabular}

${ }^{a}$ Region 0: void surrounding geometry. Regions 1-4: void at increasing distances from source.

${ }^{b}$ Regions in which adjoint source is located are highlighted.

Several interesting observations can be made from the results. First, it is observed that for the bottom sections of the tables in which the adjoint source is located in one of the four regions (indicated by highlight), the dose rate values below the highlighted values are approximately equal to the highlighted value in each column. It is also observed that the highlighted region has the lowest variance and presumably the most accurate value in each column. The conclusion demonstrated here is that if the adjoint source is located in a particular region, the best response is obtained for that region and consistent responses are obtained for regions between that region and the actual source. This is a reasonable expectation since particles must be transported through the intervening regions. For this model it is also observed that results in the table immediately above the adjoint source regions in the last three columns are also good values but have significantly larger uncertainties. Thus, the adjoint source in a region transports particles to that region from the source but to a lesser degree transports them through one more 
wall "beyond" that region. Furthermore, in the last two columns we see that that the results two or three rows above the adjoint source locations have high uncertainties and are not good values.

The second row shows results in which the adjoint source is located in a peripheral region surrounding the geometry. Here it is seen that the values in each region approximately agree with the highlighted values but have significantly larger uncertainties. The conclusion here is that the adjoint located on the outside of the geometry produces reasonable results everywhere, but not as good as the "specialized" results produced by locating the adjoint in or near the region of interest.

An important overall conclusion, at least for this simple model, is that the exterior adjoint does not lead to underestimation of neutron or photon dose rates at interior locations of the model, as was originally feared.

Some mesh tally results from the above-described calculations are shown in Figs. 59-62. Figures 59 and 61 show neutron and photon results, respectively, for two of the adjoint source locations. In the top of each of the figures, results are shown in which the adjoint source is located in the void closest to the actual source (Region 1). In the bottom of each figure, results are for the adjoint source located on the periphery of the model (Region 0). Figures 60 and 62 are the corresponding uncertainty plots for these four calculations.

Results are consistent with those discussed earlier and simply point out those results in a more dramatic visual way. For each particle type, results for the two calculations are approximately equivalent in areas in which particles are successfully transported. However, when the source is located in the first void region (slightly right of center in the images), there is a failure to transport particles beyond the region, as indicated by the white space on the right of the images and also a failure to transport particles on the other side of the source, as indicated by the white space on the left side of the image. Both cases in which the adjoint is located on the periphery result in reasonable results almost everywhere in the model. However, as indicated earlier, these cases do not give optimal results anywhere. 

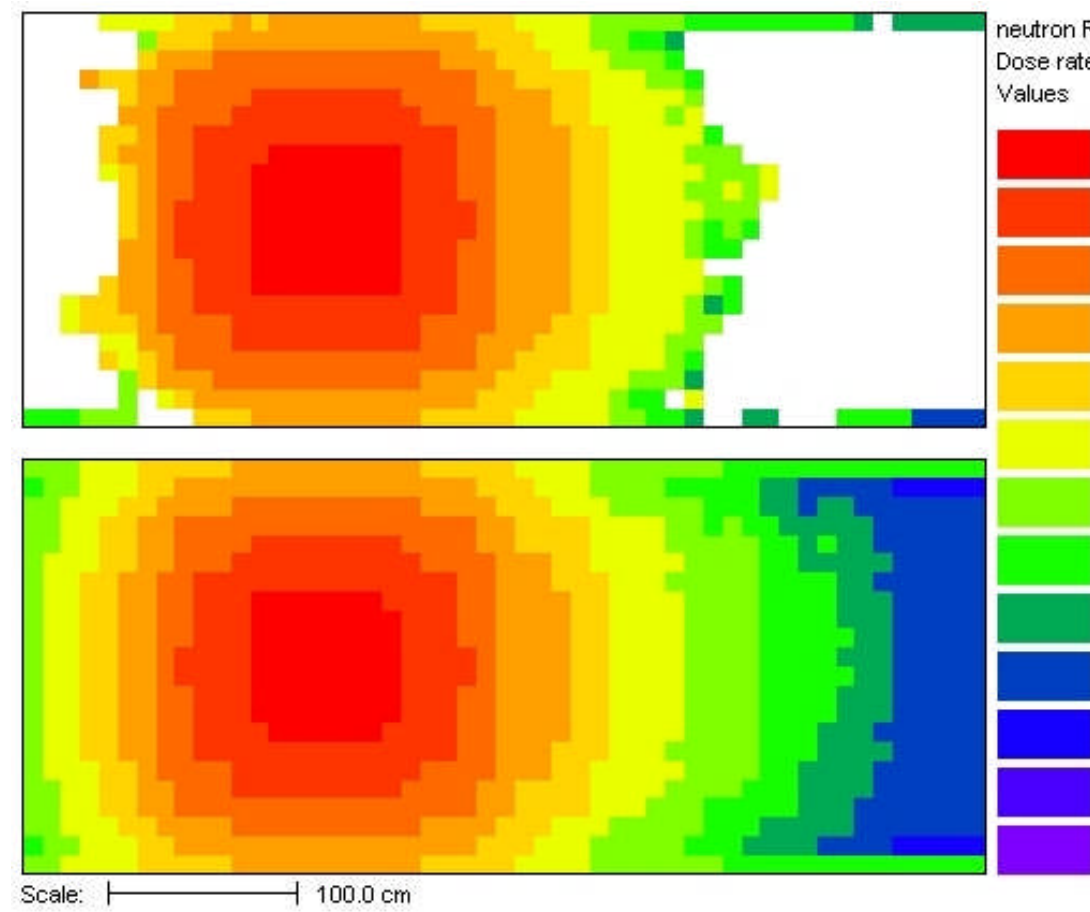

$1.00 \mathrm{E} 02-1.00 \mathrm{E} 03$

1.00E01 - 1.00E02

1.00E00 - $1.00 E 01$

1.00E-01 - $1.00 \mathrm{E} 00$

1.00E-02 - $1.00 \mathrm{E}-01$

$1.00 \mathrm{E}-03-1.00 \mathrm{E}-02$

1.00E-04 - 1.00E-03

1.00E-05 - 1.00E-04

$1.00 \mathrm{E}-06-1.00 \mathrm{E}-05$

1.00E-07 - 1.00E-06

1.00E-08 - 1.00E-07

1.00E-09 - $1.00 \mathrm{E}-08$

$1.00 \mathrm{E}-10-1.00 \mathrm{E}-09$

Fig. 59. ADVANTG neutron dose rates (in rems per hour) using (top) an adjoint source in the first void region and (bottom) an exterior boundary adjoint source.

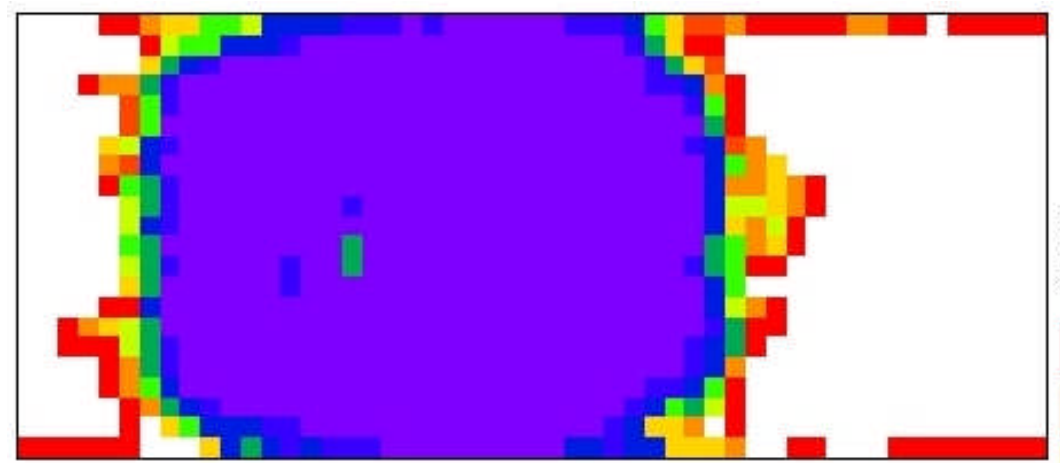

neutron Results

Dose rate (rem/hr)

Relative Uncertainty
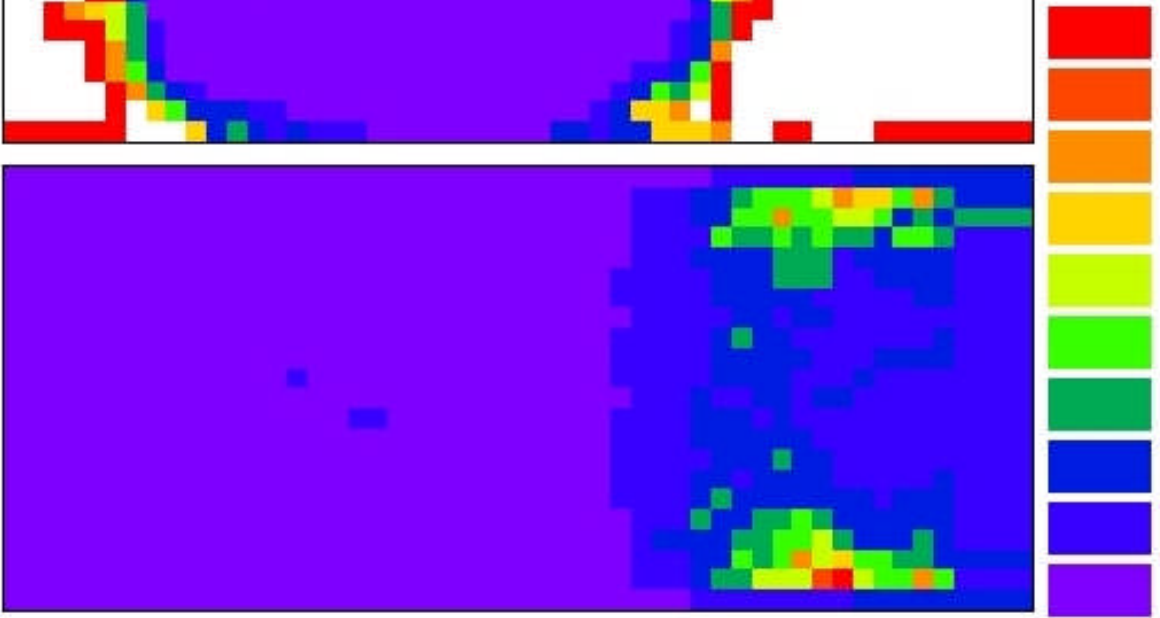

9.00E-01 - $1.00 \mathrm{E} 00$

8.00E-01 - 9.00E-01

7.00E-01 - 8.00E-01

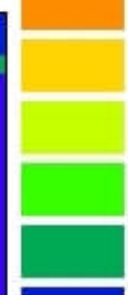

6.00E-01 - 7.00E-01

5.00E-01 - 6.00E-01

4.00E-01 - 5.00E-01

3.00E-01 - 4.00E-01

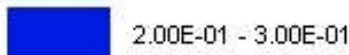

$1.00 \mathrm{E}-01-2.00 \mathrm{E}-01$

$0.00 \mathrm{E} 00-1.00 \mathrm{E}-01$

Scale:

$100.0 \mathrm{~cm}$

Fig. 60. Relative uncertainties in the neutron dose rates using (top) an adjoint source in the first void region and (bottom) an exterior boundary adjoint source. 


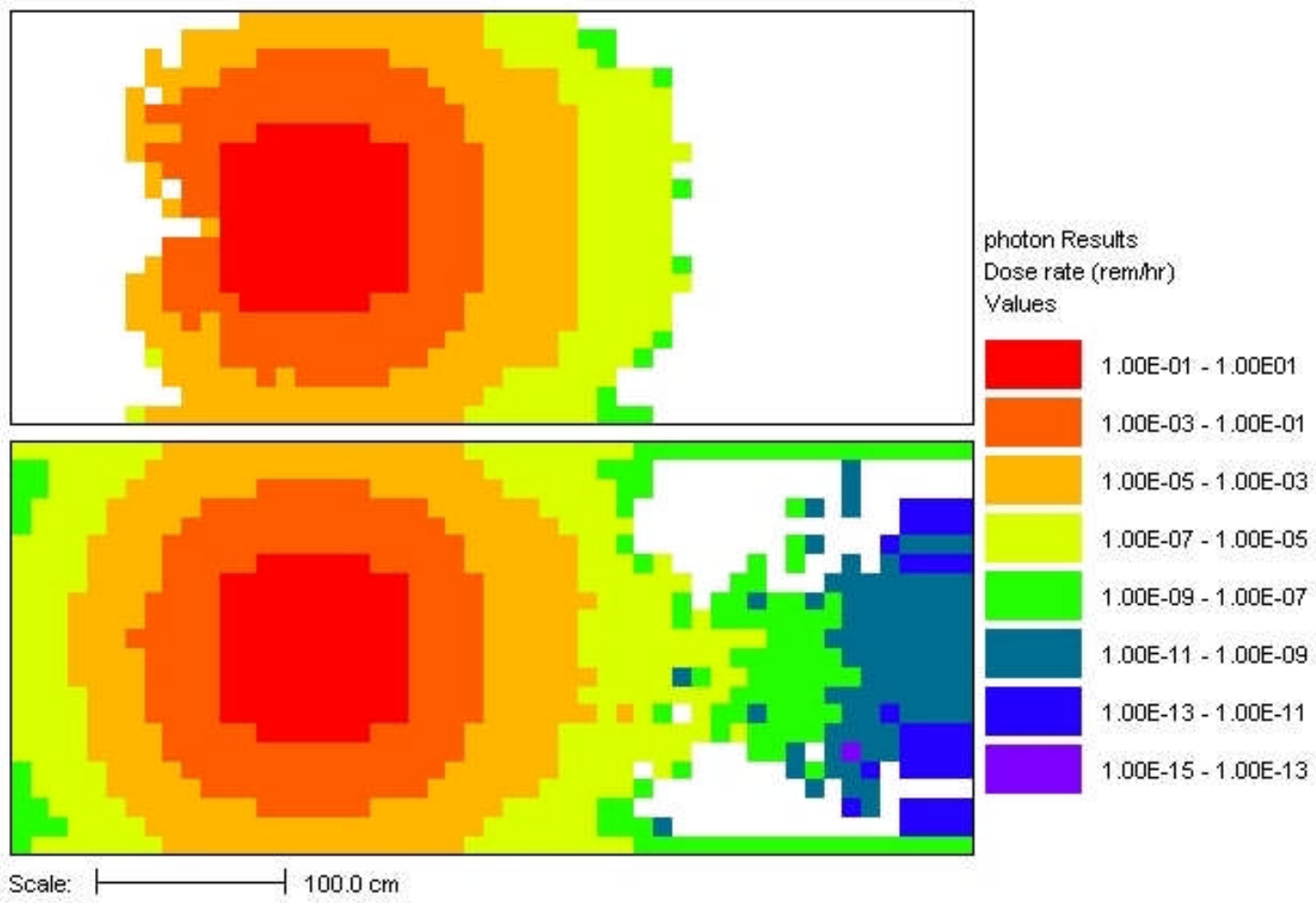

Fig. 61. ADVANTG photon dose rates (in rems per hour) using (top) an adjoint source in the first void region and (bottom) an exterior boundary adjoint source.
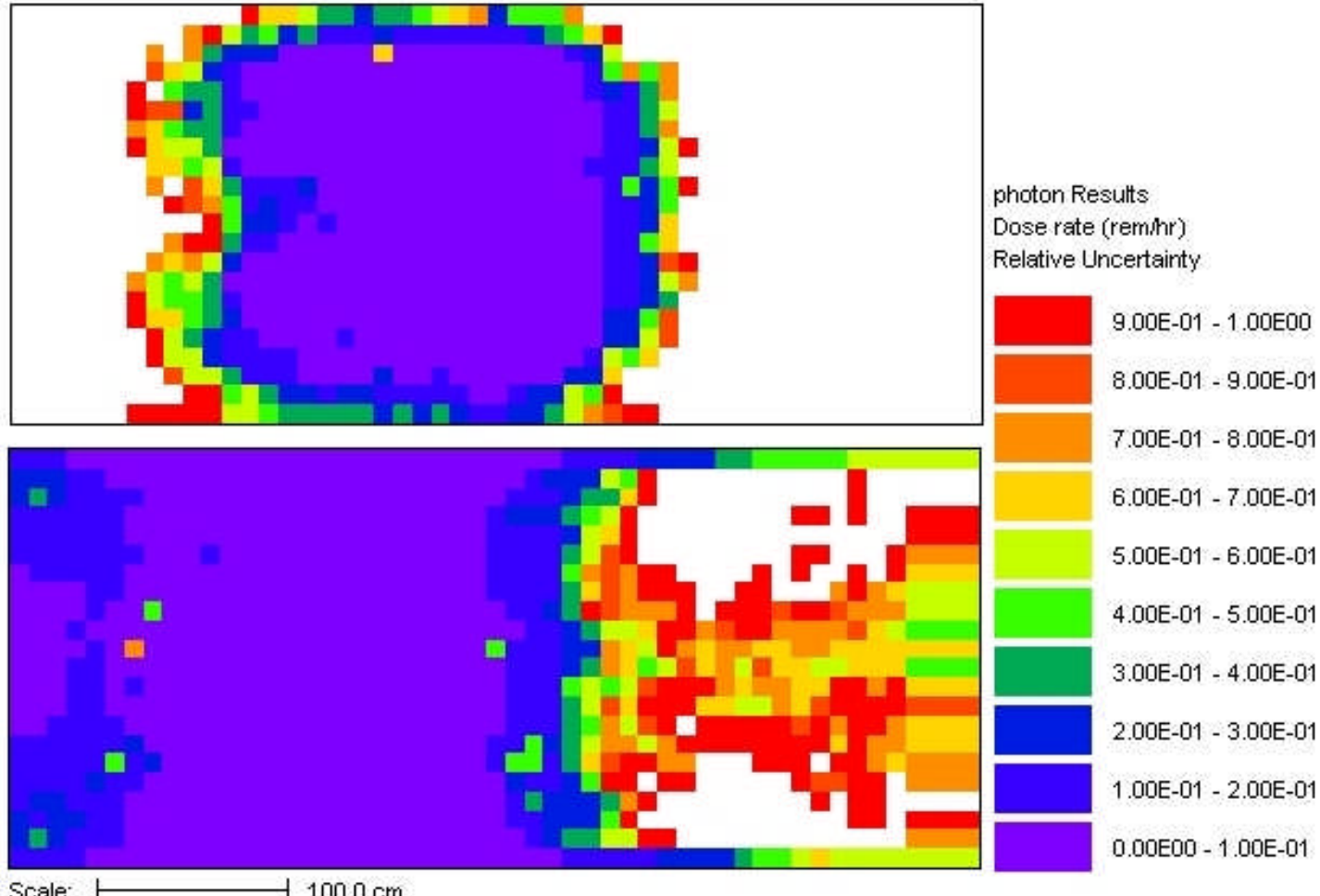

$0.00 \mathrm{E} 00-1.00 \mathrm{E}-01$

Fig. 62. Relative uncertainties in the photon dose rates using (top) an adjoint source in the first void region and (bottom) an exterior boundary adjoint source. 


\subsection{INVESTIGATION OF ADJOINT-SOURCE LOCATION WITH SIMPLIFIED CONTAINMENT MODEL}

\subsubsection{Overview}

A simplified model of the PWR facility, limited to the reactor containment, was presented in Section 2.6, and the model is shown in Figs. 15-19. This model was developed to more easily explore the computational issues involved with a large-scale simulation and, more specifically, to examine the applicability of the CADIS/ADVANTG methodology. This model was used in particular to investigate the effects of placing the adjoint source in different locations. Thus, the investigation was similar to that discussed in Section 6.1 but on a larger model more comparable to the full-scale PWR facility model. Three separate source/response calculations were implemented, as shown below in Table 14.

Table 14. MCNP model source-type summary

\begin{tabular}{|c|c|c|c|}
\hline $\begin{array}{c}\text { Source } \\
\text { description }\end{array}$ & $\begin{array}{c}\text { Type } \\
\text { transport }\end{array}$ & $\begin{array}{l}\text { Type dose } \\
\text { rate tally }\end{array}$ & $\begin{array}{c}\text { Adjoint } \\
\text { source }^{a}\end{array}$ \\
\hline Reactor neutron & Neutron & Neutron & Neutron \\
\hline Reactor photon & Photon & Photon & Photon \\
\hline Reactor neutron & Coupled neutron/photon & $(\mathrm{n}, \gamma)$ Photon $^{b}$ & Photon \\
\hline
\end{tabular}

Runs were compared in which a neutron or photon adjoint source was located in each of the Cells 0-5 (see Figs. 16-19). The base case for each of the three source model types, shown in Table 14, was one in that the adjoint source was located in Cell 0, an annulus that surrounds the containment. For each of the model types, calculations were performed with adjoint sources sequentially located in Cells 0 to 5 . For these calculations the neutron or photon dose rates in Cells 1 to 5 were tallied. Each MCNP calculation required source bias parameters and a weight windows file, both produced using the CADIS/ADVANTG methodology. The CASK-81 22- and 18-group neutron and photon energy structures and dose response multipliers were used with ADVANTG and the MCNP tallies.

\subsubsection{Calculation Results}

Results for the three calculation types listed in Table 14 are shown in Tables 15-17. In each line of each table, a different cell has been designated as the location of the adjoint source (either neutron or photon dose rate multipliers). A "box" has been placed around the values in the appropriate adjoint-source cell, highlighting the source cell. For Run A, shown on the top line of each table, the adjoint source is in Cell 0 , which is an annular cell surrounding the containment. Thus, the Run A results represent efforts to obtain suitable dose rate values everywhere in the containment by forcing particles to be transported to a location outside the containment. The other runs are efforts to optimize the results in a specific location defined by the adjoint-source cell. It is of interest, therefore, to compare within each column, values along the top row of Tables 15-17 with values in the designated source cells. This provides an assessment of how well the "general" results from Run A compare with the "specialized" results from the other cases with the adjoint located in specific cells. Tables 18-20 aid in this comparison. These tables are similar to Tables 15-17 except that values in each column are normalized to the highlighted value in that column. Thus, the values shown indicate the deviation from the presumably best value for a particular cell (i.e., the case in which the adjoint source is located in that cell). 
Table 15. Neutron dose rates and relative uncertainties in tally cells for reactor neutron source

\begin{tabular}{|c|c|c|c|c|c|c|c|c|c|c|}
\hline \multirow{3}{*}{ Run } & \multicolumn{10}{|c|}{ Dose rate and uncertainty by cell } \\
\hline & \multicolumn{2}{|c|}{ Cell 1} & \multicolumn{2}{|c|}{ Cell 2} & \multicolumn{2}{|c|}{ Cell 3} & \multicolumn{2}{|c|}{ Cell 4} & \multicolumn{2}{|c|}{ Cell 5} \\
\hline & $\begin{array}{c}\text { Dose } \\
(\text { rem/h) }\end{array}$ & Unc. & $\begin{array}{c}\text { Dose } \\
\text { (rem/h) }\end{array}$ & Unc. & $\begin{array}{c}\text { Dose } \\
(\mathrm{rem} / \mathrm{h})\end{array}$ & Unc. & $\begin{array}{c}\text { Dose } \\
(\mathbf{r e m} / \mathbf{h})\end{array}$ & Unc. & $\begin{array}{c}\text { Dose } \\
\text { (rem/h) }\end{array}$ & Unc. \\
\hline $\mathrm{A}^{a}$ & $6.56 \mathrm{E}-03$ & 0.083 & $1.04 \mathrm{E}-02$ & 0.090 & $2.91 \mathrm{E}+00$ & 0.028 & $6.97 \mathrm{E}-02$ & 0.134 & $8.28 \mathrm{E}-03$ & 0.095 \\
\hline B & $6.64 \mathrm{E}-03$ & $0.110^{b}$ & $9.74 \mathrm{E}-03$ & 0.102 & $2.89 \mathrm{E}+00$ & 0.033 & $7.95 \mathrm{E}-02$ & 0.210 & 7.97E-03 & 0.160 \\
\hline $\mathrm{C}$ & $6.65 \mathrm{E}-03$ & 0.071 & $1.02 \mathrm{E}-02$ & 0.100 & $3.06 \mathrm{E}+00$ & 0.045 & $6.07 \mathrm{E}-02$ & 0.093 & $1.18 \mathrm{E}-02$ & 0.214 \\
\hline $\mathrm{D}$ & $1.69 \mathrm{E}-02$ & 0.956 & $6.21 \mathrm{E}-03$ & 1.000 & $3.22 \mathrm{E}+00$ & 0.081 & $1.31 \mathrm{E}-01$ & 0.671 & $0.00 \mathrm{E}+00$ & 0.000 \\
\hline $\mathrm{E}$ & $5.54 \mathrm{E}-03$ & 0.125 & $9.85 \mathrm{E}-03$ & 0.127 & $2.83 \mathrm{E}+00$ & 0.031 & $5.56 \mathrm{E}-02$ & 0.090 & $1.25 \mathrm{E}-02$ & 0.318 \\
\hline $\mathrm{F}$ & $7.18 \mathrm{E}-03$ & 0.168 & $1.05 \mathrm{E}-02$ & 0.157 & $3.00 \mathrm{E}+00$ & 0.054 & $7.58 \mathrm{E}-02$ & 0.213 & $8.68 \mathrm{E}-03$ & 0.209 \\
\hline
\end{tabular}

${ }^{a}$ Values for Runs A, B, and F are based on $4 \times 10^{7}$ to $8 \times 10^{7}$ histories. Values for Runs C, D, and $\mathrm{E}$ are based on $1 \times 10^{7}$ histories.

${ }^{b}$ Highlights indicate cells for adjoint sources (e.g., Cell 1 for Run B). Adjoint source for Run A is in Cell 0.

Table 16. Photon dose rates and relative uncertainties in tally cells for reactor photon source

\begin{tabular}{|c|c|c|c|c|c|c|c|c|c|c|}
\hline \multirow{3}{*}{ Run } & \multicolumn{10}{|c|}{ Dose rate and uncertainty by cell } \\
\hline & \multicolumn{2}{|c|}{ Cell 1} & \multicolumn{2}{|c|}{ Cell 2} & \multicolumn{2}{|c|}{ Cell 3} & \multicolumn{2}{|c|}{ Cell 4} & \multicolumn{2}{|c|}{ Cell 5} \\
\hline & $\begin{array}{c}\text { Dose } \\
(\mathbf{r e m} / \mathbf{h})\end{array}$ & Unc. & $\begin{array}{l}\text { Dose } \\
(\mathrm{rem} / \mathbf{h})\end{array}$ & Unc. & $\begin{array}{c}\text { Dose } \\
(\mathbf{r e m} / \mathbf{h})\end{array}$ & Unc. & $\begin{array}{c}\text { Dose } \\
(\mathbf{r e m} / \mathbf{h})\end{array}$ & Unc. & $\begin{array}{c}\text { Dose } \\
(\mathbf{r e m} / \mathbf{h})\end{array}$ & Unc. \\
\hline $\mathrm{A}^{a}$ & $9.23 \mathrm{E}-07$ & 0.024 & $3.64 \mathrm{E}-04$ & 0.031 & $1.88 \mathrm{E}-01$ & 0.037 & $5.14 \mathrm{E}-04$ & 0.110 & $4.25 \mathrm{E}-05$ & 0.075 \\
\hline B & $8.90 \mathrm{E}-04$ & $0.011^{b}$ & $3.53 \mathrm{E}-04$ & 0.015 & $0.00 \mathrm{E}+00$ & 0.000 & 7.61E-04 & 1.000 & $1.81 \mathrm{E}-07$ & 1.000 \\
\hline $\mathrm{C}$ & $8.78 \mathrm{E}-04$ & 0.014 & $3.51 \mathrm{E}-04$ & 0.016 & $3.30 \mathrm{E}-01$ & 0.544 & $4.56 \mathrm{E}-04$ & 1.000 & $3.80 \mathrm{E}-05$ & 0.498 \\
\hline $\mathrm{D}$ & $0.00 \mathrm{E}+00$ & 0.000 & $0.00 \mathrm{E}+00$ & 0.000 & $1.76 \mathrm{E}-01$ & 0.015 & $0.00 \mathrm{E}+00$ & 0.000 & $0.00 \mathrm{E}+00$ & 0.000 \\
\hline $\mathrm{E}$ & $3.08 \mathrm{E}-03$ & 0.836 & $4.81 \mathrm{E}-04$ & 1.000 & $1.92 \mathrm{E}-01$ & 0.220 & $4.95 \mathrm{E}-04$ & 0.015 & $8.52 \mathrm{E}-05$ & 0.315 \\
\hline $\mathrm{F}$ & 7.04E-07 & 0.395 & 4.44E-04 & 0.450 & $1.69 \mathrm{E}-01$ & 0.199 & $5.13 \mathrm{E}-04$ & 0.022 & $4.31 \mathrm{E}-05$ & 0.016 \\
\hline
\end{tabular}

${ }^{a}$ All results are based on $1 \times 10^{8}$ histories.

${ }^{b}$ Highlights indicate cells for adjoint sources (e.g., Cell 1 for Run B). Adjoint source for Run A is in Cell 0. 
Table 17. $(\mathbf{n}, \gamma)$ Photon dose rates and relative uncertainties in tally cells for reactor neutron source

\begin{tabular}{|c|c|c|c|c|c|c|c|c|c|c|}
\hline \multirow{3}{*}{ Run } & \multicolumn{10}{|c|}{ Dose rate and uncertainty by cell } \\
\hline & \multicolumn{2}{|c|}{ Cell 1} & \multicolumn{2}{|c|}{ Cell 2} & \multicolumn{2}{|c|}{ Cell 3} & \multicolumn{2}{|c|}{ Cell 4} & \multicolumn{2}{|c|}{ Cell 5} \\
\hline & $\begin{array}{c}\text { Dose } \\
(\mathbf{r e m} / \mathbf{h})\end{array}$ & Unc. & $\begin{array}{c}\text { Dose } \\
(\mathbf{r e m} / \mathbf{h})\end{array}$ & Unc. & $\begin{array}{c}\text { Dose } \\
(\mathrm{rem} / \mathrm{h})\end{array}$ & Unc. & $\begin{array}{c}\text { Dose } \\
(\mathbf{r e m} / \mathbf{h})\end{array}$ & Unc. & $\begin{array}{c}\text { Dose } \\
(\mathbf{r e m} / \mathbf{h})\end{array}$ & Unc. \\
\hline $\mathrm{A}^{a}$ & $3.62 \mathrm{E}-01$ & 0.095 & $4.34 \mathrm{E}-01$ & 0.094 & $4.25 \mathrm{E}+01$ & 0.034 & $1.37 \mathrm{E}-00$ & 0.091 & $2.24 \mathrm{E}-01$ & 0.131 \\
\hline B & $3.82 \mathrm{E}-01$ & $0.093^{b}$ & 4.92E-01 & 0.103 & $3.76 \mathrm{E}+01$ & 0.240 & $1.31 \mathrm{E}-00$ & 0.289 & $9.69 \mathrm{E}-02$ & 0.359 \\
\hline $\mathrm{C}$ & $3.49 \mathrm{E}-01$ & 0.059 & $4.31 \mathrm{E}-01$ & 0.077 & $3.09 \mathrm{E}+01$ & 0.090 & 4.49E-01 & 0.094 & $2.41 \mathrm{E}-01$ & 0.298 \\
\hline $\mathrm{D}$ & $0.00 \mathrm{E}+00$ & 0.000 & $4.95 \mathrm{E}-05$ & 1.000 & $4.21 \mathrm{E}+01$ & 0.017 & $5.00 \mathrm{E}-03$ & 0.413 & $0.00 \mathrm{E}-00$ & 0.000 \\
\hline $\mathrm{E}$ & $5.11 \mathrm{E}-01$ & 0.531 & $3.81 \mathrm{E}-01$ & 0.528 & $3.66 \mathrm{E}+01$ & 0.056 & $1.60 \mathrm{E}-00$ & 0.118 & $2.37 \mathrm{E}-01$ & 0.192 \\
\hline F & $4.37 \mathrm{E}-01$ & 0.143 & $6.53 \mathrm{E}-01$ & 0.171 & $3.99 \mathrm{E}+01$ & 0.066 & $1.33 \mathrm{E}+00$ & 0.043 & $2.57 \mathrm{E}-01$ & 0.093 \\
\hline
\end{tabular}

${ }^{a}$ Values for Run A are based on $1 \times 10^{8}$ histories. Values for Runs B-F are based on $5 \times 10^{7}$ histories.

${ }^{b}$ Highlights indicate cells for adjoint sources (e.g., Cell 1 for Run B). Adjoint source for Run A is in Cell 0.

Table 18. Neutron dose rate ratios in tally cells for reactor neutron source

\begin{tabular}{|c|c|c|c|c|c|}
\hline Run & $\begin{array}{c}\text { Cell } 1 \\
\text { dose ratio }\end{array}$ & $\begin{array}{c}\text { Cell } 2 \\
\text { dose ratio }\end{array}$ & $\begin{array}{c}\text { Cell } 3 \\
\text { dose ratio }\end{array}$ & $\begin{array}{c}\text { Cell } 4 \\
\text { dose ratio }\end{array}$ & $\begin{array}{c}\text { Cell } 5 \\
\text { dose ratio }\end{array}$ \\
\hline A & $9.87 \mathrm{E}-01$ & $1.02 \mathrm{E}+00$ & $9.04 \mathrm{E}-01$ & $1.25 \mathrm{E}+00$ & $9.53 \mathrm{E}-01$ \\
\hline B & $1.00 \mathrm{E}+00^{a}$ & $9.55 \mathrm{E} 01$ & 8.99E-01 & $1.43 \mathrm{E}+00$ & $9.18 \mathrm{E}-01$ \\
\hline $\mathrm{C}$ & $1.00 \mathrm{E}+00$ & $1.00 \mathrm{E}+00$ & $9.50 \mathrm{E}-01$ & $1.09 \mathrm{E}+00$ & $1.36 \mathrm{E}+00$ \\
\hline $\mathrm{D}$ & $2.54 \mathrm{E}+00$ & $6.09 \mathrm{E}-01$ & $1.00 \mathrm{E}+00$ & $2.36 \mathrm{E}+00$ & $0.00 \mathrm{E}+00$ \\
\hline $\mathrm{E}$ & 8.34E-01 & $9.66 \mathrm{E}-01$ & $8.79 \mathrm{E}-01$ & $1.00 \mathrm{E}+00$ & $1.44 \mathrm{E}+00$ \\
\hline $\mathrm{F}$ & $1.08 \mathrm{E}+00$ & $1.03 \mathrm{E}+00$ & $9.31 \mathrm{E}-01$ & $1.36 \mathrm{E}+00$ & $1.00 \mathrm{E}+00$ \\
\hline
\end{tabular}

${ }^{a}$ Highlights indicate cells for adjoint sources (e.g., Cell 1 for Run B). Adjoint source for Run A is in Cell 0.

Values in each column are ratios of dose rates to the dose rate for the run with the highlighted cell as adjoint source. 
Table 19. Photon dose rate ratios in tally cells for reactor photon source

\begin{tabular}{|c|c|c|c|c|c|}
\hline Run & $\begin{array}{c}\text { Cell } 1 \\
\text { dose ratio }\end{array}$ & $\begin{array}{c}\text { Cell } 2 \\
\text { dose ratio }\end{array}$ & $\begin{array}{c}\text { Cell } 3 \\
\text { dose ratio }\end{array}$ & $\begin{array}{c}\text { Cell } 4 \\
\text { dose ratio }\end{array}$ & $\begin{array}{c}\text { Cell } 5 \\
\text { dose ratio }\end{array}$ \\
\hline A & $1.04 \mathrm{E}+00$ & $1.04 \mathrm{E}+00$ & $1.07 \mathrm{E}+00$ & $1.04 \mathrm{E}+00$ & $9.86 \mathrm{E}-01$ \\
\hline B & $1.00 \mathrm{E}+00^{a}$ & $1.01 \mathrm{E}+00$ & $0.00 \mathrm{E}+00$ & $1.54 \mathrm{E}+00$ & $4.20 \mathrm{E}-03$ \\
\hline $\mathrm{C}$ & $9.87 \mathrm{E}-01$ & $1.00 \mathrm{E}+00$ & $1.88 \mathrm{E}+00$ & $9.21 \mathrm{E}-01$ & 8.82E-01 \\
\hline $\mathrm{D}$ & $0.00 \mathrm{E}+00$ & $0.00 \mathrm{E}+00$ & $1.00 \mathrm{E}+00$ & $0.00 \mathrm{E}+00$ & $0.00 \mathrm{E}+00$ \\
\hline $\mathrm{E}$ & $3.46 \mathrm{E}+00$ & $1.37 \mathrm{E}+00$ & $1.09 \mathrm{E}+00$ & $1.00 \mathrm{E}+00$ & $1.98 \mathrm{E}+00$ \\
\hline $\mathrm{F}$ & 7.93E-01 & $1.26 \mathrm{E}+00$ & $9.60 \mathrm{E}-01$ & $1.04 \mathrm{E}+00$ & $1.00 \mathrm{E}+00$ \\
\hline
\end{tabular}

${ }^{a}$ Highlights indicate cells for adjoint sources (e.g., Cell 1 for Run B). Adjoint source for Run A is in Cell 0. Values in each column are ratios of dose rates to the dose rate for the run with the highlighted cell as adjoint source.

Table 20. $(n, \gamma)$ Photon dose rate ratios in tally cells for reactor neutron source

\begin{tabular}{|c|c|c|c|c|c|}
\hline Run & $\begin{array}{c}\text { Cell } 1 \\
\text { dose ratio }\end{array}$ & $\begin{array}{c}\text { Cell } 2 \\
\text { dose ratio }\end{array}$ & $\begin{array}{c}\text { Cell } 3 \\
\text { dose ratio }\end{array}$ & $\begin{array}{c}\text { Cell } 4 \\
\text { dose ratio }\end{array}$ & $\begin{array}{c}\text { Cell } 5 \\
\text { dose ratio }\end{array}$ \\
\hline A & 9.49E-01 & $1.01 \mathrm{E}+00$ & $1.01 \mathrm{E}+00$ & $8.53 \mathrm{E}-01$ & $8.70 \mathrm{E}-01$ \\
\hline B & $1.00 \mathrm{E}+00^{a}$ & $1.14 \mathrm{E}+00$ & 8.93E-01 & $8.19 \mathrm{E}-01$ & $3.77 \mathrm{E}-01$ \\
\hline $\mathrm{C}$ & $9.14 \mathrm{E}-01$ & $1.00 \mathrm{E}+00$ & 7.34E-01 & $2.81 \mathrm{E}-01$ & $9.38 \mathrm{E}-01$ \\
\hline $\mathrm{D}$ & $0.00 \mathrm{E}+00$ & $1.15 \mathrm{E}-04$ & $1.00 \mathrm{E}+00$ & $3.13 \mathrm{E}-03$ & $0.00 \mathrm{E}+00$ \\
\hline $\mathrm{E}$ & $1.34 \mathrm{E}+00$ & 8.84E-01 & $8.69 \mathrm{E}-01$ & $1.00 \mathrm{E}+00$ & $9.22 \mathrm{E}-01$ \\
\hline $\mathrm{F}$ & $1.14 \mathrm{E}+00$ & $1.52 \mathrm{E}+00$ & $9.48 \mathrm{E}-01$ & $8.31 \mathrm{E}-01$ & $1.00 \mathrm{E}+00$ \\
\hline
\end{tabular}

${ }^{a}$ Highlights indicate cells for adjoint sources (e.g., Cell 1 for Run B). Adjoint source for Run A is in Cell 0 . Values in each column are ratios of dose rates to the dose rate for the run with the highlighted cell as adjoint source. 
Results show that, in general, the above-described comparison is quite good; typical differences are a few percent. However, reasonable results may not be obtainable in a cell some distance away from the adjoint-source cell.

As discussed earlier, a concern with the use of an adjoint source on the geometry boundary is that lowenergy neutrons or photons would be undersampled at locations in the interior of the model, resulting in a reduced dose rate for primary and secondary particles (photons) in those regions. The results appear to show that this is not a significant concern. That is, the interior cell dose rates for the runs with the adjoint source in Cell 0 are not consistently less than those values for the runs with the adjoint located in specific interior cells. This is true particularly with the secondary photon generation data shown in Tables 17 and 20. Evidently, basing an adjoint source on the photon response on the perimeter of the model ensures adequate transport of low-energy neutrons throughout the model for this large-scale example.

As a further evaluation of the consistency of the results, the neutron dose rates for Cell 1 (Model Cell 995) are compared on an energy-bin-by-bin basis in Table 21 for the neutron source Runs A and B. For each energy bin that contributes appreciably to the dose rate, including the lowest (thermal) neutron energy bin, the results are seen to be equivalent. Thus, the results in a specific cell are equivalent whether the adjoint source is generalized (in the annular cell surrounding the geometry-Run A) or located within that cell (e.g., Cell 1, Run B). Not only are the total dose rates nearly the same in Cell 1, but the values in the lowest neutron energy bin are also nearly identical. Turning attention to the uncertainties, it is expected that the dose rate in Cell 1 should have a lower uncertainty in Run B since the adjoint source is located within that cell; however, the total uncertainty in Run B is approximately the same (actually slightly higher) than that in Run A. The number of histories is the same $\left(6 \times 10^{7}\right)$ for both runs. However, Run B is more efficient and required only about $50 \%$ of the computer time required by Run A. If the runs were based on equivalent times, it would be necessary to reduce the number of histories for Run A by $\sim 50 \%$ (or double the histories for Run B), in which case the uncertainties should be approximately equal.

Mesh tally dose rates were also acquired for each run. Figures 63-68 show consecutive results for (1) neutron-source/neutron-response, (2) photon-source/photon-response, and (3) neutron-source/ $(\mathrm{n}, \gamma)$ photon-response cases. For each source/response combination, the results are first shown for the case with the adjoint source located symmetrically around the outside of the containment (Figs. 63, 65, and 67) and also for the adjoint source located in Cell 1 (slightly to left of center in the figure-see Fig. 16). In all cases, the calculated dose rates are shown on the left and the relative uncertainties on the right. Results, though predictable, are interesting. For Case 1, neutron-source/neutron-response, the calculated dose rates are approximately equivalent for the two adjoint locations (Figs. 63 and 64), although the run with the adjoint in Cell 1 (Fig. 64) fails to produce results outside the containment. The right-side results show that the uncertainty is lower at locations near the adjoint source (Cell 1) and somewhat higher at locations remote to Cell 1, particularly if there are intervening walls (i.e., below and to right of center). The effect is more dramatic for Case 2, photon-source/photon-response (Figs. 65 and 66). In this case, the run with the adjoint in Cell 1 (Fig. 66) fails to transport any particles to large areas on the right side of the reactor. Results in this case are highly localized. The presumed reason for this effect is that because photons do not scatter as much as neutrons, there is little contribution to the photon response in Cell 1 attributable to scattering events on the right side of the reactor. Therefore, when the results are based on an adjoint source located in Cell 1, there is no significant importance assigned to particles in the right-hand region and thus no particles are transported there. This same localization effect is also seen in Case 3, neutronsource/(n, $\gamma$ )photon-response (Figs. 67 and 68). Here, however, the effect is mitigated by the fact that the initial source is neutrons, which tend to scatter, thus spreading out the resulting $(n, \gamma)$ photon source. Thus, particle transport has some importance everywhere, regardless of where the adjoint source is located. 
Table 21. Average Cell 1 energy-dependent neutron dose rates and uncertainties for Runs A and B

\begin{tabular}{cccccc}
\hline \multirow{2}{*}{$\begin{array}{c}\text { Energy } \\
(\mathbf{M e V})\end{array}$} & \multicolumn{2}{c}{ Run A results } & & \multicolumn{2}{c}{ Run B results } \\
\cline { 2 - 3 } \cline { 5 - 6 } & $\begin{array}{c}\text { Dose } \\
\text { (rem/h) }\end{array}$ & Unc. & & $\begin{array}{c}\text { Dose } \\
\text { (rem/h) }\end{array}$ & Unc. \\
\hline $4.14 \mathrm{E}-07$ & $1.18 \mathrm{E}-03$ & 0.1083 & & $1.10 \mathrm{E}-03$ & 0.0675 \\
$1.12 \mathrm{E}-06$ & $1.33 \mathrm{E}-04$ & 0.1114 & & $1.22 \mathrm{E}-04$ & 0.0712 \\
$3.06 \mathrm{E}-06$ & $1.23 \mathrm{E}-04$ & 0.1128 & & $1.16 \mathrm{E}-04$ & 0.0767 \\
$1.07 \mathrm{E}-05$ & $1.32 \mathrm{E}-04$ & 0.1182 & & $1.23 \mathrm{E}-04$ & 0.0812 \\
$2.90 \mathrm{E}-05$ & $9.65 \mathrm{E}-05$ & 0.1242 & & $9.16 \mathrm{E}-05$ & 0.0905 \\
$1.01 \mathrm{E}-04$ & $9.70 \mathrm{E}-05$ & 0.1131 & & $9.21 \mathrm{E}-05$ & 0.0908 \\
$5.83 \mathrm{E}-04$ & $1.15 \mathrm{E}-04$ & 0.1007 & & $1.12 \mathrm{E}-04$ & 0.1001 \\
$3.35 \mathrm{E}-03$ & $9.00 \mathrm{E}-05$ & 0.0898 & & $8.72 \mathrm{E}-05$ & 0.0977 \\
$1.11 \mathrm{E}-01$ & $3.10 \mathrm{E}-03$ & 0.0939 & & $3.13 \mathrm{E}-03$ & 0.1290 \\
$5.50 \mathrm{E}-01$ & $1.35 \mathrm{E}-03$ & 0.1460 & & $1.54 \mathrm{E}-03$ & 0.1928 \\
$1.11 \mathrm{E}+00$ & $9.58 \mathrm{E}-05$ & 0.3697 & & $8.31 \mathrm{E}-05$ & 0.3089 \\
$1.83 \mathrm{E}+00$ & $1.61 \mathrm{E}-05$ & 0.4695 & & $2.12 \mathrm{E}-05$ & 0.4329 \\
$2.35 \mathrm{E}+00$ & $6.52 \mathrm{E}-06$ & 0.5410 & & $1.33 \mathrm{E}-05$ & 0.6020 \\
$2.46 \mathrm{E}+00$ & $2.03 \mathrm{E}-06$ & 0.6651 & & $1.14 \mathrm{E}-06$ & 0.5351 \\
$3.01 \mathrm{E}+00$ & $9.35 \mathrm{E}-06$ & 0.5941 & & $4.58 \mathrm{E}-06$ & 0.5852 \\
$4.06 \mathrm{E}+00$ & $2.05 \mathrm{E}-06$ & 0.6642 & & $2.28 \mathrm{E}-06$ & 0.7699 \\
$4.96 \mathrm{E}+00$ & $9.14 \mathrm{E}-08$ & 0.6353 & & $5.12 \mathrm{E}-07$ & 0.6701 \\
$6.36 \mathrm{E}+00$ & $6.49 \mathrm{E}-08$ & 0.7307 & & $7.51 \mathrm{E}-07$ & 0.6135 \\
$8.18 \mathrm{E}+00$ & $3.79 \mathrm{E}-08$ & 0.7925 & & $1.00 \mathrm{E}-07$ & 0.6723 \\
$1.00 \mathrm{E}+01$ & $0.00 \mathrm{E}+00$ & 0.0000 & & $3.57 \mathrm{E}-10$ & 0.7815 \\
$1.22 \mathrm{E}+01$ & $0.00 \mathrm{E}+00$ & 0.0000 & & $0.00 \mathrm{E}+00$ & 0.0000 \\
$1.50 \mathrm{E}+01$ & $0.00 \mathrm{E}+00$ & 0.0000 & & $0.00 \mathrm{E}+00$ & 0.0000 \\
\hline Total & $\mathbf{6 . 5 6 E - 0 3}$ & $\mathbf{0 . 0 8 3 3}$ & & $\mathbf{6 . 6 4 E - 0 3}$ & $\mathbf{0 . 1 1 0 3}$ \\
\hline
\end{tabular}
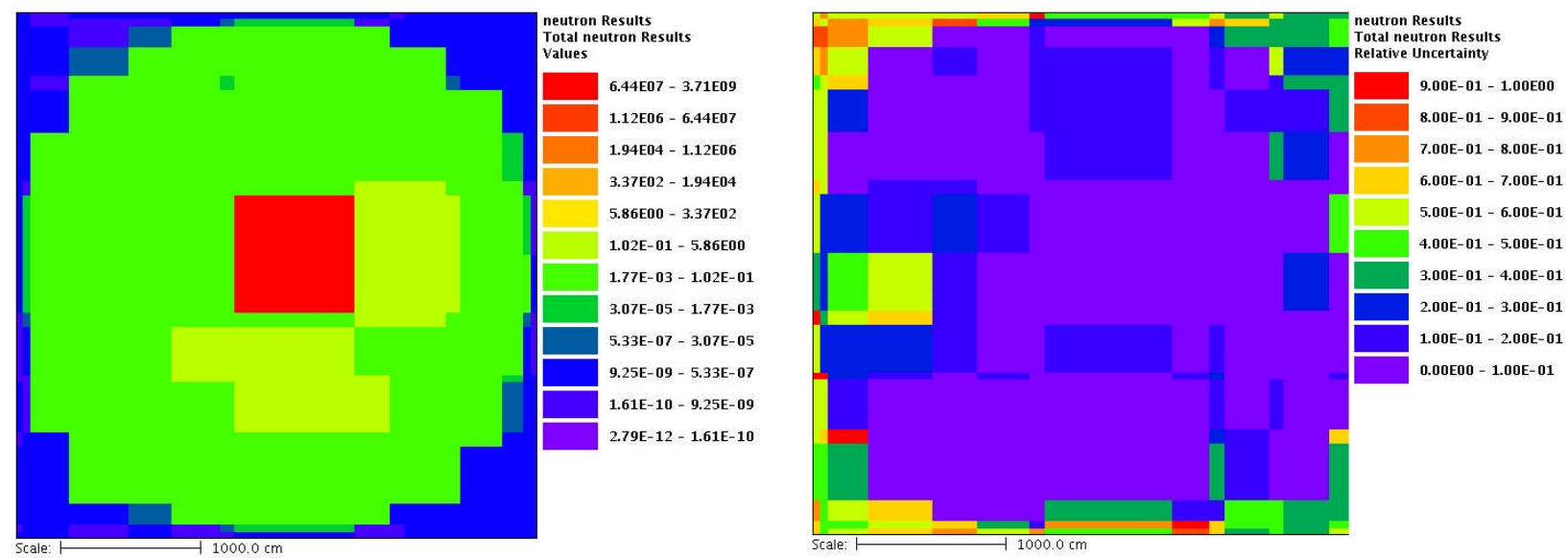

Fig. 63. MCNP mesh tally dose rates (in rems per hour) (left) and relative uncertainties (right) from neutron calculation with adjoint source located around periphery of containment for $6 \times 10^{7}$ source particle histories. Results are shown in X-Y plane (plan view) at elevation $18,500 \mathrm{~cm}$. 

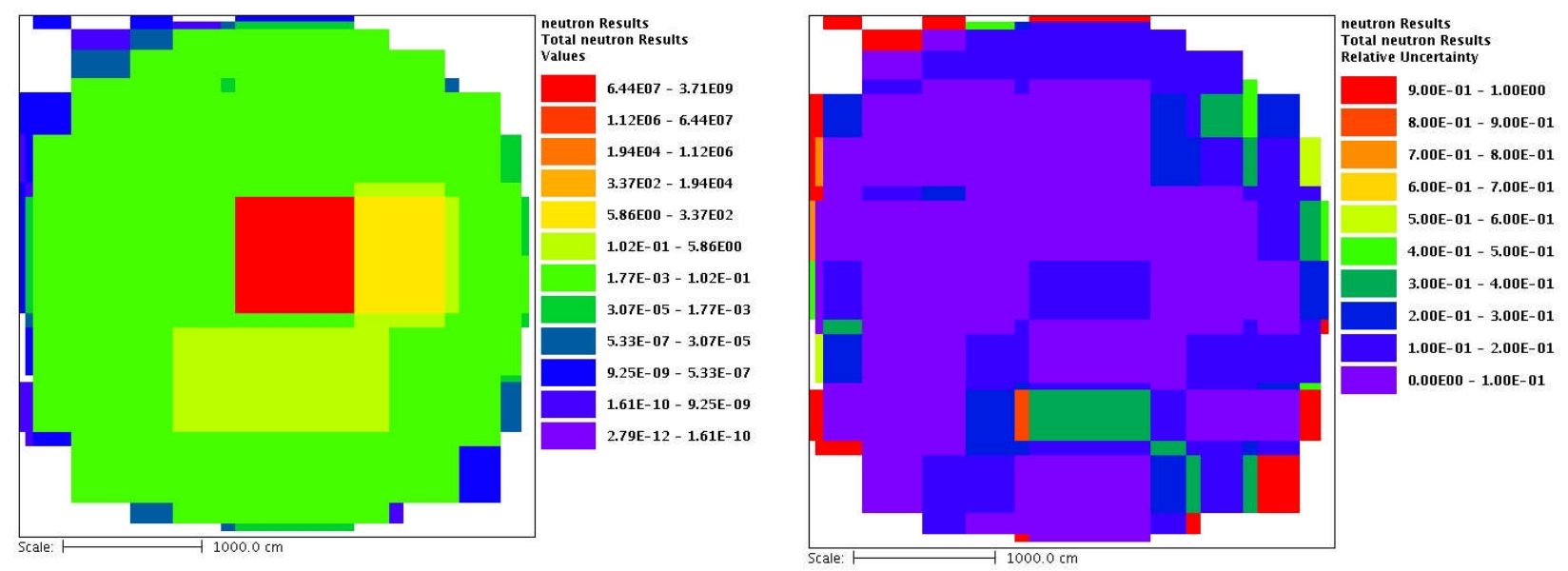

Fig. 64. MCNP mesh tally dose rates (in rems per hour) (left) and relative uncertainties (right) from neutron calculation with adjoint source located in Cell 1 (slightly to left of center in above images) for $8 \times 10^{7}$ source particle histories. Results are shown in X-Y plane (plan view) at elevation $18,500 \mathrm{~cm}$.
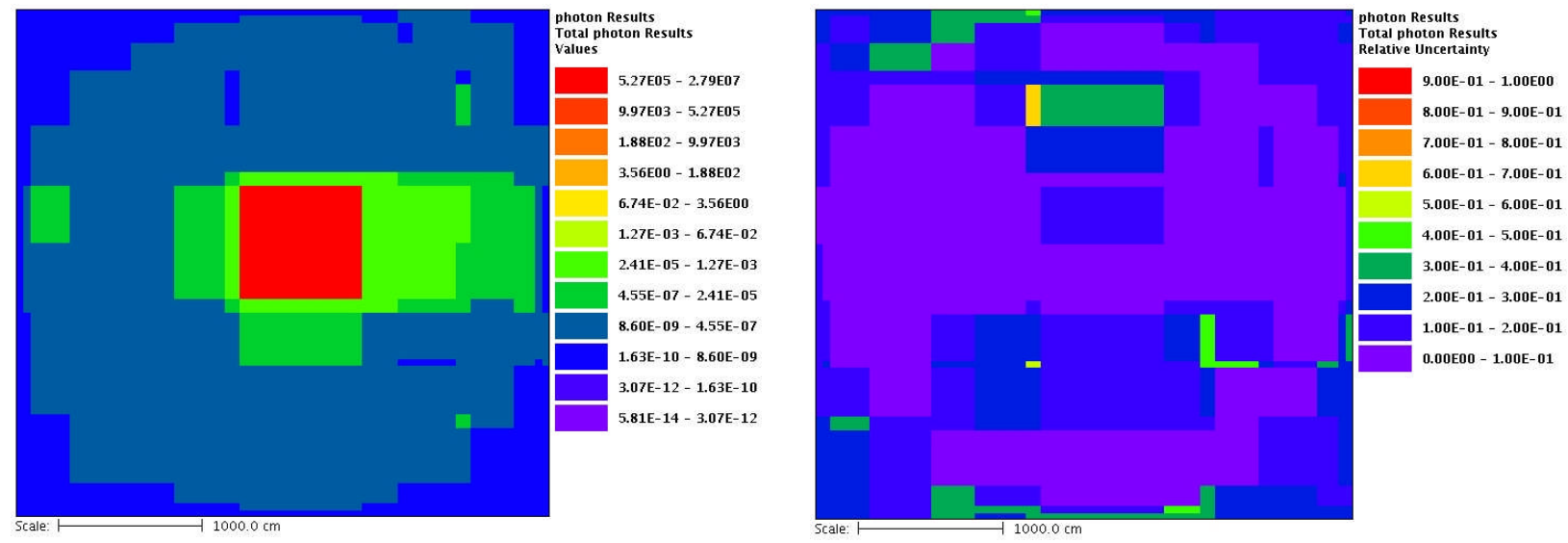

Fig. 65. MCNP mesh tally dose rates (in millirems per hour) (left) and relative uncertainties (right) from photon calculation with adjoint source located around periphery of containment for $1 \times 10^{8}$ source particle histories. Results are shown in X-Y plane (plan view) at elevation 18,500 cm. 

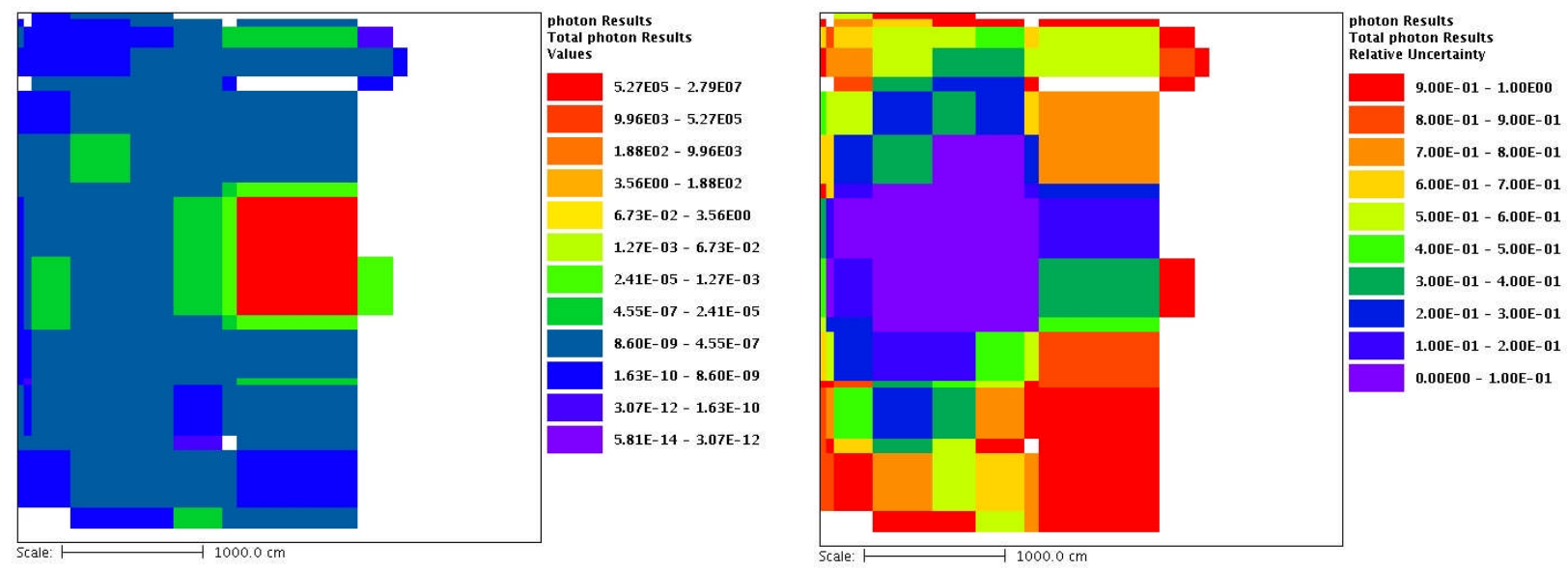

Fig. 66. MCNP mesh tally dose rates (in millirems per hour) (left) and relative uncertainties (right) from photon calculation with adjoint source located in Cell 1 (slightly to left of center in above images) for $1 \times 10^{8}$ source particle histories. Results are shown in X-Y plane (plan view) at elevation $18,500 \mathrm{~cm}$.
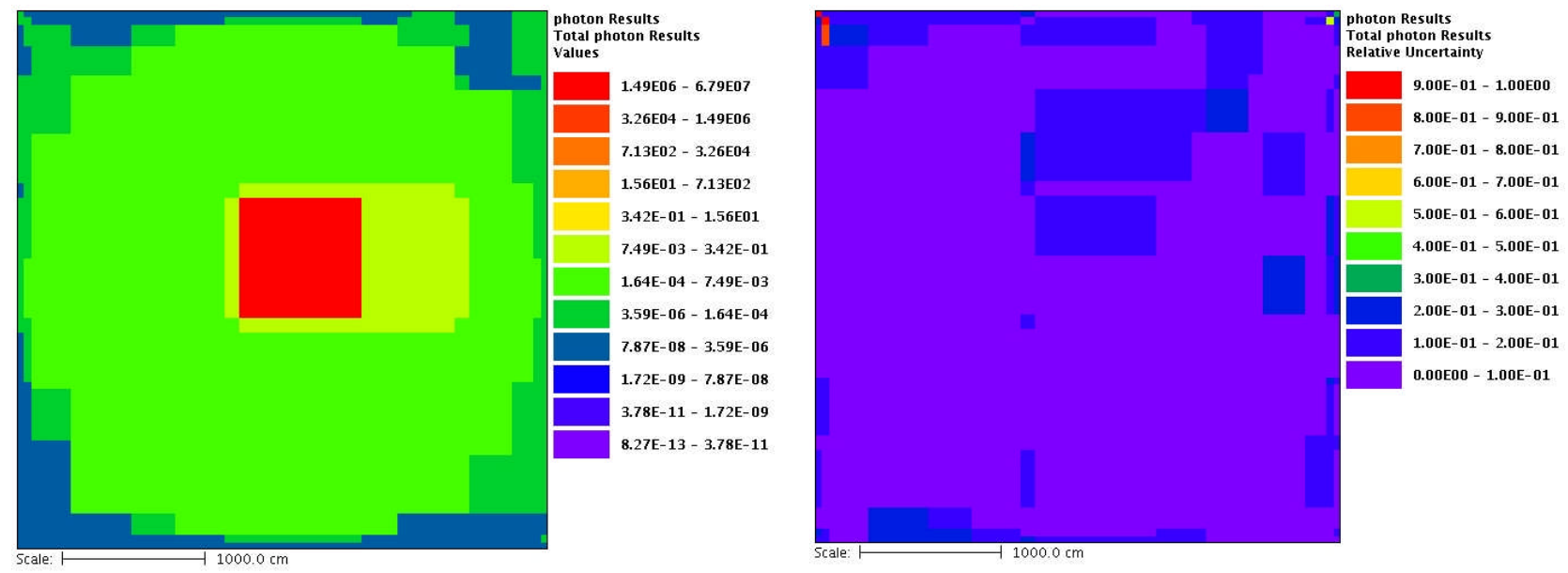

Fig. 67. MCNP mesh tally dose rates (in millirems per hour) (left) and relative uncertainties (right) from calculation of $(n, p)$ photons with adjoint source located around periphery of containment for $1 \times 10^{8}$ source particle histories. Results are shown in X-Y plane (plan view) at elevation $18,500 \mathrm{~cm}$. 

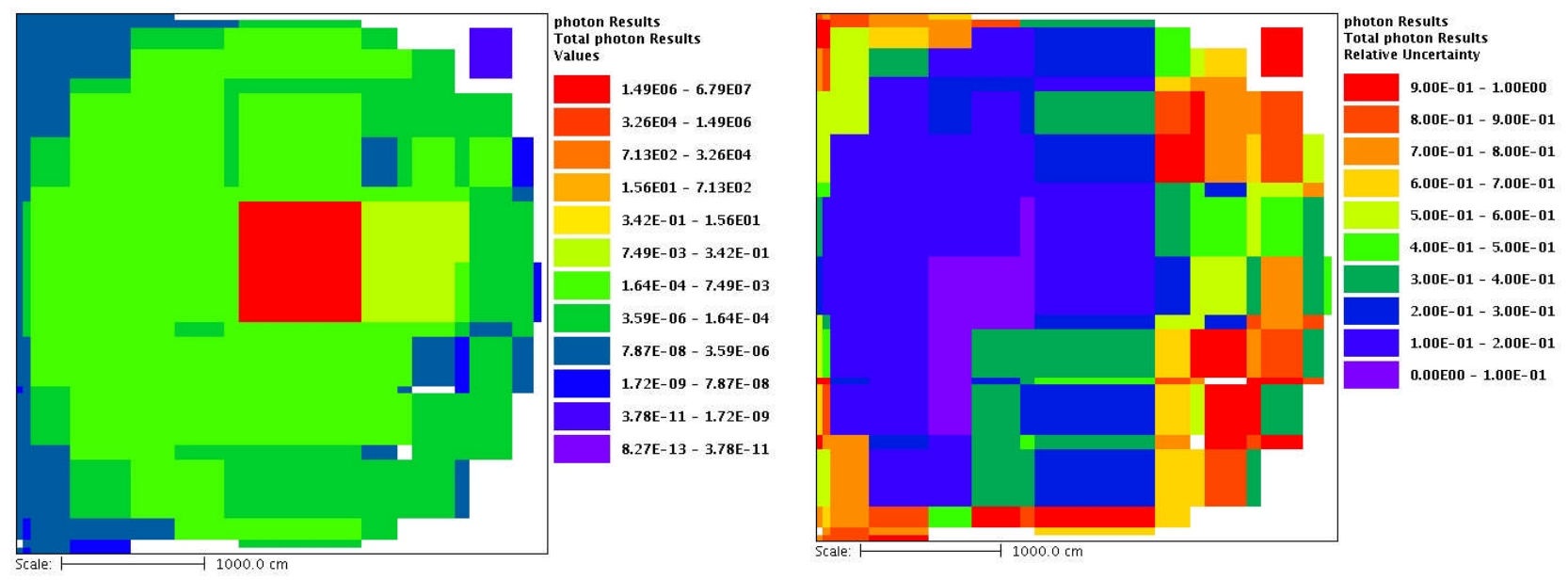

Fig. 68. MCNP mesh tally dose rates (in millirems per hour) (left) and relative uncertainties (right) from calculation of $(n, p)$ photons with adjoint source located in Cell 1 (slightly to left of center in above images) for $5 \times \mathbf{1 0}^{7}$ source particle histories. Results are shown in X-Y plane (plan view) at elevation $18,500 \mathrm{~cm}$.

These results appear to be consistent with earlier discussions and provide a graphical depiction.

\subsubsection{Discussion}

We are confident that calculations employing different adjoint source locations will ultimately give equivalent results at the same locations for all energy ranges. This conjecture must be tempered with a certain judgment. If an adjoint source is isolated from a particular region of interest (e.g., for this example) with the adjoint source on one side of the reactor and the region of interest on the other, one cannot expect to obtain reasonable results at that region of interest. This is particularly the case if both the source and response are photons. In the same sense, if results are required only at a specific location, it is more efficient to locate the adjoint source at or near that location instead of at a general global location (e.g., outside of and surrounding the entire geometry). Nevertheless, for the problem considered, reasonable results were obtained everywhere (within five large cells) for a global source.

It also must be noted that the tally cells used in this model are quite large. It is an obvious but unfortunate reality that in large models of this type, it is extremely difficult to obtain suitable results within a small region. One must average over a relatively large region to obtain results with low uncertainties.

The above results were anticipated. However, the quantification of these results to a large model that though a simplification approximating the actual full-scale PWR model, is of considerable interest. It is of particular interest that satisfactory results can be obtained globally with a generalized boundary adjoint source. It should be kept in mind, however, that the model is limited to the containment only, whereas the full unsimplified PWR facility model includes the adjacent auxiliary, turbine, and transformer buildings. Although not discussed here, some initial tests for the full model indicate that the boundary adjoint source as implemented with "guessed" weightings at the periphery of the plant, may be inadequate to achieve detailed global results for all source particle combinations within areas of these adjacent buildings. 


\section{FORWARD-WEIGHTED CADIS}

The CADIS methodology is best suited for optimizing the Monte Carlo calculation towards one specific response in one specific region of the model. In this work, the area to optimize was defined as the layer of void at the boundary of the entire plant. The thought was that if the dose rates at the boundary were optimized, all of the dose rates in between the radiation source and the boundary would be calculated also. The previous section confirmed that this approach is reasonable but may have required more adjoint source at the plant boundary past the turbine building to better complete the dose rate map. Finding the right amounts to use to weight the boundary adjoint source on each side of the plant would be a long and iterative process.

Thus, while the exterior boundary adjoint-source method used in this report is good, it is probably not the best. In order to optimize the Monte Carlo calculation to obtain similar relative uncertainties for tallies in different regions (or to optimize the Monte Carlo calculation to compute a mesh tally with similar relative uncertainties in each mesh cell), the basic question is this: what kind of adjoint source should be used to generate the weight windows and biased source?

In this section, we propose that in order to calculate reasonable relative uncertainties in each mesh cell of a mesh tally extending over a large volume of the problem, the amount of adjoint source used in each mesh cell of the adjoint calculation should be inversely proportional to the expected forward dose rate in that mesh cell. Similar to the boundary adjoint method, this will help draw Monte Carlo particles to areas of low dose. Unlike the boundary adjoint method, since every mesh cell has some amount of adjoint source, every mesh cell is important to the final Monte Carlo calculation and should be well sampled in every energy group.

This method, called here the FW-CADIS (Forward-Weighted CADIS) method, requires two discrete ordinates calculations, each of which needs only to be approximate. The first is the forward calculation of expected dose rates. This is used to distribute adjoint source for the adjoint calculation-more adjoint source where the forward flux is low and less adjoint source where the forward flux is high. The resulting adjoint flux is then used in a typical CADIS calculation to form the biased source distribution and the target weight values for space/energy weight windows.

\subsection{IMPLEMENTATION USING CURRENT CADIS/ADVANTG-BASED METHOD}

A flowchart of the standard three-step procedure for using the ADVANTG/CADIS to produce weight windows and source bias parameters for MCNP was shown in Fig. 34 in Section 4.3. A similar flowchart of an enhanced procedure to implement MCNP weight-windows-based variance reduction using an adjoint source weighted by the reciprocal of the forward response is shown in Fig. 69. The basic idea of this approach is to use an adjoint source everywhere in the model and to weight the source by the reciprocal of the estimated dose (or flux or other quantity of interest). The desired effect is to enhance the importance of regions with low response and deemphasize those regions with high response. In so doing, responses everywhere should tend to have equivalent uncertainties. Current unautomated implementation of this procedure expands the usual three-step (including running MCNP) process to a seven-step process. Also, manual editing steps must be performed as is indicated by the additional column in the flowchart. The procedure is initiated by a standard ADVANTG Step 1 run. However, this step is terminated prior to running the TORT model. Thus, in this step GIP and TORT input files and GIP adjoint cross sections are produced. Both input files are then modified for forward calculation using the problem's forward source (e.g., reactor neutrons). (The forward source is produced by using a utility code to map the MCNP "sdef" description into the TORT mesh cells.) Next, a GIP/TORT sequence is run in Steps 2 and 3, and a TORT forward flux ("varscl" format) file is produced. In Step 4, a utility code, FORADJ, is used to calculate the 
dose at every TORT mesh cell in the model, invert the values to reciprocals, and write the data to TORT source arrays. These arrays are then substituted into the modified TORT input, and a TORT adjointsource case is run in Step 5 to produce an adjoint flux file. Steps 6 and 7 correspond to the normal ADVANTG Steps 2 and 3. In Step 7, MCNP is run using standard methodology.

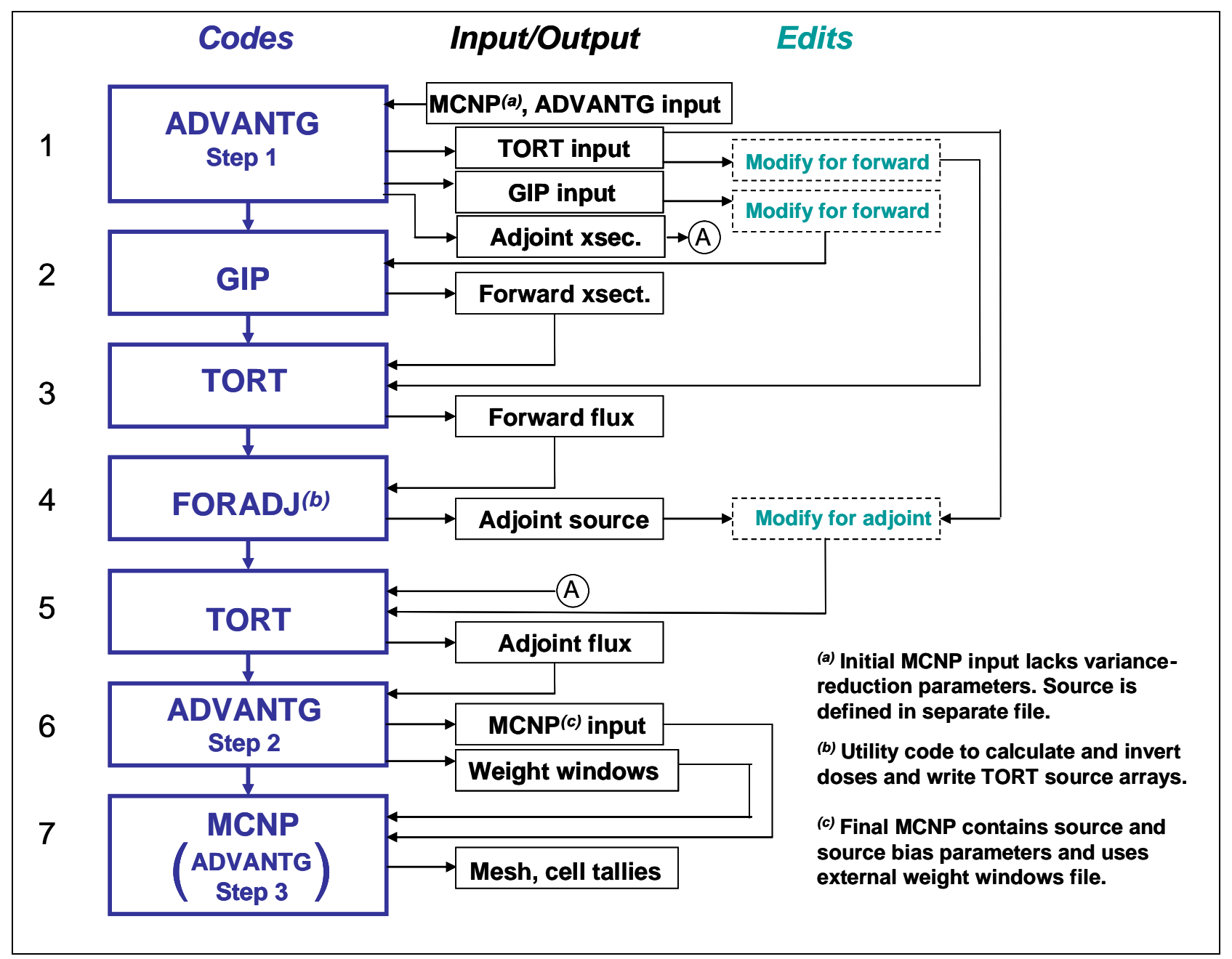

Fig. 69. Flowchart for using ADVANTG to implement variance reduction in MCNP through the production of an adjoint source weighted by the reciprocal of the forward response.

The above forward-based enhanced procedure at present requires considerably more effort than the standard ADVANTG methodology. The procedure could, however, be integrated into ADVANTG (Steps 1-5 would become the new ADVANTG Step 1), with options as to which approach to take. The following discussion presents results that indicate that the procedure would be a desirable addition to ADVANTG.

The utility code FORADJ, shown in Step 4 of Fig. 69, was used to "read in" the forward fluxes from the TORT "varscl" file produced in Step 3, calculate the dose for each voxel, and then create an adjoint TORT source that is inversely proportional to the dose for that voxel and normalized (proportional) to the volume of the voxel. The source is written in a format such that it can be included in a TORT input. FORADJ is written in FORTRAN 90. 


\subsection{RESULTS USING FORWARD-BASED PROCEDURE ON PWR MODEL}

The enhanced ADVANTG procedure was implemented for the full facility PWR model, and results are compared with those obtained earlier using the standard ADVANTG/CADIS methodology based on a boundary adjoint source surrounding the exterior of the model. Representative dose rate values that were calculated from the TORT forward fluxes produced in Step 5 (see Fig. 69) are shown in Figures 70 and 71. These values, as expected, are highest in the reactor core region and drop off $\sim 20$ orders of magnitude at the model boundaries. Values calculated at the boundaries are clearly far lower than actual expected background values. Overall, the plot shows that the values produced by TORT are consistent and behave as expected. For models with point or nearly point sources and large void spaces in which ray effects are prominent, it is likely that the GRTUNCL3D code, from the DOORS system, could be run prior to the TORT. GRTUNCL3D calculates the uncollided flux that is used to calculate a distributed scattering source for TORT. Ray effects are mitigated because the spatially confined source has been converted into an effective distributed source.

As a matter of practicality, because of the extremely large size of the PWR facility, an extremely coarse mesh spacing was necessary in our TORT representation, with mesh intervals varying from $20 \mathrm{~cm}$ to several hundreds of centimeters, rather than the few-centimeter intervals normally required in dense materials such as concrete. Also, a low-order quadrature $\left(\mathrm{S}_{4}\right)$ was used to reduce memory usage, file size, and run times. Consequently, inaccuracies in model representation and particle transport occurred such that it is highly unlikely that the results produced are accurate to within more than an order of magnitude. However, the results are considered suitable to provide a response to be used for weighting an adjoint source at all locations within a model. On the other hand, it is interesting to estimate the size of a discrete ordinates model that would be required to accurately represent the current MCNP model. The volume of the model is estimated to be $\sim 5 \times 10^{11} \mathrm{~cm}^{3}$. If an average orthogonal mesh cell of $\sim 5 \times 5 \times 5 \mathrm{~cm}^{3}$ were used (still coarse by some standards), the resulting model would require $\sim 10^{10}$ mesh cells, a horrendous number by today's available state-of-the-art methods. We do acknowledge, however, that it may be feasible to develop a reasonable deterministic model using an available variable-mesh code in which large void areas are represented by very coarse meshes or to use unstructured meshes. Thus, we are not entirely discounting the use of discrete ordinates or deterministic methods to accurately represent the geometry and produce reasonable results and would look forward to seeing this happen.

Comparison of MCNP results based on a boundary adjoint source with those based on the forwardweighted adjoint source at all locations (global) in the model is shown in Figs. 72-75. The left-hand side of Fig. 72 and the top of Fig. 74 show plan and elevation views of neutron dose rate results based on the boundary source. The left and top sections, respectively, of Figs. 73 and 75 also show the corresponding uncertainties. These results show the failure of the model to transport particles through the auxiliary and turbine buildings in a dramatic way. Adequate results are obtained beyond those buildings only by transport of particles that exit near the top of the containment building and pass through a minimum number of walls. Since the adjoint is located at the boundary, there is no "incentive" for the model to transport particles through the interior of the buildings if they do not contribute significantly to the response at the boundary. Evidently they do not. The right-hand side of Fig. 72 and the bottom of Fig. 74 show results using the forward-weighted adjoint methodology. Similarly, the right and bottom sections of Figs. 73 and 75 show the corresponding uncertainties. In this case, there is considerably more particle transport achieved in the building interior, since there is emphasis on acquiring a response everywhere, not just at the boundary. The forward-weighted adjoint case is far from converged at these locations; however, it is far better than the boundary-based adjoint case. It is emphasized that the overall problem, due to its sheer size and the large overall shielding thickness, represents an enormous challenge. The MCNP results show a range of $\sim 30$ orders of magnitude. Consequently, calculated dose rates are well below any actual background value. The boundary-based-source run utilized $10^{9}$ particle histories and 
required $\sim 30,000 \min$ ( 21 days) calculation time. The inverse-dose-weighted run used $7.5 \times 10^{8}$ histories but required approximately the same run time. Both runs were actually performed in parallel as a set of smaller runs, using different random number starting points, with results then added.

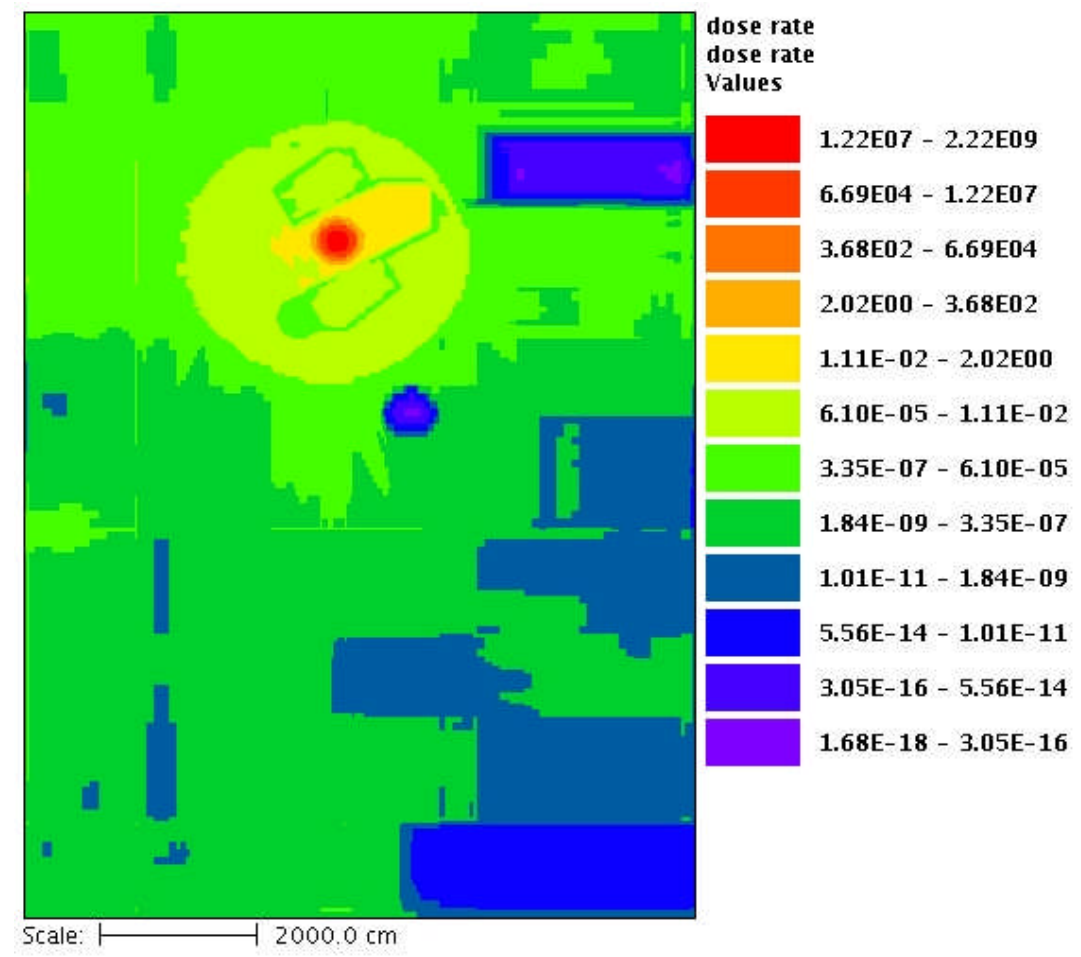

Fig. 70. Plan (X-Y) view of TORT-calculated dose rate (in rems per hour) from reactor source for PWR model at $z \sim 18,500 \mathrm{~cm}$. 


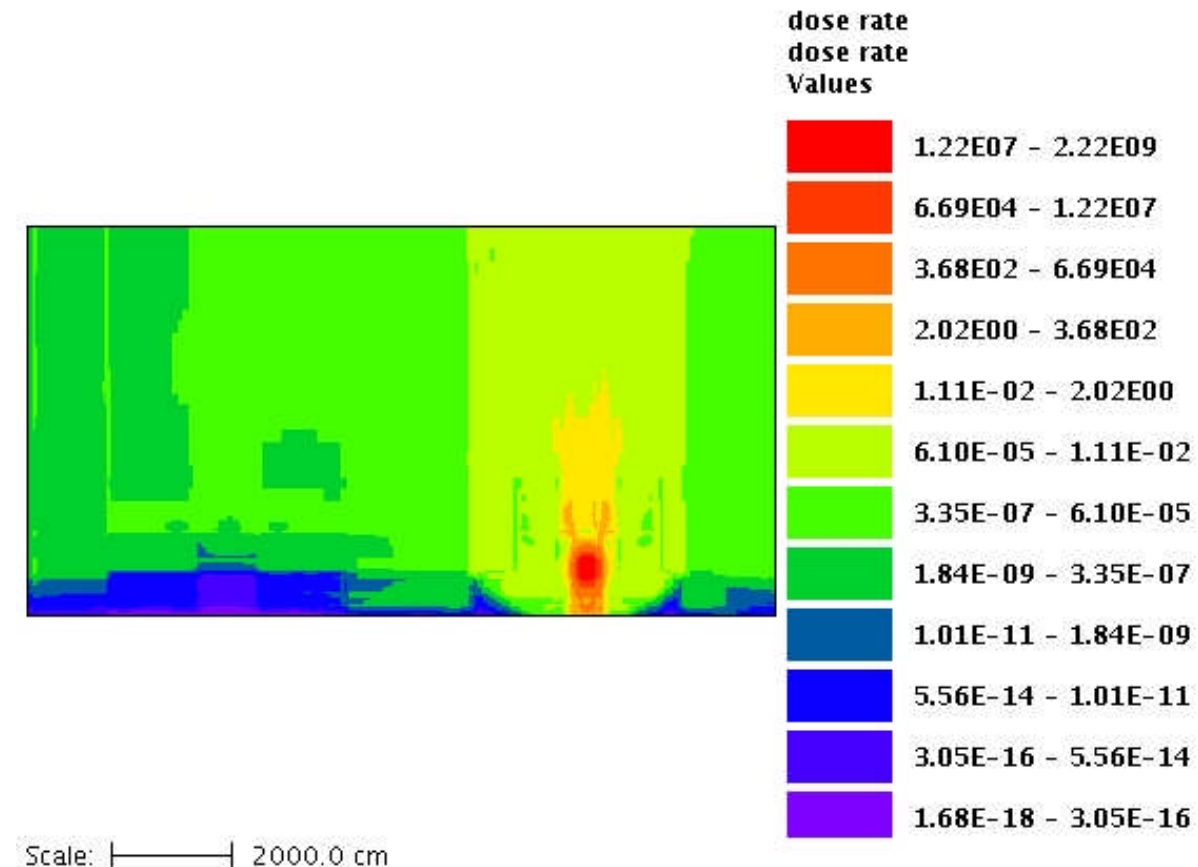

Fig. 71. Elevation (Y-Z) view of TORT-calculated dose rate (in rems per hour) from reactor source for PWR model at plane through center of reactor $(x=122 \mathrm{~cm})$.
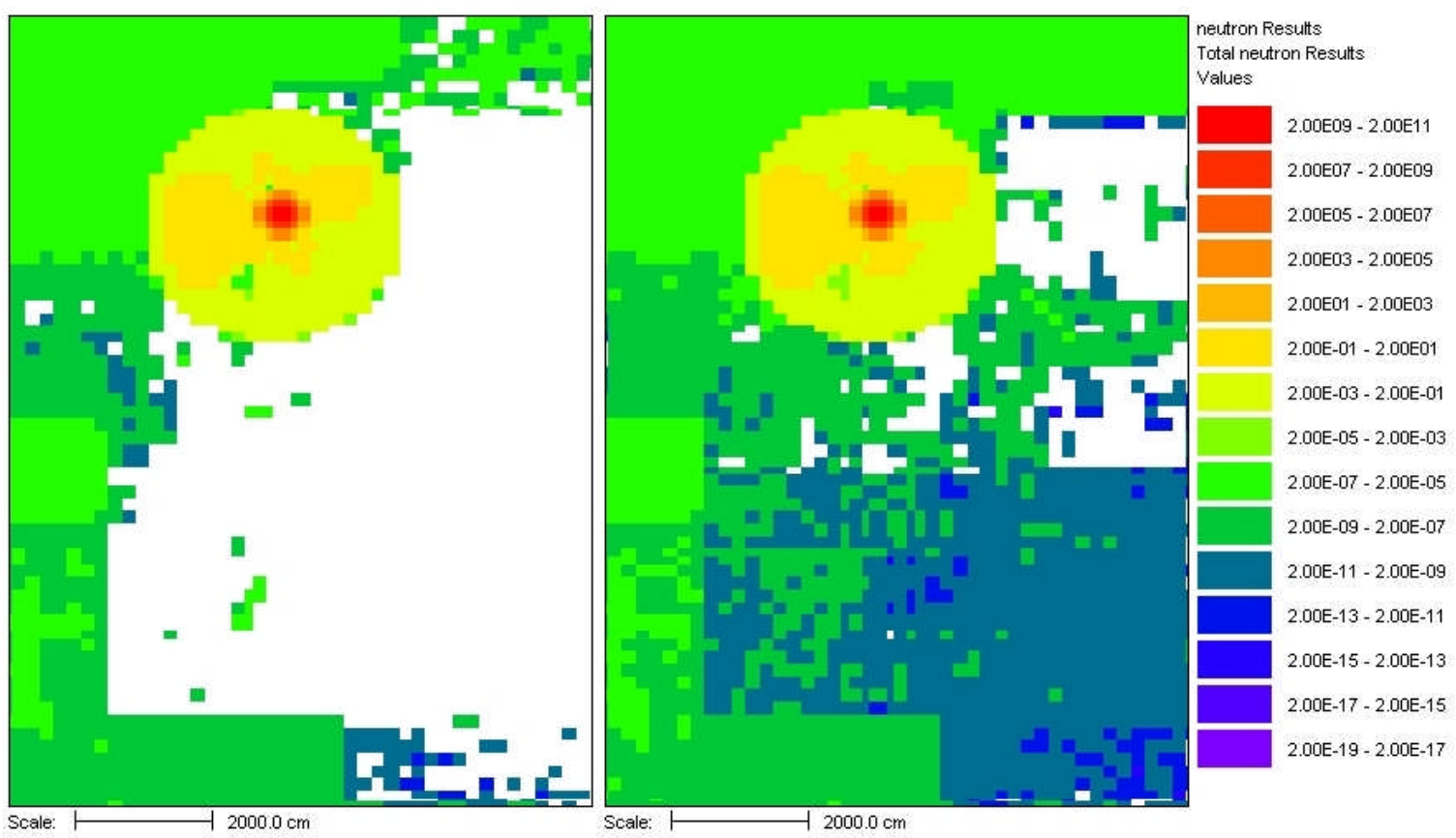

Fig. 72. Plan (X-Y) views of MCNP neutron dose rate (in rems per hour) from the reactor source for the PWR model at $z \sim 18,500 \mathrm{~cm}$ using weight windows obtained from a boundary-based adjoint source (left) and from a forward-weighted global adjoint source (right). White spaces show regions in which neutrons were not transported. 

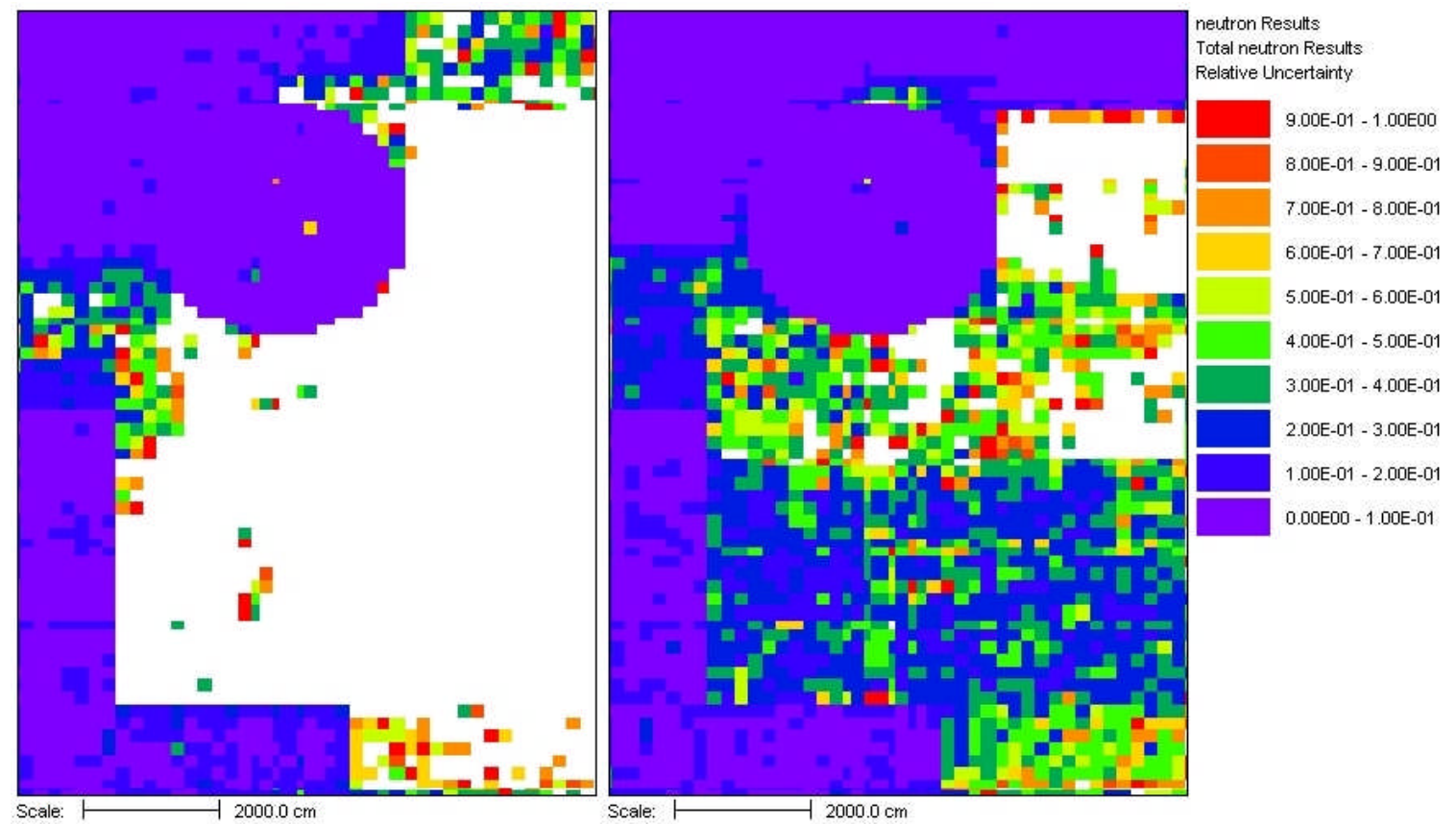

Fig. 73. Plan (X-Y) views of MCNP neutron dose uncertainties from the reactor source for the PWR model at $z \sim 18500 \mathrm{~cm}$ using weight windows obtained from a boundary-based adjoint source (left) and from a forward-weighted global adjoint source (right). White spaces show regions in which neutrons were not transported. 


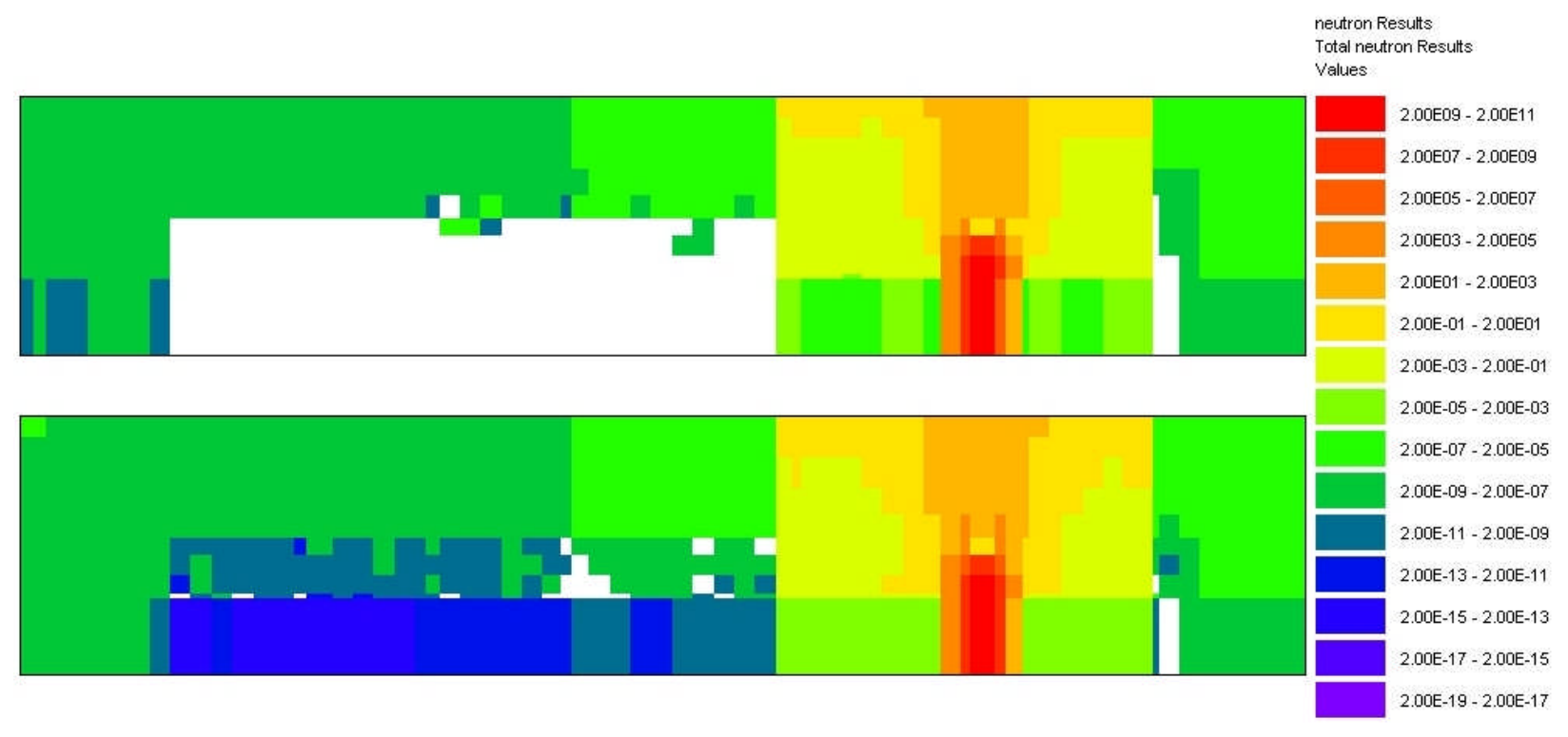

Scale: $\longmapsto 2000.0 \mathrm{~cm}$

Fig. 74. Elevation (Y-Z) views of MCNP-calculated neutron dose rate (in rems per hour) from the reactor source for the PWR model on a plane through the reactor center $(x \sim 122 \mathrm{~cm})$ using weight windows obtained from a boundary-based adjoint source (top) and from a forward-weighted global adjoint source (bottom). White spaces show regions in which neutrons were not transported.
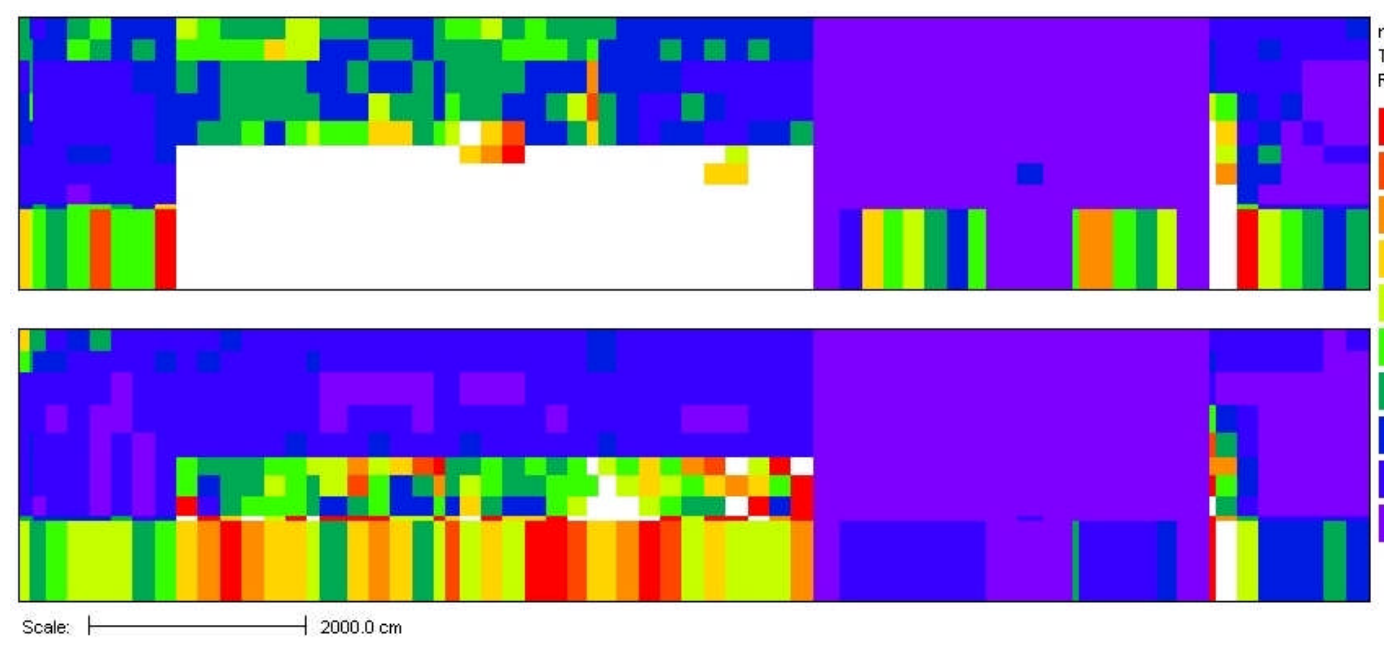

Fig. 75. Elevation (Y-Z) views of MCNP-calculated neutron dose uncertainties from the reactor source for the PWR model on a plane through the reactor center $(x \sim 122 \mathrm{~cm})$ using weight windows obtained from a boundary-based adjoint source (top) and from a forward-weighted global adjoint source (bottom). White spaces show regions in which neutrons were not transported. 



\section{SUMMARY}

The feasibility of modeling a PWR facility and calculating dose rates at all locations within the containment and adjoining structures using MCNP5 with mesh tallies has been presented. A variety of sources were examined, including neutron and photon sources from the reactor (operating and shut down for various periods) and the spent fuel pool, as well as the photon source from the primary coolant loop. It was evident at the outset that advanced variance-reduction methods would be required due to the size and shielding mass of any PWR facility. The method of choice was to use weight windows and source bias as calculated with the CADIS/ADVANTG approach. ADVANTG uses a three-step procedure to calculate adjoint fluxes with a discrete ordinates TORT model in Step 1 and to generate weight windows and source bias parameters in Step 2. The TORT model is automatically generated from an MCNP geometry model. The weight windows parameters are written to a separate file, and the source bias parameters are written to the MCNP file. Altogether, a final MCNP input file is produced and is then run as Step 3. For this analysis, the adjoint source was located on the geometry boundary. The motivation for this approach was that an adjoint source at the periphery of the model would force the transport of particles through all regions of the model and produce adequate results everywhere. A concern with this approach, however, was that lower-energy particles would not be transported adequately and calculated dose rates would be too low. Validation calculations were subsequently performed using (1) a simple block model and (2) a simplified but full-scale model of the PWR facility containment to assess this issue. In these calculations the adjoint source was placed in various regions of the models as well as at the periphery. It was found that for calculations in which the dose rates could be calculated with a small uncertainty, the results were approximately the same regardless of the adjoint-source location. Thus, the above issue proved to be of marginal concern and the approach using the adjoint source at the periphery was deemed valid.

Using the above approach, we were unable to calculate dose rates at all locations for the "intact" geometry because of the sheer size of the model and the immense amount of shielding within a typical PWR containment. The model was not able to produce results beyond the containment building within the auxiliary and turbine buildings where, for some of these locations, the overall attenuation was up to $\sim 30$ orders of magnitude. Thus, our original stated goal of calculating the dose rate everywhere within the facility proved to be not only overly ambitious but also unnecessary, because the fact that the typical dose rates outside the containment are negligible. As a simple demonstration showed, this statement would not be true if the facility geometry is altered, but in this case the model developed was able to provide dose rates wherever required. In summary, we have achieved our goal of calculating the dose rates everywhere within the facility for dose rates of consequence to personnel safety (comparable to or larger than background).

Calculations were performed and presented for all the sources considered including the reactor core, spent fuel pool, and primary coolant loop. Dose rates produced by secondary photons produced by neutron capture were not calculated for the full PWR model but were produced for the simplified containment model.

Although we feel our model was adequate for practical problems, the inability to calculate responses at all locations (evident by the "white spaces" in the mesh tally plots) inspired us to seek improved variancereduction methodologies. A modification to the CADIS/ADVANTG methodology was studied in which the source for the discrete ordinates adjoint flux calculation was located everywhere throughout the model but was weighted by the reciprocal of the dose response calculated by an earlier forward discrete ordinates calculation. This method was evaluated for the full PWR model, and results were much improved over those using the standard CADIS/ADVANTG approach with the adjoint located at the periphery. Reasonable, though not fully converged, results were obtained over most of the entire model 
geometry. This revised variance-reduction methodology requires two discrete ordinates calculations and has not yet been automated into the CADIS/ADVANTG software. It is suggested that this be done as part of future work and the approach, which appears to offer great promise, be more fully evaluated. 


\section{REFERENCES}

ANS 6.1.1Working Group. 1997. Neutron and Gamma-Ray Flux-to-Dose Rate Factors, ANSI/ANS6.1.1-1977, American Nuclear Society, LaGrange Park, Ill.

ANSI/ANS-18.1-1999. 1999. American National Standard "Radioactive Source Term for Normal Operation of Light Water Reactors," prepared by the American Nuclear Society, Standards Committee, Working Group ANS-18.1, and published by the American Nuclear Society.

"CASK-81.” 1983. "CASK-81: 22 Neutron, 18 Gamma-Ray Group, P3 Cross Sections for Shipping Cask Analysis," DLA-23, Radiation Safety Information Computational Center, Oak Ridge National Laboratory, Oak Ridge, Tenn.

Chilton, A. B., J. K. Shultis, and R. E. Faw. 1984. Principles of Radiation Shielding, Prentice-Hall, Englewood Cliffs, N.J.

Cranberg L., G. Frye, N. Nereson, and L. Rosen. 1956. "Fission Neutron Spectrum of ${ }^{235}$ U," Phys. Rev. 103, 662-670.

DOE. 2002. DOE Energy Information Administration, Form RW-859, Nuclear Fuel Data File.

DOORS 3.1. 1996. RSICC Computer Code Collection, CCC-650, Radiation Safety Information Computational Center, Oak Ridge National Laboratory, Oak Ridge, Tenn.

Haghighat, A., and J. C. Wagner. 2003. "Monte Carlo Variance Reduction with Deterministic Importance Functions," Prog. Nucl. Energy 42(1), 25-53.

Hermann, O. W., C. V. Parks, and J. P. Renier. 1994. Technical Support for a Proposed Decay Heat Guide Using SAS2H/ORIGEN-S Data, NUREG/CR-5625 (ORNL-6698), Oak Ridge National Laboratory, Oak Ridge, Tenn., September.

Madland, D. G., and J. R. Nix. 1982. "New Calculation of Prompt Fission Neutron Spectra and Average Prompt Neutron Multiplicities," Nucl. Sci. Eng. 81, 213-271.

Peplow, D. E., and J. C. Wagner. 2006. "Automated Variance Reduction for SCALE Shielding Calculations," pp. 391-393 in Proceedings of the American Nuclear Society's 14th Biennial Topical Meeting of the Radiation Protection and Shielding Division, Carlsbad, N.M., April 2-6.

Peplow, D. E., C. D. Sulfredge, R. L. Sanders, R. H. Morris, and T. A. Hann. 2004. "Calculating Nuclear Power Plant Vulnerability Using Integrated Geometry and Event/Fault Tree Models," Nucl. Sci.

Eng. 146(1), 71-87.

Peplow, D. E., S. M. Bowman, J. E. Horwedel, and J. C. Wagner. 2006. "Monaco/MAVRIC:

Computational Resources for Radiation Protection and Shielding in SCALE," Trans. Am. Nucl. Soc. 95, 669-671.

Rhoades, W. A., and R. L. Childs. 1987. The TORT Three-Dimensional Discrete Ordinates Neutron/ Photon Transport Code, ORNL-6268, Oak Ridge National Laboratory, Oak Ridge, Tenn.

Rinard, P. M., G. E. Bosler, and J. R. Phillips. 1981. Calculated Neutron Source Spectra from Selected Irradiated PWR Fuel Assemblies, LA-9125-MS, Los Alamos National Laboratory, Los Alamos, N.M. 
SCALE. 2006. SCALE: A Modular Code System for Performing Standardized Computer Analyses for Licensing Evaluation, ORNL/TM-2005/39, Version 5.1, Vols. I-III, November 2006. Available from Radiation Safety Information Computational Center at Oak Ridge National Laboratory as CCC-732.

SKB. 2003. Personal communication to Lennart Agrenius, SKB, Stockholm.

Wagner, J. C. 1997. Acceleration of Monte Carlo Shielding Calculations with an Automated Variance Reduction Technique and Parallel Processing, Ph.D. dissertation, Pennsylvania State University, University Park.

Wagner, J. C. 2002. "An Automated Deterministic Variance Reduction Generator for Monte Carlo Shielding Applications," American Nuclear Society/Radiation Protection \& Shielding Division 12th Biennial Topical Meeting, Santa Fe, N.M., April 14-18.

Watt, B. E. 1952. "Energy Spectrum of Neutrons for Thermal Fission of U²," Phys. Rev. 87(6): 1037-1041.

X-5 Monte Carlo Team. 2003. MCNP-A General Monte Carlo N-Particle Transport Code, Version 5. Volume I: Overview and Theory, LA-UR-03-1987, Los Alamos National Laboratory, Los Alamos, N.M. 
ORNL/TM-2007/133

\section{INTERNAL DISTRIBUTION}

$\begin{aligned} \text { 1. } & \text { H. Akkurt } \\ 2-5 . & \text { E. D. Blakeman } \\ 6 . & \text { S. N. Cramer } \\ 7 . & \text { T. M. Evans } \\ 8 . & \text { P. D. Ferguson } \\ 9 . & \text { I. C. Gauld } \\ \text { 10. } & \text { J. C. Gehin } \\ \text { 11. } & \text { J. O. Johnson } \\ \text { 12. } & \text { T. M. Miller } \\ \text { 13. } & \text { R. H. Morris } \\ \text { 14. } & \text { D. E. Mueller } \\ \text { 15. } & \text { B. D. Murphy } \\ \text { 16. } & \text { C. V. Parks }\end{aligned}$

17. D. E. Peplow

18. R. T. Primm

19. G. Radulescu

20. I. Remec

21. J. E. Rushton

22. R. L. Sanders

23. C. O. Slater

24. C. D. Sulfredge

25. J. C. Wagner

26. M. L. Williams

27. ORNL Office of Technical Information and Classification

\section{EXTERNAL DISTRIBUTION}

28. Peter L. Angelo, BWXT Y-12, P.O. Box 2009, 301 BCR, Oak Ridge, TN 37831-8010

29. Andrew B. Barto, U.S. Nuclear Regulatory Commission, OWFN, 13 D13, Washington, DC 20555-0001

30. Todd A. Hann, Chief, Nuclear Weapons Effects Division, Defense Threat Reduction Agency, Attn: NTE, 8725 John J. Kingman Road Stop 6201, Ft. Belvoir, VA 22060-6201

31. Eric R. Nelson, Defense Threat Reduction Agency, Attn: NTES, 8725 John J. Kingman Road Stop 6201, Ft. Belvoir, VA 22060-6201

32. LTC Michael A. Ortelli, Defense Threat Reduction Agency, Attn: NTES, 8725 John J. Kingman Road Stop 6201, Ft. Belvoir, VA 22060-6201

33. Everett L. Redmond, Nuclear Energy Institute, 1776 I Street, NW, Suite 400, Washington, DC 20006

34. Michael Rooney, Chief, System Vulnerability and Response Branch, Defense Threat Reduction Agency, Attn: NTES, 8725 John J. Kingman Road Stop 6201, Ft. Belvoir, VA 22060-6201

35. Charlotta E. Sanders, Bechtel SAIC Company, LLC, 1930 Village Center Cir 3-256, Las Vegas, NV 89134 